Claudia Ferreira dos Santos Ruiz Figueiredo

\title{
EFEITO DA ESPIRONOLACTONA SOBRE A FUNÇÃO E MORFOLOGIA RENAL DE RATOS HIPERTENSOS POR INFUSÃO CRÔNICA DE ANGIOTENSINA II
}

Tese apresentada ao Programa de Pós-Graduação em Fisiologia Humana do Instituto de Ciências Biomédicas da Universidade de São Paulo, para obtenção do Título de Doutor em Ciências. 
Claudia Ferreira dos Santos Ruiz Figueiredo

\section{EFEITO DA ESPIRONOLACTONA SOBRE A FUNÇÃO E MORFOLOGIA RENAL DE RATOS HIPERTENSOS POR INFUSÃO CRÔNICA DE ANGIOTENSINA II}

Tese apresentada ao Programa de Pós-Graduação em Fisiologia Humana do Instituto de Ciências Biomédicas da Universidade de São Paulo, para obtenção do Título de Doutor em Ciências.

Área de concentração: Fisiologia Humana

Orientadora: Maria Oliveira de Souza

Versão original.

São Paulo

2012 
DADOS DE CATALOGAÇÃO NA PUBLICAÇÃO (CIP)

Serviço de Biblioteca e Informação Biomédica do Instituto de Ciências Biomédicas da

Universidade de São Paulo

reprodução não autorizada pelo autor

Ferreira-Figueiredo, Claudia.

Efeito da Espironolactona sobre a função e morfologia renal de ratos hipertensos por infusão crônica de Angiotensina II / Claudia

Ferreira dos Santos Ruiz Figueiredo. -- São Paulo, 2012.

Orientador: Profa. Dra. Maria Oliveira de Souza.

Tese (Doutorado) - Universidade de São Paulo. Instituto de Ciências

Biomédicas. Departamento de Fisiologia e Biofísica. Área de concentração:

Fisiologia Humana. Linha de pesquisa: Influência da Hipertensão arterial induzida por Angiostensina II na função e morfologia renal.

Versão do título para o inglês: Effect of spironolactone on renal function and morphology of hypertensive rats by Ang. Il chronic infusion.

1. Angiotensina II 2. Aldosterona 3. Renina 4. Hipertensão 5.Função

renal 6. Eletrólitos I. Souza, Profa. Dra. Maria Oliveira de

II. Universidade de São Paulo. Instituto de Ciências Biomédicas. Programa de Pós-

Graduação em Fisiologia Humana III. Título. 


\section{UNIVERSIDADE DE SÃO PAULO INSTITUTO DE CIÊNCIAS BIOMÉDICAS}

Candidato(a): $\quad$ Claudia Ferreira dos Santos Ruiz Figueiredo.

Título da Tese: Efeito da Espironolactona sobre a função e morfologia renal de ratos hipertensos por infusão crônica de Angiotensina II.

Orientador(a): $\quad$ Profa. Dra. Maria Oliveira de Souza.

A Comissão Julgadora dos trabalhos de Defesa da Tese de Doutorado, em sessão pública realizada a considerou

\section{( ) Aprovado(a) ( ) Reprovado(a)}

Examinador(a): Assinatura:

Nome:

Instituição:

Examinador(a): $\quad$ Assinatura:

Nome:

Instituição:

Examinador(a): Assinatura:

Nome:

Instituição:

Examinador(a): Assinatura:

Nome:

Instituição:

Presidente: Assinatura:

Nome:

Instituição: 


\section{UNIVERSIDADE DE SÃO PAULO}

\section{INSTITUTO DE CIÊNCIAS BIOMÉDICAS}

Cidade Universitária "Armando de Salles Oliveira"

Av. Prof. Lineu Prestes, 2415 - cep. 05508-000 São Paulo, SP - Brasil

Telefone :(55) (011) 3091.7733 - telefax : (55) (011) 30917438

e-mail: cep@icb.usp.br

Of.CEUA.018.11

São Paulo, 19 de agosto de 2011.

\section{REF.: Protocolo n'108/08.}

"Fatores moduladores do transporte de Na+renal na hipertensão ou diabetes"

Prezada Professora,

Informo que a sua licença para uso de animais em experimentação, constante no protocolo em epígrafe, foi prorrogada até 19.11.2014.

Reitero que havendo alteração de metodologia e inserção de novos alunos ao projeto de pesquisa vinculado à referida licença a CEUA/ICB deverá ser informada.

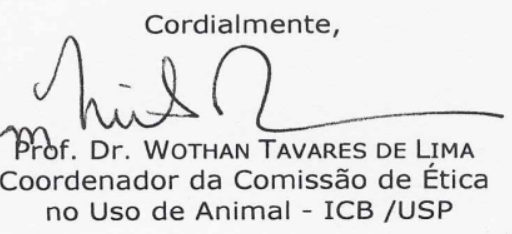

Ilma. Sra.

Profa Dra. Maria Oliveira de Souza

Departamento de Fisiologia e Biofísica

Instituto de Ciências Biomédicas - USP 


\section{Öminha mãe}

Àtodos que me acompanharam durante esta jornada,

A todos que um dia utilizem este trabaltho como uma fonte de pesquisa 


\section{AGRADECIMENTOS}

Senhor, por agraciar-me com o talento da tolerância e pelo respeito conquistado daqueles que me são caros, e são capazes de me reconhecer como " $A$ Mãe".

Ao incondicional apoio de meus familiares, minha base, meu apoio... Minha essência! Àos Lucianos da minha vida, companheiros e protetores.

À professora Maria por me mostrar o valor do saber, e todos os colegas de laboratório que contribuíram na minimização das dificuldades cotidianas. À Olivia por se tornar uma amiga íntima.

À toda a infraestrutura proporcionada por uma universidade de excelência.

Obrigada! 
Este trabalho foi realizado com apoio do $\mathbf{C N P q}$ (Conselho Nacional de Desenvolvimento Científico e Tecnológico) e FAPESP (Fundação de Amparo à Pesquisa do Estado de São Paulo). 
"A mente que se abre a uma nova ideia jamais voltará ao tamanho original" Albert Cinsten 


\section{RESUMO}

FERREIRA-FIGUEIREDO, C. S. R. Efeito da espironolactona sobre a função e morfologia renal de ratos hipertensos por infusão crônica de Angiotensina II. 2012. 83 f. Tese (Doutorado em Fisiologia Humana) - Instituto de Ciências Biomédicas, Universidade de São Paulo, São Paulo, 2012.

O objetivo do atual estudo foi investigar a participação da espironolactona, um antagonista dos receptores MR de aldosterona, sobre as respostas renais induzidas pela hiperatividade do SRAA. Para tal, utilizamos 2 grupos de animais tratados com Ang II ( 15 e 28 dias). Cada grupo foi subdivido em: controles (Sham), tratados com Ang II (200 $\mathrm{ng} / \mathrm{kg} / \mathrm{min}$ ), veículos (tratados com óleo mineral), tratados com espironolactona (100 $\mathrm{mg} / \mathrm{kg} / \mathrm{dia}$ ) e tratados com Ang II + espironolactona. O final de cada tratamento, os animais foram submetidos aos experimentos de função renal pelo método de clerance de paraminohipurato de sódio e inulina, para avaliar o fluxo plasmático renal (FPR) e Ritmo de filtração glomerular (RFG), respectivamente. Em seguida, se avaliou os parâmetros eletrolíticos no plasma e na urina, expressão proteica por western blot, e morfologia renal pela técnica de Hematoxilina Eosina (HE). Nossos resultados indicam que, nos dois períodos, a Ang II induziu hipertensão arterial, queda do FPR e do RFG, com consequente aumento da fração de filtração (FF). A Ang II induziu também queda no fluxo urinário e a espironolactona corrigiu os efeitos da Ang II sobre todos os parâmetros acima descritos. A Ang II e/ou espironolactona não modificaram a carga excretada de NH4, $\mathrm{Na}^{+}$ou $\mathrm{K}^{+}$. No entanto, a Ang II aumentou a expressão de NHE3, resposta corrigida pela espironolactona. A Ang II aumentou a área glomerular e em ambos os períodos de tratamento, a Ang II induziu alterações morfológicas essencialmente no túbulo proximal, incluindo perda da borda em escova e morte celular. A espironolactona corrigiu parcialmente tais alterações. Em conjunto, os resultados indicam que a hiperatividade do SRAA induz aumento na concentração plasmática de aldosterona e esta por sua vez, é em grande parte, a responsável pelos efeitos deletérios do SRAA sobre a função e morfologia renal.

Palavras chave: Ang II, Aldosterona, Renina, Hipertensão, Função renal, Eletrólitos. Suporte financeiro: CNPq e FAPESP. 


\begin{abstract}
FERREIRA-FIGUEIREDO, C. S. R Effect of spironolactone on renal function and morphology of hypertensive rats by Ang II chronic infusion. 2012. 83 p. [PhD

Thesis (Human Physiology)] - Instituto de Ciências Biomédicas, Universidade de São Paulo, São Paulo, 2012.

This study investigated the effect of spironolactone (MR antagonist) on renal function and morphology in hypertensive rats with chronic Ang II infusion for 15 or 28 days. Four-weeks-old male Wistar rats were divided in eight groups and respective controls: Sham or treated with Ang II (200 $\mathrm{ng} / \mathrm{kg} / \mathrm{min})$ by 15 or 28 days, vehicle or treated with Ang II plus spironolactone (100 mg/kg/dia), using osmotic minipumps (Alzet). Blood pressure (BP) was monitored weekly by tail cuff plethysmography. Renal plasmatic flow (RPF) and glomerular filtration rate (GFR) were determined by paraaminohippurate sodium (PAH) and inulin clearance. Plasmatic levels of renin and aldosterone were analyzed by Enzime Immunoassay Kit (EIA), Urinary excretion of ions were also analyzed. The protein expression was analyzed by Western Blot and renal morphology by Hematoxylin-eosin (HE) method. Our results showed that the dose of Ang II used was enough to induce hypertension in rats treated for 15 and 28 days $[109 \pm 1,5$ and $111 \pm 0,8$ (Sham), respectively vs $142 \pm 2,7$ and $163 \pm 3,6$ (Ang II)p $<0,05]$ (mmHg). RPF decreased [24,89 $\pm 0,93$ and 23,76 \pm 0,78 (Sham) vs 14,28 \pm $0,87$ and $13,91 \pm 0,18$ (Ang II) $\mathrm{ml} / \mathrm{kg} / \mathrm{min} \mathrm{p}<0,05]$. The GFR decreased $[8,11 \pm 0,29$ and 8,07 $\pm 0,24$ (Sham) vs 5,77 $\pm 0,29$ and 5,65 $\pm 0,25$ (Ang II) $\mathrm{ml} / \mathrm{kg} / \mathrm{min}, \mathrm{p}<0,05]$. Ang II increased the filtration fraction (FF) and decreased the urinary flux. Spironolactone impaired all effect of Ang II above described. The plasma renin and aldosterone levels increased and spironolactone amplified both. Urinary $\mathrm{Na}^{+}$and $\mathrm{K}^{+}$did not changed in Ang II and/or spironolactone rats treated. Ang II increased the NHE3 expression, induced proximal tubule injury and cellular apoptosis. Spironolactone impaired the effect of Ang II on these parameters. In conclusion, spironolactone has a beneficial effect on renal injury induced by hyperactivity of renin-angiotensinaldosterone system RAAS).
\end{abstract}

Key words: Angiotensin II, Aldosterone, Renin, Hypertension, Renal function, Electrolytes.

Financial Support: CNPq and FAPESP. 


\section{LISTA DE ILUSTRAÇÕES}

Figura 1 - Esquema representativo dos principais componentes do sistema reninaangiotensina

Figura 2 - Esquema representativo dos grupos de animais: A) Divisão dos grupos e B) Evolução temporal dos experimentos......................................................................................31

Figura 3 - Efeito da Ang II e/ou espironolactona sobre a pressão arterial.......................40

Figura 4 - Efeito da Ang II e/ou Espironolactona sobre o Fluxo Plasmático Renal (FPR)

Figura 5 - Efeito da Ang II e/ou Espironolactona sobre o Ritmo de Filtração Glomerular (RFG)

Figura 6 - Efeito da Ang II e/ou espironolactona sobre a Fração de Filtração (FF).....46

Figura 7 - Efeito da Ang II e/ou espironolactona sobre Fluxo Urinário (V)...................47

Figura 8 - Efeito da Ang II e/ou espironolactona sobre o pH e a carga excretada (CE)

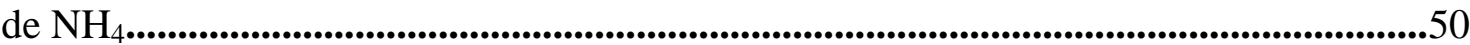

Figura 9 - Efeito da Ang IIe/ou espironolactona sobre a fração de Excreção do íon

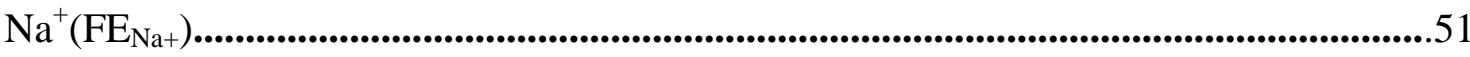

Figura 10 - Efeito da Ang II e/ou espironolactonasobre a fração de Excreção de $\mathrm{K}^{+}\left(\mathrm{FE}_{\mathrm{K}}{ }^{+}\right) . .53$ Figura 11 - Efeito da Ang II e/ou espironolactona sobre alterações na área

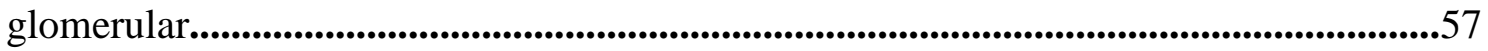

Figura 12 - painel 1 - Grupo tratado com Ang II e/ou espironolactona por 15

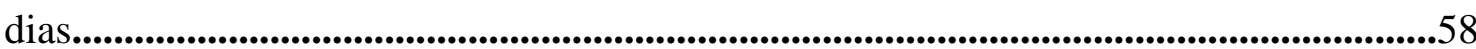

Figura 12 - painel 2 - Grupo tratado com Ang II e/ou espironolactona por 28

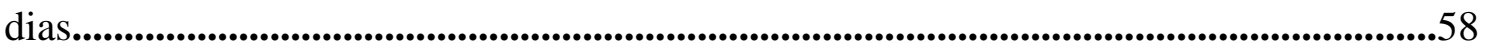




\section{LISTA DE TABELAS}

Tabela 1 - Efeito da Ang II e/ou espironolactona sobre a Pressão Arterial......................40

Tabela 2 - Variação do peso corpóreo...................................................................41

Tabela 3 - Efeito da Ang II sobre o peso absoluto de órgãos...........................................42

Tabela 4 - Efeito da Ang II e/ou espironolactona sobre as concentrações plasmáticas de renina e aldosterona..........................................................................................................43

Tabela 5 - Efeito da Ang II e/ou espironolactona sobre os parâmetros hemodinâmicos e de função tubular de ratos..........................................................................................48

Tabela 6 - Efeito da Ang II e/ou espironolactona sobre o pH da urina ou plasma e sobre

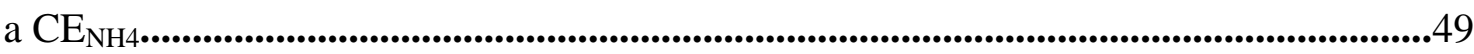

Tabela 7 - Efeito da Ang II e/ou espironolactona sobre as concentrações do íon $\mathrm{Na}^{+}$no

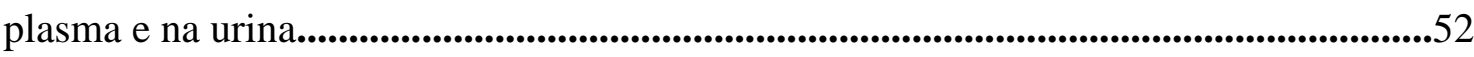

Tabela 8 - Efeito da Ang II e/ou espironolactona sobre a fração de Excreção de $\mathrm{K}^{+}$ $\left(\mathrm{FE}_{\mathrm{K}}^{+}\right)$

Tabela 9 - Efeito da Ang II e/ou espironolactona sobre a osmolalidade da urina e

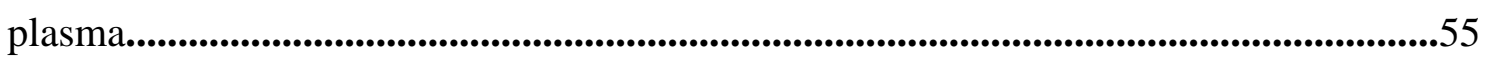

Tabela 10 - Efeito da Ang II e/ou espironolactona sobre alterações na área glomerular. .56 


\section{LISTA DE ABREVIATURAS E SIGLAS}

OMS - Organização Mundial de Saúde

SRA - Sistema Renina Angiotensina

SRAA - Sistema Renina Angiotensina Aldosterona

Ang II - Angiotensina II

Ang 1-7 - Angiotensina 1-7

$\mathrm{AT}_{1}$ - Receptor para angiotensina II isoforma 1

$\mathrm{AT}_{2}$ - Receptor para angiotensina II isoforma 2

Mas - Receptor para Angiotensina 1-7

MR - Receptor para mineralocorticoide

GR - Receptor para glicocorticoide

AMPc - Adenosina momofosfato cíclico

PKA - Proteína Kinase A

PKC - Proteína Kinase C

CREB - cAMP response element - binding

AVP - Arginina vasopressina

PLA2 - Fosfolipase A2

PLD - Fosfolipase D

AC - Adenil ciclase

PI3K - phosphoinositide 3-kinase

FPR - Fluxo Plasmático Renal

RFG - Ritmo de Filtração Glomerular

V - Fluxo Urinário

FF - Fração de Filtração

$\mathrm{CF}$ - Carga Filtrada

CE - Carga Excretada

FE - Fração de excreção

mTOR - Mammalian target of rampamicin

SGK1 - Serum and glucocorticoid induced kinase 1

NFkB - Nuclear factor kB

TGF $\beta$ - Transforming growth factor $\beta$

$\mathrm{O}_{2}^{-}-$Ânion superóxido

$\mathrm{H}_{2} \mathrm{O}_{2}$ - Peróxido de Hidrogênio 


\section{LISTA DE FÓRMULAS}

FÓRMULA

PARÂMETRO

(1) $\mathbf{C}_{\mathrm{x}}=\left(\mathbf{U}_{\mathrm{x}} \times \mathbf{F U}\right) / \mathbf{P}_{\mathrm{x}}$

...Clearance

(2) $\mathrm{CE}_{\mathrm{x}}=\mathbf{U}_{\mathrm{x}} \mathbf{x} \mathbf{F U}$.

..Carga excretada

(3) $\quad \mathbf{F E}_{\mathrm{x}}=\left(\mathrm{CE}_{\mathrm{x}} / \mathrm{CF}_{\mathrm{x}}\right) \times 100 \%$.............................................Fração de excreção 


\section{SUMÁRIO}

1 INTRODUÇÃO........................................................................................................................18

\subsection{Aspectos Gerais}

1.2 Sistema Renina-Angiotensina....................................................................18

1.2.1 Angiotensinogênio.................................................................................................18

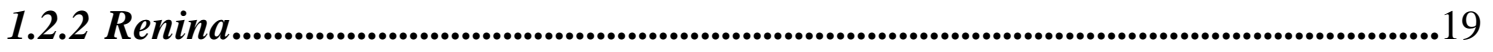

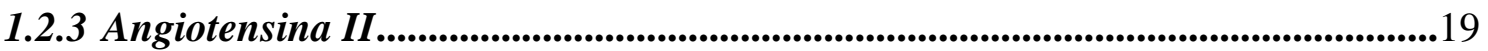

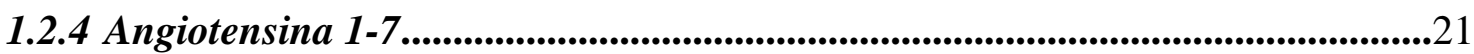

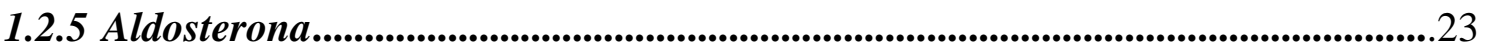

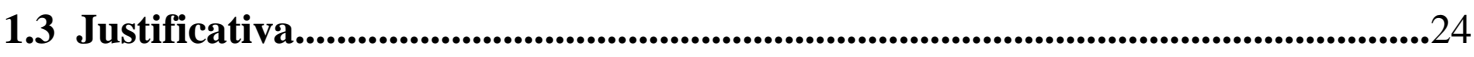

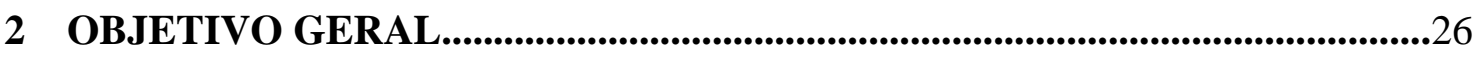

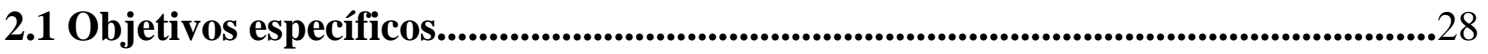

3 MATERIAL E MÉTODOS..................................................................................28

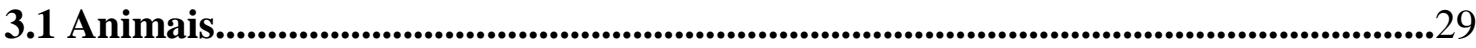

3.1.1 Obtenção dos modelos animais...................................................................29

3.1.2 Indução da hipertensão arterial ......................................................................29

3.1.3 Tratamento com espironolactona .........................................................................................30

3.2 Medidas de Pressão Arterial..................................................................................................32

3.3 Estudo da função renal pelo método de clearance.................................................32

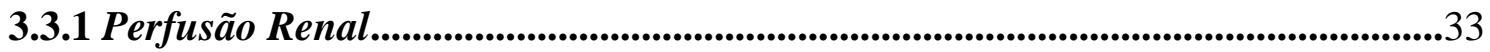

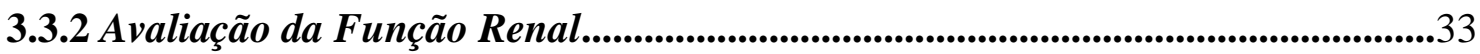

3.3.3 Parâmetros renais e plasmáticos.........................................................................34

3.4 Ensaios enzimáticos para a dosagem de renina e hormônios.................................35

3.5 Análise da expressão proteica por Western Blot..................................................35

3.5.1 Preparação de membranas.............................................................................35

3.5.2 Transferência de proteínas do gel para a membrana de nitrocelulose ................36

3.6 Análise morfológica dos rins...................................................................................................36

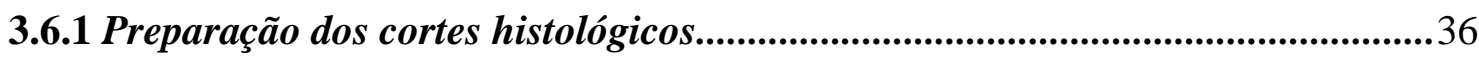

3.6.2 Determinação da área glomerular ..........................................................................37

3.6.3 Análise da morfologia glomerular, tubular proximal e intersticial....................37

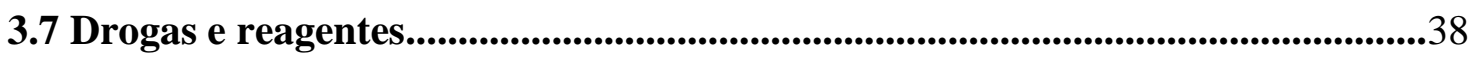

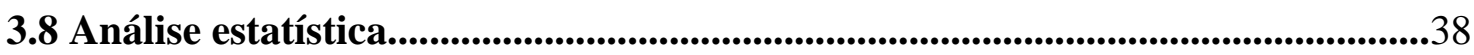


4 RESULTADOS. .39

4.1 Efeito da Ang II e/ou espironolactona sobre a pressão arterial. .39

4.2 Efeito do Tratamento com Ang II e/ou epironolactona sobre o desenvolvimento dos animais

4.3 Efeito da Ang II e/ou Espironolactona sobre as concentrações plasmáticas de renina e aldosterona. .42

4.4 Estudos de Função Renal. .43

4.4.1 Efeito da Ang II e/ou Espironolactona sobre o Fluxo Plasmático Renal $($ FPR $)$

4.4.2 Efeito da Ang II elou Espironolactona sobre o Rítmo de Filtração Glomerular $(\boldsymbol{R F G})$

4.4.3 Efeito da Ang II e/ou Espironolactona sobre a Fração de Filtração (FF).........46

4.4.4 Efeito do tratamento com Ang II e/ou Espironolactona sobre o Fluxo Urinário $(\mathrm{V})$

4.5 Efeito da Ang II e/ou Espironolactona sobre os parâmetros urinários................48

4.5.1 Efeito da Ang II e/ou espironolactona sobre o pH e a carga excretada (CE) de $\mathrm{NH}_{4}$

4.5.2 Efeito da Ang II e/ou Espironolactona sobre a Fração de Excreção de $\mathrm{Na}^{+}$ $\left(\boldsymbol{F E} E_{\mathrm{Na}+}\right.$

4.5.3 Efeito da Ang II elou Espironolactona sobre a Fração de Excreção de $\mathrm{K}^{+}$ $\left(F E_{K+}\right)$

4.5.4 Efeito da Ang II e/ou Espironolactona sobre a Osmolalidade da urina e

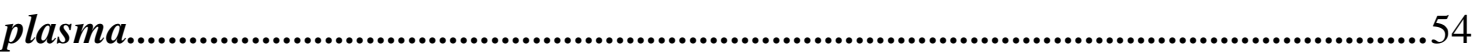

4.6 Efeito da Ang II e/ou espironolactona sobre a área glomerular.........................56

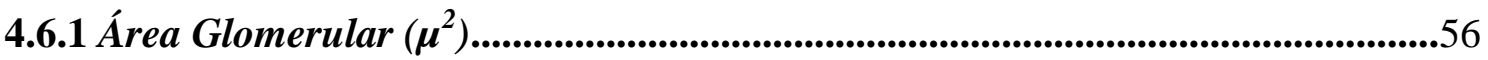

4.8 Efeito da Ang II e/ou Espironolactona sobre e expressão de NHE3....................57

4.8 Efeito da Ang II e/ou Espironolactona sobre a morfologia renal.........................58

5 DISCUSSÃO

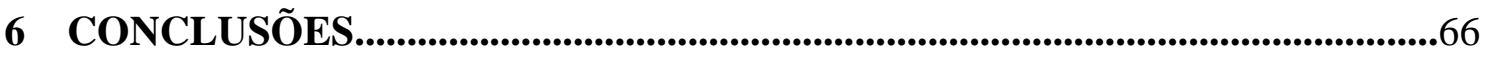

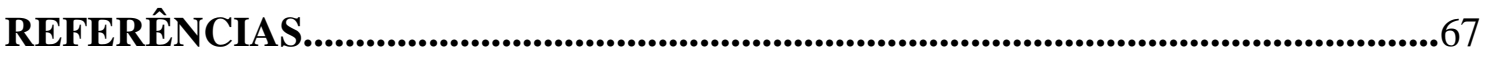




\section{INTRODUÇÃO}

\subsection{Aspectos gerais}

A hipertensão arterial é uma das doenças com maior prevalência no mundo moderno e é caracterizada pelo aumento da pressão arterial. Considera-se hipertenso o indivíduo que mantém permanentemente uma pressão arterial acima de 140 por $90 \mathrm{mmHg}$. Em 2004, a Organização Mundial de Saúde (OMS) informou que, $20 \%$ da população mundial apresentavam hipertensão arterial. No Brasil, 35\% da população brasileira acima de 40 anos são de hipertensos Mancia et al. 2009. Desses, cerca de 5\% apresentam causas conhecidas para o aumento da pressão arterial, geralmente um distúrbio endócrino como, por exemplo, a resistência à insulina. Esses casos enquadram-se na classificação de hipertensão secundária. Na grande maioria dos pacientes, entretanto, não há uma causa específica que possa justificar a elevação mantida de pressão arterial. Assim, considera-se uma hipertensão primária ou $\underline{\text { essencial, }}$ associada a inúmeros fatores, incluindo os genéticos e ligados aos hábitos de vida (HAMEL et al., 1998). Em ambos os casos, a hipertensão arterial, pode induzir alterações no sistema cardiovascular e aumentar o risco de doenças como: hipertrofia cardíaca, infarto do miocárdio, acidente vascular cerebral (AVC) e insuficiência renal (FROHLICH, 2001; KAMPER; PEDERSEN; STRANDGAARD, 2009).

Entre os mecanismos gerais de regulação da pressão arterial, destacam-se: 1) os controles neurais, feitos pelo sistema nervoso autônomo (SNA), que atua tanto no coração quanto nos vasos periféricos, principalmente nas arteríolas e 2) os controles humorais feitos essencialmente por uma variedade de hormônios e mediadores quimícos, que interferem, principalmente, na modulação do tônus arteriolar. Neste caso, se destaca a importância do sistema renina-angiotensina-aldosterona.

\subsection{Sistema Renina-Angiotensina}

O sistema renina-angiotensina (SRA) é altamente conservado em muitas espécies de vertebrados (TAKEI et al., 2004) e além de ser essencial na regulação da pressão arterial, também participa do controle do volume do fluido extracelular. Este controle depende de diversos efeitos do hormônio angiotensina II (Ang II), incluindo: vasoconstrição e aumento da reabsorção de sódio, tanto por ação direta do hormônio no túbulo proximal renal quanto por ação indireta, através de seus efeitos hemodinâmicos (FENTON; KNEPPER, 2007; PETI- 
PETERDI; BELL; WARNOCK, 2002; SUBRAMANYA et al., 2006). O SRA (Figura 1) é representado como uma cascata biológica multienzimática, na qual o angiotensinogênio é o substrato mais importante. A síntese de Ang II é iniciada e principalmente regulada pela renina, enzima sintetizada essencialmente pelas células justaglomerulares renais, (MINDEL; MORRISON, 2005; YOO et al., 2007). A renina cliva o angiotensinogênio circulante, produzido principalmente no fígado, para liberar o decapeptídeo angiotensina I, que por sua vez, sofre ação da enzima conversora de angiotensina I (ECA) e libera o octapeptídeo ativo, angiotensina II. Esta por sua vez, pode atuar em vários tecidos via receptores específicos $\left(\mathrm{AT}_{1}\right.$ e $\mathrm{AT}_{2}$ ) e pode também ser clivada pela enzima conversora de angiotensina II (ECA2) para liberar a angiotensina 1-7, cujo efeito biológico nos diferentes tecidos depende de sua interação com o receptor do tipo Mas.

Figura 1 - Esquema representativo dos principais componentes do sistema reninaangiotensina.

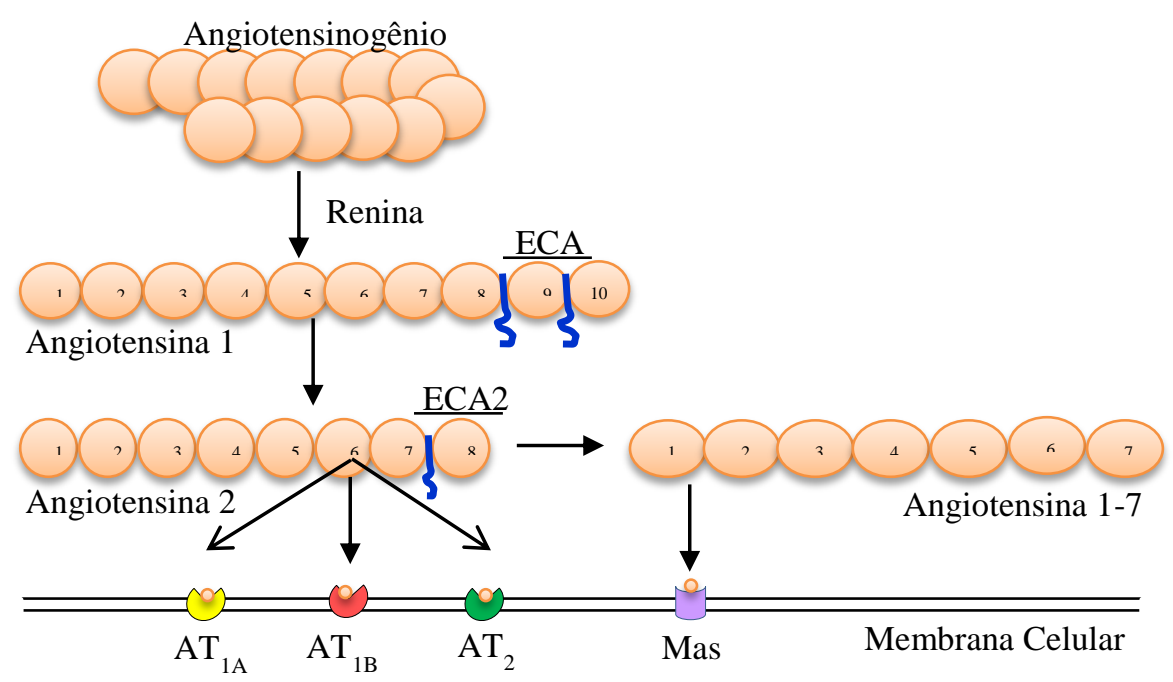

ECA: enzima conversora da angiotensina I, ECA2: enzima conversora da angiotensina II, AT1 e AT2: receptores para angiotensina II (isoformas 1 e 2), Mas: receptor para angiotensina 1-7.

Fonte: O autor. 


\subsubsection{Angiotensinogênio}

O angiotensinogênio é uma alfa-2 globulina com 411 aminoácidos de origem essencialmente hepática e cuja produção é estimulada em resposta aos glicocorticóides, estrogênios e citocinas inflamatórias como a interleucina-1 e o fator de necrose tumoral (MORGAN; BROUGHTON; KALSHEKER, 1996). Além do tecido hepático, sabe-se também que o angiotensinogênio pode ser sintetizado em outros tecidos como o cérebro, o sistema imune e os rins (MATTHEW et al., 2006). Nos rins, a síntese dessa proteína ocorre predominantemente no túbulo proximal, onde é regulada pela angiotensina II (KOBORI et al., 2001; NAVAR et al., 2011). No plasma, o angiotensinogênio circula como um peptídeo biologicamente inativo, cuja concentração é variável e fica muito próxima do valor correspondente à metade da velocidade máxima de atividade $(\mathrm{Km})$ da renina (SEALEY; GERTEN-BANES; LARAGH, 1972).

\subsubsection{Renina}

A renina é uma enzima proteolítica do grupo das aspartil-proteases, que cliva o angiotensinogênio no aminoácido denominado aspartato e foi descrita pela primeira vez por Tigerstedt, Bergman et al., (1898), utilizando extrato de córtex renal de coelho. A transcrição do gene para renina é estimulada essencialmente pela cascata de sinalização celular regulada pelos elementos AMPc/PKA/CREB. A adenosina monofosfato cíclico (AMPc) estimula a proteína quinase A (PKA), que em seguida, é translocada para o núcleo celular e fosforila o fator de transcrição conhecido como cAMP response element-binding (CREB). Uma vez ativado, o CREB interage com a sequência cAMP response element (CRE), característico da região promotora do gene da renina e modula a transcrição da enzima (KLAR; KURTZ; VITZTHUM, 2002; MONTMINY, 1997, PAN et al., 2001).

Inicialmente, a renina é sintetizada como uma proteína denominada pré-pró-renina, a qual é rapidamente transformada em pró-renina. Esta por sua vez, é armazenada em grânulos das células justaglomerulares renais, de onde pode ser secretada para exercer seus efeitos biológicos (DEINUM, 1999) ou por ação das proteases intracelulares, ser convertida em renina ativa (PRATT et al., 1987). Segundo Toffelmire et al. (1989), a secreção de pró-renina e renina é complexa. Quando o estímulo é agudo predomina-se a exocitose de grânulos contendo apenas renina. Porém, quando o estímulo é crônico, aumentam as concentrações circulantes tanto de pró-renina quanto de renina. 
A secreção de renina ativa é regulada basicamente por quatro mecanismos distintos: 1) os barorreceptores intra-renais localizados na face endotelial das arteríolas aferentes, junto ao aparelho justaglomerular, que detectam alterações na pressão de perfusão renal; 2) alterações na concentração de cloreto de sódio $(\mathrm{NaCl})$ detectadas pelas células da mácula densa do tubo distal; 3) estimulação nervosa simpática via receptores adrenérgicos $\beta$-1; e 4) feedback negativo por ação direta da Ang II nas células justaglomerulares (BELL,. 2003; BOCK, 1992; BROWN, 2006; HAMEL et al., 1998). Sua concentração plasmática é de 900 a 2.200 ng/mL e sua atividade é bastante variável: de 0.5 a $2.8 \mathrm{ng} / \mathrm{ml} /$ hora (quando a excreção de sódio é de $150 \mathrm{mEq} / \mathrm{dia}$ ) ou cerca de $21 \mathrm{ng} / \mathrm{ml} / \mathrm{hora}$ (quando a excreção de sódio é de $50 \mathrm{mEq} / \mathrm{dia}$ ) (SEALEY; GERTEN-BANES; LARAGH, 1972). Uma vez no plasma, a renina cliva 10 aminoácidos no domínio amino-terminal do angiotensinogênio para formar o decapeptídeo angiotensina I (Ang I) (PAECH, 1977). Esta, por ação da enzima conversora de angiotensina (ECA), presente no endotélio, dá origem ao octapeptídeo biologicamente ativo denominado angiotensina II (CAREY; SIRAGY, 2003).

Além da clássica função da renina, estudos realizados por Nguyen et al., (2002) sugerem que vários tecidos (placenta, cérebro, coração, endotélio vascular e rim) expressam receptores de membrana específicos para a pró-renina e renina. Segundo os autores, estes receptores têm uma ação pró-fibrótica e pró-inflamatória, estimulam a proliferação celular e poderão contribuir para o desenvolvimento de nefropatias. Outros estudos mais recentes revelam que em camundongos e humanos, a atividade da renina pode ser diretamente inibida pelo agente farmacológico denominado alisquireno (RASHIKH et al., 2012).

\subsubsection{Angiotensina II}

A Ang II é o mais potente dos produtos biologicamente ativos do sistema renina angiotensina (SRA). Em condições fisiológicas, a concentração de Ang II no plasma é de 1-10 pM e sua meia vida é de aproximadamente 2 minutos, devido à rápida clivagem em Ang III e IV, através da remoção de aminoácidos da porção N-terminal por aminopeptidases. Existe ainda um heptapeptídeo [Ang (1-7)] formado a partir da Ang I ou da clivagem da Ang II, por ação de peptidases, uma das quais possui homologias estruturais com a ECA, designando-se ECA2 (REUDELHUBER, 2005).

A Ang II sistêmica atua como vasoconstritor em células da musculatura lisa vascular, aumenta a contratilidade miocárdica, estimula a síntese de aldosterona e de catecolaminas na glândula adrenal, aumenta a atividade do sistema nervoso simpático (SNS), estimula o apetite 
ao sal, a sede, a liberação de AVP e o transporte de sódio em células epiteliais do intestino e do rim (BADER, 2010; KOBORI et al., 2007). O conceito de que o SRA é puramente endócrino tem sido motivo de discussão nas últimas décadas. Hoje se sabe que o cérebro, coração, vasos, tecido adiposo e rim são capazes de produzir angiotensinogênio, renina, ECA e Ang II, indicando a presença de SRA locais. (BADER, 2010 ; DZAU et al., 1987, KLICKSTEIN ; KAEMPFER, 1982 ; LOMEZ et al., 2002 ; MULLER et al., 1995 ; PINTEROVA ; KRIZANOVA ; ZORAD, 2000).

Os rins são os órgãos que mais contribuem para a formação de Ang II sistêmica, uma vez que as células justaglomerulares possuem alta capacidade de síntese e liberação de renina. No entanto, em humanos, ratos e camundongos, as células dos túbulos proximais e dos ductos coletores também sintetizam e secretam todos os elementos do SRA, sugerindo a presença deste nos distintos segmentos do néfron, o que justifica a concentração do hormônio na urina

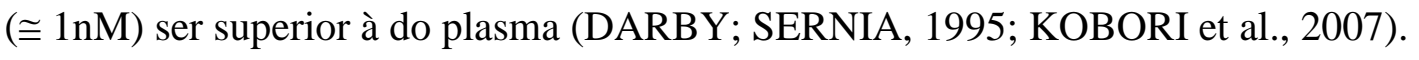

As múltiplas ações da Ang II dependem de sua interação com receptores específicos do tipo AT1 e AT2 e são mediadas por complexas vias de sinalização intracelular (GRIENDLING; LASSEGUE; ALEXANDER, 1996). O receptor AT1 é sensível a vários inibidores como losartan e candesartan (DAHLOF; DEVEREUX; KJELDSEN, 2002; JULIUS; KJDELDSEN; WEBER, 2004) e a interação da Ang II com o AT1 estimula a proteína Gq, que por sua vez, modula inúmeras vias de sinalização celular. Os efeitos da Ang II via AT1, são classificados como eventos de curto ou longo prazo. Entre os eventos de curto prazo, incluem: 1) ativação da fosfolipase C (PLC) que por sua vez, induz a formação de inositol trifosfato (IP3) e diacilglicerol (DAG), promovendo subsequente liberação de cálcio dos estoques intracelulares e ativação da PKC, respectivamente; 2) ativação da fosfolipase A2 - PLA2, enzima que cliva os fosfolipídios da membrana celular em ácidos graxos, liberando ácido aracdônico (AA) e 3) ativação da fosfolipase D (PLD), tirosina quinase (TK) fosfatidilinisitol 3 quinase (PI3K) e MAP quinases (MAPKs). Já nos eventos de longo prazo, a Ang II permite a amplificação dos eventos de curto prazo acima descritos e, além disso, ao estimular a PLA $\mathrm{P}_{2}$ e PLD, induz aumento de espécies reativas de oxigênio como o ânion superóxido $\left(\mathrm{O}_{2}^{-}\right)$e o peróxido de hidrogênio $\left(\mathrm{H}_{2} \mathrm{O}_{2}\right)$, os quais estimulam o crescimento, diferenciação e migração celular, apoptose, deposição de matriz extracelular e hipertrofia, além de regular a expressão gênica e síntese proteíca (CASTROP et al., 2010; NAVAR et al., 2000; RHIAN; ERNESWT, 2000; TIMMERMANS et al., 1993).

Os receptores AT2 são abundantes em vários tecidos durante o período fetal, mas o seu número é reduzido após o nascimento (SHANMUGAN; SANDBERG, 1996). A ativação 
desses receptores produz efeitos benéficos, como a vasodilatação, anti-proliferação (fibroblastos, endotélio e miócitos), melhora da função cardíaca e queda na reabsorção de sódio pelo túbulo proximal renal (HERNADEZ; ZHOU, 2007). A atividade dos receptores AT2 é eficientemente bloqueada pelo antagonista denominado PD 123177. Contudo, o próprio AT2, por dimerização, pode atuar como antagonista do receptor AT1 (ABDALLA et al., 2001).

\subsubsection{Angiotensina 1-7}

Santos et al., (1988) caracterizaram a Ang 1-7 como um peptídeo derivado da clivagem da Ang II pela ECA2. Além disso, o mesmo grupo passou a investigar os principais efeitos biológicos da Ang 1-7 sobre os tecidos cardiovascular e cerebral (CAMPAGLIONESANTOS et al., 1989; SCHIAVONE et al., 1988). A partir desses estudos, a Ang 1-7 se tornou alvo de pesquisas, essencialmente por ter sido observado que os seus efeitos biológicos se opõem aos efeitos deletérios induzidos por altas concentrações plasmáticas de Ang II (FERRARIO et al., 1997; SANTOS; ANDRADE; CAMPAGLIONE-SANTOS, 2000). Em condições fisiológicas, a concentração plasmática de Ang 1-7 encontra-se na faixa de picomolar como a Ang II. Além disso, a Ang 1-7 pode também ser encontrada em concentrações elevadas nos diferentes segmentos do néfron, incluindo os túbulos proximais, distais e ductos coletores e é excretada pela urina (DILAURO; BURNS, 2009).

Os efeitos da Ang 1-7 dependem de sua interação com o receptor do tipo Mas o qual é acoplado à proteína $\mathrm{G}$ e sensível ao antagonista A-(779) (CHAPPELL et al., 2004). O receptor Mas é amplamente distribuído no cérebro, coração, vasos e rins (CHRISTENSEN; BIRN, 2002, ZIMPELMANN; BURNS, 2009) e quando está sob efeito da Ang 1-7, induz a geração de óxido nítrico (NO) e vasodilatação (HEITSCH et al., 2001), atenua a hipertrofia cardíaca, processos inflamatórios e o estresse oxidativo (BROSNIHAN; FERRARIO, 1996). Sobre a hemodinâmica renal, os efeitos da Ang 1-7 são bastante conflitantes, uma vez que a vasculatura renal é muito sensível a Ang II (DILAURO; BURNS, 2009). Contudo, a Ang 1-7 apresenta um efeito "dose-dependente" sobre o transporte de $\mathrm{Na}^{+}$no túbulo proximal renal. Ou seja, em abaixas concentrações estimula e em altas concentrações inibe a reabsorção do íon (GARCIA; GARVIN, 1994). 


\subsubsection{Aldosterona}

É um mineralocorticóide sintetizado e secretado pelas células glomerulosas localizadas no córtex da glândula adrenal. Seu efeito fisiológico sobre a função renal foi descrito por Simpson et al. (1953), ano em que a aldosterona foi oficialmente integrada ao SRA, que passou a se chamar sistema renina-angiotensina-aldosterona (SRAA). Estudos com ratos indicam que em condições fisiológicas, a concentração plasmática de aldosterona é cerca de $1 \mathrm{nM}$ (GEERING et al.,1985). Os principais fatores estimuladores da síntese e secreção de aldosterona são potássio $\left(\mathrm{K}^{+}\right)$e Ang II. Assim, o aumento do íon $\mathrm{K}^{+}$no meio extracelular induz despolarização da membrana das células glomerulosas e conseqüentemente, a abertura de canais de $\mathrm{Ca}^{2+}$. O aumento da $\left[\mathrm{Ca}^{2}\right]_{\mathrm{i}}$ estimula a síntese e secreção de aldosterona, que por sua vez, modula a reabsorção renal de $\mathrm{Na}^{+}$e secreção de $\mathrm{K}^{+}$no néfron distal (GIEBISH, 2002). A Ang II se liga ao receptor AT1 na membrana das células glomerulosas e via ativação da $\mathrm{PG} \alpha_{\mathrm{q}} / \mathrm{PLC} / \mathrm{DAG}-\mathrm{IP}_{3} / \mathrm{Ca}^{2}{ }_{\mathrm{i}}$ ou $\mathrm{Ca}^{2} /$ calmodulina, estimula a secreção de aldosterona (SPAT; HUNYADY, 2004). Além das células glomerulosas, outros tecidos como miócitos cardíacos, células da musculatura lisa vascular e células mesangiais glomerulares também podem sintetizar aldosterona (HATAKEYAMA et al., 1994; NISHIKAWA et al., 2005; SILVESTRE et al., 1999)

O efeito da aldosterona nos diferentes tecidos depende de sua interação com receptores de membrana (mAR) e receptores nucleares de alta afinidade, como os de mineralocorticóides (MR, com $\mathrm{K}_{\mathrm{d}}$ de 0,5-3 nM) ou de baixa afinidade, como os de glicocorticóides (GR, com $\mathrm{K}_{\mathrm{d}}$ de $20-65 \mathrm{nM}$ ) (ARRIZA et al., 1987). Os receptores do tipo mAR estão associados aos efeitos não genômicos e genômicos da aldosterona, que através das vias de sinalização celular moduladas por AC/AMPc/PKA; RhoA (família das pequenas GTPases); phosphoinositide 3quinase (PI3K) e PKC, podem modular o deslocamento e atividade do ENaC (Canal epitelial de sódio), da subunidade alfa da $\mathrm{Na}^{+} / \mathrm{K}^{+}$- ATPase (WARREN; BRIAN, 2011), da $\mathrm{H}^{+}$-ATPase do tipo vacuolar e do trocador $\mathrm{Na}^{+} / \mathrm{H}^{+}$(BRAGA-SOBRINHO; LEITE-DELOVA; MELLOAIRES, 2012; LEITE-DELLOVA; MALNIC; MELLO-AIRES, 2011). Os receptores MR e GR são preferencialmente associados aos efeitos genômicos da aldosterona. Neste caso, a ativação da via AC/AMPc/PKA/CREB modula a transcrição gênica para a síntese proteica (WARREN; BRIAN, 2011). Contudo, foi observado recentemente, um efeito genômico da aldosterona sobre a atividade da isoforma 1 do trocador $\mathrm{Na}^{+} / \mathrm{H}^{+}$(NHE1) (BRAGASOBRINHO; LEITE-DELOVA; MELLO-AIRES, 2012). 
No rim, os receptores MR são expressos nas células mesangiais, células justaglomerulares, podócitos e nos diferentes segmentos do néfron, incluindo o túbulo proximal, segmento espesso da alça de Henle, túbulo distal e ducto coletor (LEITEDELLOVA et al., 2008; WARREN; BRIAN et al., 2011). O receptor GR é ubiquamente distribuído em todo o tecido renal (ACKERMANN et al., 2010). Em doses fisiológicas, a aldosterona modula o transporte renal de $\mathrm{Na}^{+}$e a secreção de $\mathrm{K}^{+}$tubular (GIEBISCH, 2002, NISHIKAWA et al., 2005). Em doses supra-fisiológicas decorrentes, por exemplo, de uma hiperatividade crônica do SRAA, a interação da aldosterona com o receptor MR pode induzir um aumento na expressão do receptor para o fator de crescimento epidermal (EGFR) e do fator-alfa de necrose tumoral (TNF- $\alpha$ ), condição que favorece a expressão de citocinas próinflamatórias (WARREN; BRIAN, 2011). Estudos "in vitro" complementam esses achados e indicam que a aldosterona via ativação do EGFR pode estimular a proliferação de células mesangiais por ativar a ERK1/2 (NISHIYAMA et al., 2005).

As repostas biológicas da aldosterona podem ser atenuadas com espironolactona, um potente antagonista do receptor MR (FUNDER et al., 1988). No rim, a espironolactona entra na célula através da membrana basolateral, liga-se aos receptores MR e atua como inibidor competitivo, interrompendo a translocação dos MRs para o núcleo (COURETTE et al., 1992; FANESTIL, 1988) e portanto, impedindo a transcrição gênica induzida por aldosterona via MR. Em doses de até $100 \mathrm{mg} / \mathrm{dia}$ ), a espironolactona apresenta uma discreta ação natriurética, por estimular levemente a excreção de sódio (1\% - 2\%) (KAGAWA, 1960; LIDDLE, 1966). Por isso, é utilizada na clínica para corrigir a pressão arterial de pacientes com moderada hipertensão arterial (LIEW; KRUN, 2003). Em doses acima de 150 mg/dia, a espironolactona pode no entanto, induzir queda na excreção de potássio e hidrogênio (BRADLEY; MARON, 2008).

Sabe-se também que no hiperaldosteronismo primário ou secundário (ex. síndrome nefrótica ou cirrose), a espironolactona induz uma melhora na sobrevida, embora os mecanismos celulares envolvidos com tal resposta ainda não sejam conhecidos (PITT; ZANNAD; REMME, 1999). Estudos atuais revelam que a espironolactona corrigiu a hipertrofia cardíaca de ratos tratados com o beta-adrenérgico isoproterenol (MARTÍNFERNÁNDEZ et al., 2012), por reduzir a expressão da proteína "Serum and glucocorticoid regulated kinase type 1" (SGK-1), aumentada por aldosterona. O efeito da espironolactona sobre o reparo de lesões no tecido renal ainda não foi elucidado. 


\subsection{Justificativa}

Considerando o exposto acima, pode-se afirmar que em condições fisiológicas, o eixo renina-angiotensina-aldosterona tem função essencial na regulação da pressão arterial e do volume do fluido extracelular, principalmente por conduzir respostas celulares através de receptores específicos.

Contudo, sabe-se também que inúmeras patologias são associadas às irregularidades funcionais de um ou de todos os elementos do SRAA, que de uma maneira ou de outra, afeta a função de células, tecidos e consequentemente, de vários órgãos vitais. Estudos clínicos demonstram que além de contribuir com a hipertensão arterial, a Ang II em altas concentrações plasmáticas, também induz lesões no tecido renal, levando o rim a uma condição de gerador e mantenedor da hipertensão arterial (NAVAR, 2005, PAUL; MEHR; KREUTZl, 2006). Outros achados com modelos animais demonstram que, em ratos, a infusão crônica de Ang II induz a ativação do SRA intrarenal, hipertensão arterial, aumento da síntese e liberação de aldosterona e proteinúria, sendo esta última associada às alterações da expressão de nefrina e apoptose de podócitos (KOBORI; HARRISON-BERNARD; NAVAR, 2001; JUNYA et al., 2008; PRIETO-CARRASQUERO et al., 2004). O efeito intrarenal da Ang II nesse modelo animal pode contribuir com a freqüente queda na excreção de $\mathrm{Na}^{+}$, devido às alterações na expressão e atividade dos trocadores $\mathrm{Na}^{+} / \mathrm{H}^{+}$, cotransportador $\mathrm{Na}^{+}-\mathrm{Cl}^{-}$, canal epitelial de sódio $(\mathrm{ENaC}), \mathrm{Na}^{+} / \mathrm{K}^{+}$-ATPase e canais de $\mathrm{K}^{+}$, proteínas que podem ser moduladas tanto por Ang II, via AT1 ou AT2, quanto por aldosterona (FENTON; KNEPPER, 2007; McENEANEY; HARVEY; THOMAS, 2008; PETI-PETERDI; WARNOCK; BELL, 2002; SUBRAMANYA et al., 2006; WELLING et al., 1993). Por outro lado, a participação da aldosterona nos processos celulares envolvidos com o desenvolvimento de doenças renais, ainda é pouco conhecida.

Nas últimas décadas, os estudos sobre o SRAA, foram enriquecidos com abordagens sobre a eficácia dos diversos antagonistas, incluindo: Alisquireno (para renina), losartan e cadesartan (para AT1) e ramipril (para ECA). Tais antagonistas, além de bloquear etapas específicas do SRAA, podem induzir o reparo de lesões geradas por esse sistema no tecido cardíaco ou renal. Por outro lado, pouco se sabe a respeito do possível efeito protetor da espironolactona (antagonista do MR) sobre esses tecidos.

O efeito da infusão crônica de Ang II vem sendo investigado em modelos animais, cujo tratamento varia de 7 a 15 dias, porém com doses muito variadas do hormônio (80 a 400 ng/kg/min, respectivamente) (JUNYA et al., 2008; KOBORI; HARRISON-BERNARD; 
NAVAR, 2001; PRIETO-CARRASQUERO et al., 2004), o que gera conflitos entre os resultados obtidos. Um fato interessante é que independente da dose de tratamento observa-se um aumento na síntese de renina, independentemente do grau de hipertensão (PRIETOCARRASQUERO et al., 2005; PRIETO-CARRASQUERO et al., 2008). Tais fatos nos levaram escolher uma dose intermediária (200 ng/kg/min) e estender o período de tratamento (15 a 28 dias), condições que nos permitiria investigar os parâmetros associados à função renal no período em que a pressão arterial está se deslocando (15 dias de infusão) e no período em que os animais já estão definitivamente hipertensos (28 dias de infusão). 


\section{OBJETIVO GERAL}

O objetivo desse estudo foi investigar o efeito da espironolactona sobre a função e morfologia renal de ratos com hipertensão arterial induzida por Ang II.

\subsection{Objetivos específicos}

1) Induzir a hipertensão arterial por infusão crônica (15 ou 28 dias) de Ang II (200 $\mathrm{ng} / \mathrm{kg} / \mathrm{min})$;

2) Avaliar a função renal pelo método de clearance com para-aminohipurato de sódio e inulina, em animais controle ou tratados com Ang II;

3) Tratar os animais hipertensos com espironolactona para investigar a participação da aldosterona na indução de possíveis lesões renais.

4) Investigar o efeito da Ang II e/ou espironolactona sobre a expressão da isoforma 3 do trocador $\mathrm{Na}^{+} / \mathrm{H}^{+}$.

5) Investigar o efeito da Ang II e/ou espironolactona sobre morfologia glomerular e tubular proximal. 


\section{MATERIAL E MÉTODOS}

Todos os procedimentos experimentais foram aprovados pela Comissão de Ética no Uso de Animal do Instituto de Ciências Biomédicas/USP, protocolo número 108/08.

\subsection{Animais:}

Foram utilizados ratos machos Wistar, com idade de 21 dias, adquiridos no biotério do Instituto de Ciências Biomédicas (ICB) da Universidade de São Paulo (USP), os quais foram mantidos no biotério do Departamento de Fisiologia e Biofísica do ICB/USP, sob condições de controle da temperatura e ciclo claro-escuro de 12 horas, com livre acesso à água e à alimentação (ração Nuvilab). Após 1 semana de aclimatação, se iniciou o monitoramento da pressão arterial.

\subsubsection{Obtenção dos modelos experimentais}

Os animais com 30 dias de vida foram subdivididos em 04 grupos: 1) grupo controle ou "Sham", onde os animais foram submetidos à cirurgia fictícia com apenas uma pequena incisão subcutânea no dorso; 2) grupo tratado com Ang II [(200 ng/ kg/ min) (Bachem)] diluída em salina (KELLY et al., 2004, WU; LAPLANTE; DE CHAMPLAIN, 2004); 3) grupo Veículo, onde os animais receberam injeções subcutâneas diárias de 200 a $300 \mu$ da solução contendo 90\% de óleo mineral + 10\% de Dimetilsulfóxido (DMSO); 4) grupo tratado com espironolactona [(100 $\mathrm{mg} / \mathrm{kg} / \mathrm{dia})$ (Sigma)], diluída em óleo mineral + DMSO (WILKINSON-BERKA et al., 2009) e 5) grupo tratado com Ang II e que receberam diariamente injeções subcutâneas de espironolactona.

\subsubsection{Indução da hipertensão arterial}

Os animais com 30 dias de vida foram anestesiados com uma mistura anestésica (Quetamina $75 \mathrm{mg} / \mathrm{kg}+$ Xilazina: $8,0 \mathrm{mg} / \mathrm{kg}$ de peso corporal, por via intramuscular) e mantidos sob respiração espontânea. Após a perda completa dos reflexos de dor, uma pequena incisão subcutânea foi feita no dorso dos animais e uma mini bomba osmótica (AlzetMiniOsmotic Pump Model 2004) foi inserida. A mini bomba tem capacidade para 200 ul com taxa 
de liberação de $0.25 \mu \mathrm{l} / \mathrm{h}$ durante 28 dias. Assim, os animais receberam uma dose de Ang II de $200 \mathrm{ng} / \mathrm{kg} / \mathrm{min}$. Após a cirurgia os animais foram higienizados com clorexidina $2 \%$ e mantidos em gaiolas individuais sob monitoramento semanal da pressão arterial até o final do tratamento. Cada grupo tratado teve seu grupo controle "Sham" correspondente.

Com o intuito de investigar se a progressão ou a permanência da hipertensão arterial está associada às alterações da função e morfologia renal, bem como a expressão de proteínas transportadoras, os animais tratados com Ang II foram subdivididos em grupos de 15 e 28 dias, conforme esquemas a seguir. Assim, no $15^{\circ}$ dia de tratamento com Ang II, interrompeuse o tratamento em um grupo de animais, os quais foram submetidos aos experimentos de função renal. $\mathrm{O}$ grupo remanescente permaneceu com o tratamento até o $28^{\circ}$ dia e em seguida, foram também submetidos aos experimentos de função renal.

\subsubsection{Tratamento com espironolactona}

Após 7 dias de tratamento, quando o deslocamento da pressão arterial foi confirmado, cada animal passou a receber diariamente uma injeção subcutânea de 200 a $300 \mu$ l solução contendo espironolactona (100 mg/kg/dia) diluída em 90\% de óleo mineral e 10\% de DMSO por um período de 8 dias, totalizando 15 dias de tratamento. No $15^{\circ}$ dia de tratamento um grupo de animais foi submetido aos experimentos de função renal. Cada grupo tratado teve seu grupo controle "Veículo" correspondente. Outro grupo de animais que no $7^{\circ}$ dia de tratamento com Ang II passou a receber injeções de espironolactona, manteve o tratamento por 21 dias, totalizando 28 dias. Ao final do tratamento, o grupo de animais foi submetido aos experimentos de função renal. 
Figura 2 - Esquema representativo dos grupos de animais:

A)
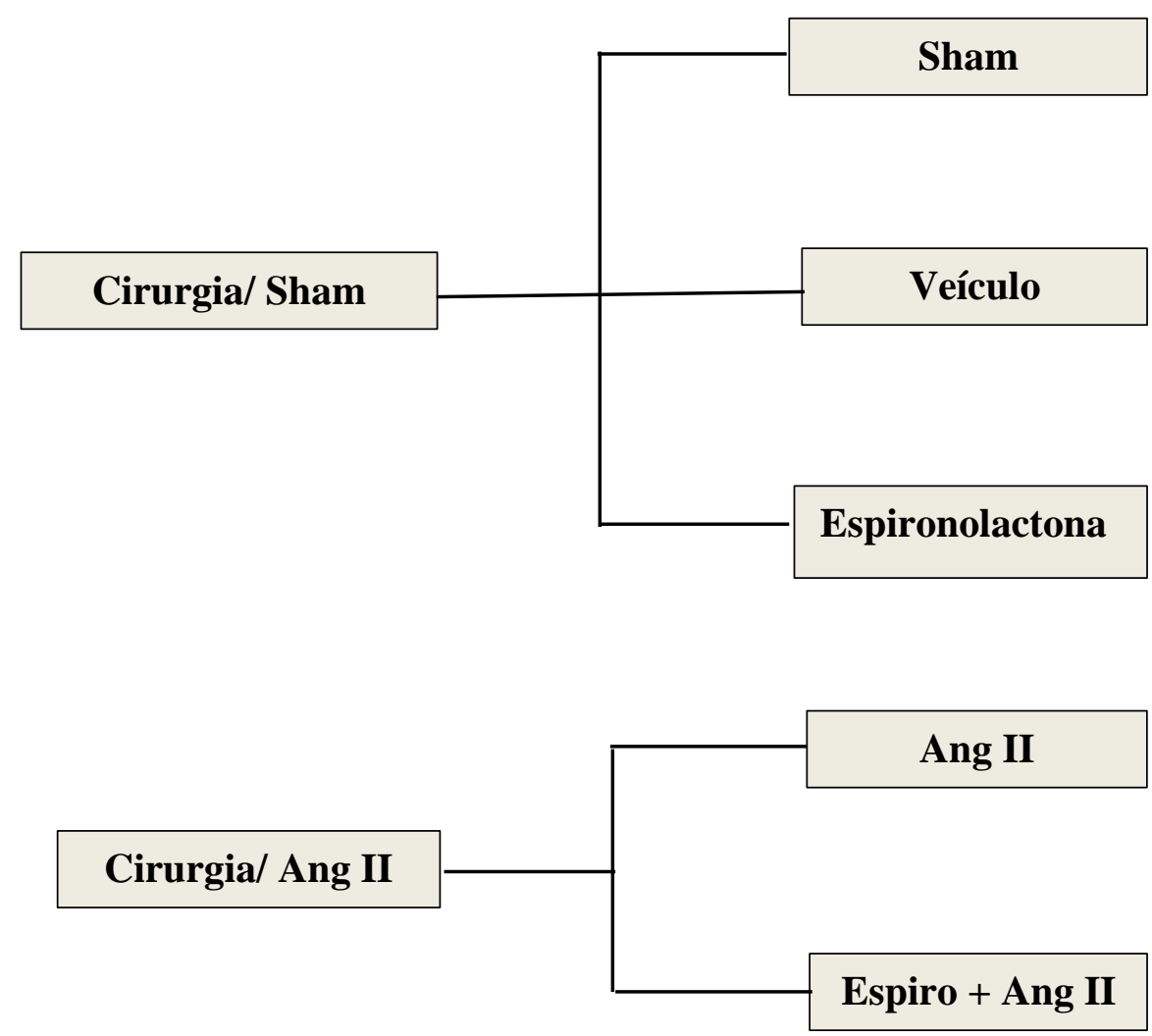

B)

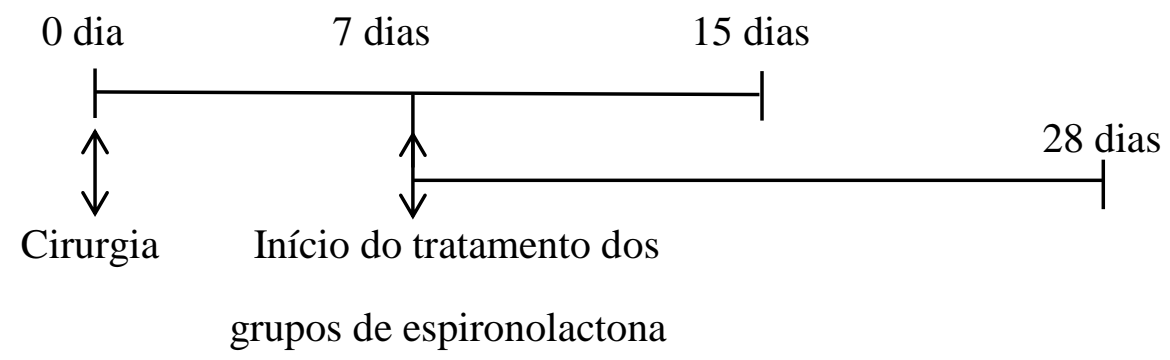

A) Divisão dos grupos e B) evolução temporal dos experimentos.

Fonte: O autor. 


\subsection{Medidas de Pressão Arterial}

Para avaliar a progressão da hipertensão nos períodos de tratamento, semanalmente os animais controle ou tratados, foram submetidos à avaliação da pressão arterial, pelo método de pletismografia de cauda (LE 5001, Panlabs.I. Barcelona, Espanha) (ISHIGURO et al, 2007). Os valores serão apresentados como média aritmética de 8 a 10 aferições por animal a cada semana.

\subsection{Estudo da função renal pelo método de clearance}

Os animais foram removidos da gaiola metabólica e anestesiados com injeção intramuscular de Zoletil (50 mg/kg) e Xilazina (5 mg/kg), sendo que doses adicionais foram administradas durante o procedimento, quando necessário. Após a perda completa dos reflexos de dor, a traquéia foi canulada com cateter de polietileno (PE 260 - Sigma), para manutenção da ventilação adequada do animal. Em seguida, a artéria carótida direita e a veia jugular esquerda foram canuladas com cateteres de polietileno PE 10 e PE 50 (Sigma) heparinizados, para coleta de sangue e infusão de diferentes soluções, respectivamente. No início do experimento, os animais receberam infusão endovenosa contínua por 30 minutos, de solução composta por $0,9 \%$ de $\mathrm{NaCl}$ e $3 \%$ de manitol à velocidade constante de $100 \mu 1 / \mathrm{min}$, através de uma bomba infusora (Perfusor E, B. BraunMelsungen AG). Após este período, uma dose inicial (“primer”), no volume de $1 \mathrm{ml}$, contendo inulina (90 mg por animal) e ácido para-amino-hipúrico (PAH; 2mg por animal) foi administrada, em bolus. A manutenção foi feita através de infusão contínua de inulina $(1,5 \mathrm{mg} / \mathrm{ml})$ e PAH $(4 \mathrm{mg} / \mathrm{ml})$ por todo o experimento. Foram realizadas 4 coletas de sangue e urina, em intervalos de 30 minutos, sendo a primeira iniciada após 30 minutos de infusão de inulina + PAH. As amostras de sangue obtidas durante os experimentos foram centrifugadas a $14.000 \mathrm{rpm}$ durante 10 minutos. Em seguida, o plasma foi coletado em tubos de 1,5 ml. A urina coletada também foi armazenada em tubos de 1,5 ml. Considerando que o PAH na urina não é estável, imediatamente após os experimentos de clearance, as amostras de plasma ou urina foram submetidas às análises para obtenção dos valores do fluxo sanguíneo renal e do ritmo de filtração glomerular. Durante os procedimentos de coletas, todas as amostras foram mantidas em recipiente com gelo, para evitar degradação de componentes biológicos. 


\subsubsection{Perfusão Renal}

Ao final de cada experimento de clearance, a artéria aorta descendente abdominal foi canulada com cateter de polietileno PE 50 (Sigma). O rim direito foi removido para análise da expressão proteica e a perfusão do rim esquerdo foi realizada com tampão fosfato salino (PBS) - [NaCl 150 (mM), Fosfato de Sódio Monobásico (2.8 mM), Fosfato de Sódio Dibásico $(7.2 \mathrm{mM})$ ] gelado, a uma velocidade média de $4 \mathrm{ml} / \mathrm{min}$, através da bomba peristáltica (Milan - Equipamentos Científicos), por aproximadamente $10 \mathrm{~min}$. Em seguida, o rim esquerdo foi reperfundido com uma solução de formalina tamponada a $4 \%$ por cerca de 10 min, removido e armazenado na mesma solução de formalina por 24 horas. Após este período, o rim foi transferido para uma solução de álcool $70 \%$ e emblocado com parafina para procedimentos de análises histológicas.

\subsubsection{Avaliação da Função Renal}

Para avaliar o Ritmo de Filtração Glomerular (RFG), utilizamos os dados obtidos com o clearance de inulina [análise pelo método de antrona, modificado por Jermyn et al. (1956). Os valores de fluxo plasmático renal (FPR) foram obtidos através do clearance de PAH (pela reação com N-Naftil), conforme demonstrado por Smith et al. (1945), uma vez que esta substância é totalmente eliminada pelos rins.

As concentrações de inulina e PAH no plasma e na urina foram avaliadas por espectrofotometria colorimétrica. Para calcularmos o clearance (C) dessas substâncias, utilizamos a equação:

$$
\mathbf{C}_{\mathbf{x}}=\left(\mathbf{U}_{\mathbf{x}} \mathbf{x} \mathbf{V}\right) / \mathbf{P}_{\mathbf{x}}
$$

Onde:

$\mathbf{U}_{\mathbf{x}}$ é a concentração de inulina ou PAH na urina

V é o fluxo urinário e

$\mathbf{P}_{\mathbf{x}}$ é a concentração de inulina ou PAH no plasma 


\subsubsection{Parâmetros renais e plasmáticos}

As osmolalidades $\left(\mathrm{mOsm} / \mathrm{kgH}_{2} \mathrm{O}\right)$ da urina e do plasma foram mensuradas no osmômetro (Micro Osmometer, Precision Systems). $\mathrm{O} \mathrm{pH}$ das amostras foi avaliado utilizando pHmetro (ABL 5, Rodiometer Compenhagen). Os níveis de $\mathrm{Na}^{+}$e $\mathrm{K}^{+}$na urina e no plasma foram avaliados no fotômetro de chama (9180 Electrolyte Analyzer, Roche). A carga excretada de amônia foi analisada por método colorimétrico e as cargas excretadas (CE) de $\mathrm{Na}^{+}$e $\mathrm{K}^{+}$, foram calculadas pela fórmula:

$$
\mathrm{CE}_{\mathbf{x}}=\mathbf{U}_{\mathbf{x}} \mathbf{x} \mathbf{V}
$$

Onde:

$\mathbf{U}_{\mathbf{x}}$ é a concentração do íon na urina

V é o fluxo urinário.

A Fração de Excreção (FE) dos íons $\mathrm{Na}^{+}$e $\mathrm{K}^{+}$, foi obtida a partir da equação:

$$
\mathrm{FE}_{\mathrm{x}}=\left(\mathrm{CE}_{\mathrm{x}} / \mathrm{CF}_{\mathrm{x}}\right) \times 100 \%
$$

Onde:

CE é a carga excretada

CF é a carga filtrada $\left(R F G \times P_{x}\right)$

\subsection{Ensaios enzimáticos para a dosagem de renina e hormônios}

O sangue foi coletado e após a centrifugação a $14.000 \mathrm{rpm}$ em ambiente refrigerado o plasma foi coletado e congelado. Em seguida, de acordo com o protocolo de cada fabricante, os reagentes de cada kit foram preparados em placas de 96 poças junto com amostras de plasma. Após a reação enzimática proposta em cada kit, realizou-se por espectrofotometria, a quantificação plasmática de renina e aldosterona. 
$2 \mathrm{O}$ tecido renal foi triturado em nitrogênio líquido utilizando-se um tampão RIPA mais "cocktail" de inibidores de proteases (pestatina - 0,7 $\mathrm{mg} / \mathrm{ml}$, leupeptina - 0,5 $\mathrm{mg} / \mathrm{ml}$ e PMSF (phenylmethylsulfonylfluoride) - $40 \mathrm{mg} / \mathrm{ml}$ ). Em seguida, as amostras foram homogeneizadas através do sonicador (Sonic vibracel - VCX 130 PB) e mantidas em agitação por 2 horas a $4{ }^{\circ} \mathrm{C}$. Após este período, as amostras foram centrifugadas a $4.000 \mathrm{rpm}$ por 60 minutos a $4{ }^{\circ} \mathrm{C}$ e apenas o sobrenadante foi coletado. Para cada amostra se determinou a concentração de proteínas totais, utilizando como base o método descrito por Lowry (1951) e o espectofotômetro (BioTek XS2).

\subsection{Análise da expressão protéica por Western Blot}

O tecido renal foi triturado em nitrogênio líquido utilizando-se um tampão RIPA mais “cocktail" de inibidores de proteases (pestatina - 0,7 mg/ml, leupeptina - 0,5 mg/ml e PMSF (phenylmethylsulfonylfluoride) - $40 \mathrm{mg} / \mathrm{ml}$ ). Em seguida, as amostras foram homogeneizadas através do sonicador (Sonic vibracel - VCX 130 PB) e mantidas em agitação por 2 horas a 4 ${ }^{\circ} \mathrm{C}$. Após este período, as amostras foram centrifugadas a $4.000 \mathrm{rpm}$ por 60 minutos a $4{ }^{\circ} \mathrm{C} \mathrm{e}$ apenas o sobrenadante foi coletado. Para cada amostra se determinou a concentração de proteínas totais, utilizando como base o método descrito por Lowry (1951) e o espectofotômetro (BioTek XS2).

\subsubsection{Preparação de membranas}

Após a avaliação da concentração de proteínas totais, as amostras foram diluídas em tampão para eletroforese (Tris-HCl62.5 mM; pH 6,8; SDS 2\%; glicerol 20\%; $\beta$ mercaptoetanol $1,96 \%$ e azul de bromofenol 0,05\%) e incubado a $100{ }^{\circ} \mathrm{C}$ por 15 minutos. Em seguida, as amostras foram aplicadas, juntamente com um padrão de massa molecular específico (Bio-Rad), no gel de poliacrilamida (10\% com espessura de 1,5 mm), o qual foi submerso em tampão de eletroforese (Tris-base $25 \mathrm{mM}$; glicina $192 \mathrm{mM}$ e pH 7,3). A corrida das amostras no gel foi efetuada a $150 \mathrm{~mA}$, sendo interrompida quando a linha do corante de azul de bromofenol atingir a extremidade inferior do gel. 


\subsubsection{Transferência de proteínas do gel para a membrana de nitrocelulose}

Após a eletroforese em gel de poliacrilamida-SDS, os polipeptídeos contidos no gel foram transferidos para uma membrana de nitrocelulose (Immobilon-P TransferMembrane, Millipore). A membrana foi previamente tratada com tampão de transferência (Tris base 25 mM; glicina 192 mM e metanol 20\%), por cerca de 20 minutos. Para a transferência, foi utilizado um sistema tipo sanduíche, submerso em tampão de transferência, sobre o qual foi aplicada uma voltagem de $100 \mathrm{mV}$, durante 1 hora. Após esse período, a membrana foi transferida para uma solução de bloqueio $(\mathrm{NaCl} 150$ mM; Fosfato de Sódio Monobásico (2,8 mM); Fosfato de Sódio Dibásico (7,2 mM); leite em pó desnatado (5\%); Tween 20 $(0,1 \%)$ (Sigma) por uma hora, para bloquear possíveis ligações inespecíficas. Em seguida, a membrana foi incubada com anticorpo primário específico previamente diluído em solução de bloqueio $(1: 1000 \mathrm{v} / \mathrm{v})$, por 12 horas a $4^{\circ} \mathrm{C}$, com leve agitação. Para remover o excesso do anticorpo, foram realizadas 8 lavagens com solução de bloqueio (cada uma por 5 minutos). Em seguida, a membrana foi incubada por mais 1 hora com anticorpo secundário conjugado, em solução de bloqueio (1:2000 v/v) e novamente lavada como acima descrito. Após essas etapas, a membrana foi exposta ao reagente para imunodetecção através de luminescência ECL (Amersham), por 1 minuto. Subseqüentemente, foi exposta em filme Hyperfilm ${ }^{\mathrm{TM}}$ MP (Amersham), por 30 segundos ou mais, a temperatura ambiente).

A proteína analisada por Western blot foi o NHE3, identificada pelo anticorpo antiNHE3 (Santa Cruz Biotechnology).

\subsection{Análise morfológica dos rins}

\subsubsection{Preparação dos cortes histológicos}

Os rins foram removidos e seccionados em corte transversal. Em seguida foram mergulhados na solução de formalina $4 \%$ por 24 horas. Após este período, os rins foram transferidos para uma solução de álcool 70\%, emblocados com parafina e encaminhados para o setor de Patologia da Faculdade de Medicina da USP, para preparação de cortes 
histológicos, com expessura de $4 \mu \mathrm{m}$ e coloração pela técnica de hematoxilina e eosina (HE) (EHRLICH, 1886).

\subsubsection{Determinação da área glomerular}

Os cortes histológicos foram observados em microscópio triocular (Nikon) acoplado em uma câmera de vídeo (Nikon) e as imagens adquiridas foram projetadas em uma tela de microcomputador. Para análise da área glomerular, foram estudados 50 campos corticais aleatórios, em cada lâmina. Utilizando-se o programa de análise de imagens (Nis Elements Nikon), foram avaliados os diâmetros glomerulares e a área de todos os glomérulos identificados em cada campo. As imagens foram adquiridas em aumento de 200x.

\subsubsection{Análise da morfologia glomerular, tubular proximal e intersticial.}

Utilizando as mesmas lâminas coradas pela técnica de HE, se avaliou possíveis alterações morfológicas nos glomérulos, interstício e principalmente no túbulo proximal, principal segmento de reabsorção no néfron. As análises foram realizadas em todos os cortes histológicos em aumento de 400x e para aquisição das imagens foi utilizado o programa de análise de imagens (Nis Elements - Nikon).

\subsection{Drogas e Reagentes}

Sigma: Inulina, PAH e espironolactona; Bachem: Angiotensina II; Abcam: anticorpo primário anti-actina; Santa Cruz : anticorpo primário anti-NHE3; StressMark: anti- $\alpha, \beta, \gamma-$ Enac; JacksonImmuno Research: anticorpos secundários: anti-mouse e anti-rabbit; Amersham: sistema de quimiluminescência para Western blot; Roche: liquemine (heparina); Verbac: Zoletil; Vetbrands: Xilasina e Quetamina. Enzo life Science: kits para detecção de aldosterona; Antigenassay kit: Kits para detecção de renina; As demais drogas e reagentes foram procedentes da Invitrogen, Sigma e Fisher Scientific. 


\subsection{Análise Estatística}

A análise estatística dos dados foi realizada por teste $t$ - Student para dados nãopareados, ou análise de variância (ANOVA) de uma ou duas vias, completamente randomizada, seguida pelo teste post-hoc de Bonferroni, realizados a partir do programa GraphPadPrism Software (San Diego, CA, USA). Valores de $\mathrm{p}<0,05$ foram considerados estatisticamente significativos. Os resultados serão apresentados como um valor médio \pm erro padrão. A intensidade dos blots será avaliada por densitometria óptica, utilizando o software ScionImage (imlD - Pharmacia Biotech, Uppsala, SW) e os valores normalizados pelos valores médios de actinas. 


\section{RESULTADOS}

Com o intuito de investigar a importância tanto da progressão quanto da permanência da hipertensão arterial induzida por Ang II, sobre as possíveis alterações na função e morfologia renal, o estudo foi inicialmente realizado em dois grupos de animais tratados com Ang II: 1) ratos tratados por 15 dias, período em que se observa um acentuado deslocamento da pressão arterial e 2) ratos tratados por 28 dias, período em que se espera uma hipertensão mais estável.

Além disso, foi também investigado a participação da aldosterona na função e morfologia renal. Para tal, dois grupos adicionais foram tratados com Ang II e espironolactona (inibidor do receptor MR): Ang II 15 dias + espironolactona e Ang II 28 dias + espironolactona.

Todos os grupos tratados serão apresentados com seus respectivos controles.

\subsection{Efeito da Ang II e/ou espironolactona sobre a pressão arterial}

Conforme apresentado na Figura 3 e Tabela 1, os resultados indicam que os animais submetidos ao tratamento com Ang II apresentaram aumento da pressão arterial já na primeira semana de tratamento. Conforme esperado, este aumento foi progressivo em ambos os grupos (15 ou 28 dias de tratamento) e curiosamente, ao final do tratamento do grupo de 28 dias, a pressão arterial encontrava-se ainda com um pequeno deslocamento, indicando a necessidade de um período maior para instalação definitiva da hipertensão arterial induzida por Ang II na dose utilizada.

A espironolactona, quando administrada sozinha, não alterou a pressão arterial dos grupos estudados (15 e 28 dias), mas reduziu parcialmente o efeito pressórico da Ang II nos dois grupos. 
Figura 3 - Efeito da Ang II e/ou espironolactona sobre a pressão arterial.

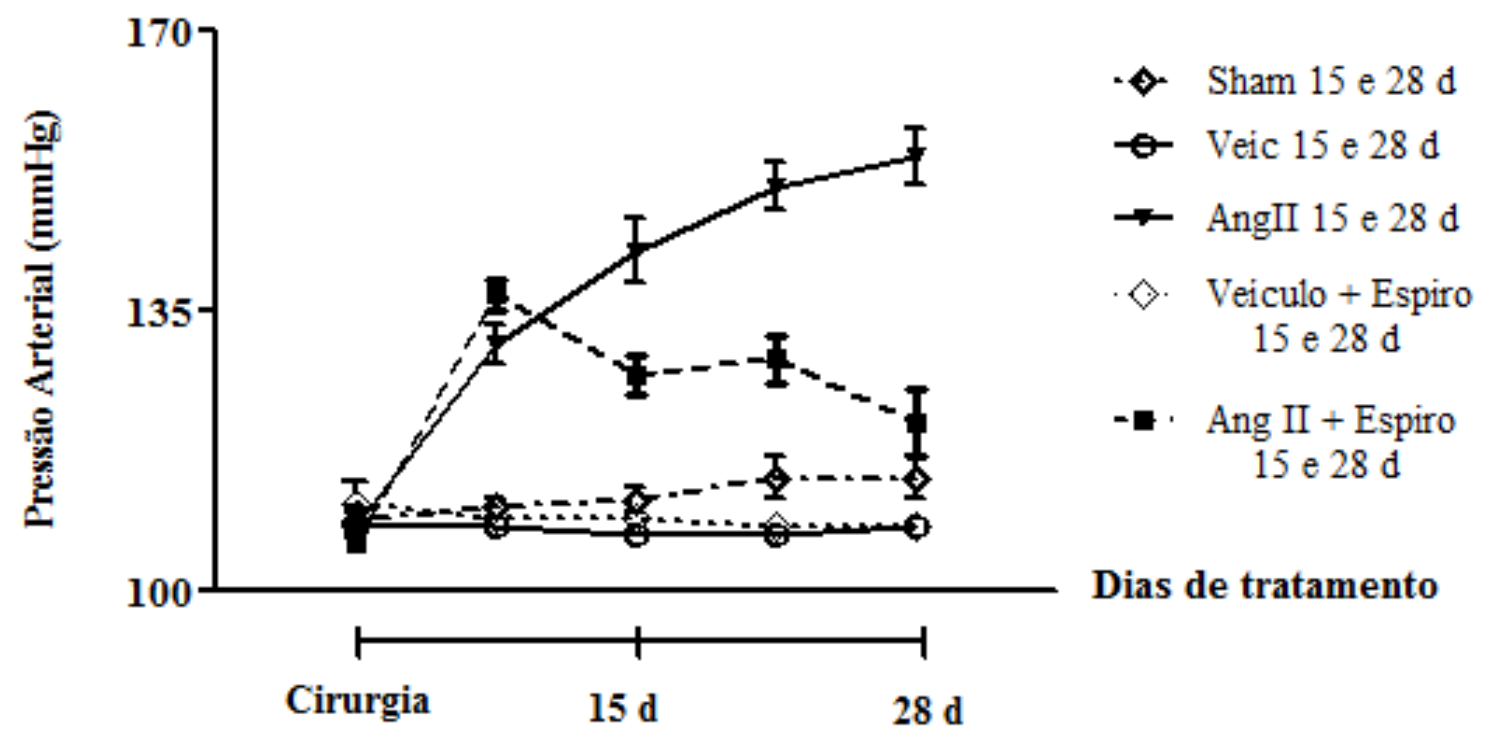

Ang II (200 ng/kg/min) e/ou espironolactona (100 mg/kg/dia). Valores expressos como média \pm erro padrão.

Fonte: $\mathrm{O}$ autor.

Tabela 1 - Efeito da Ang II e/ou espironolactona sobre a Pressão Arterial.

\begin{tabular}{|c|c|c|c|c|c|}
\hline & & Pressão & Arterial & (mmHg) & \\
\hline Grupos & Sham & Ang II & Veículo & Espiro & Esp.+ Ang II \\
\hline 15 dias & $109 \pm 1,5(5)$ & $142 \pm 2,7(5)^{*}$ & $107 \pm 0,6(6)$ & $109 \pm 0,5(5)$ & $124 \pm 2,9(5)^{+\$ \#}$ \\
\hline 28 dias & $111 \pm 0,8(5)$ & $163 \pm 3,6(5)^{*}$ & $108 \pm 0,4(5)$ & $108 \pm 0,5(6)$ & $127 \pm 5,3(5)^{+\$ \#}$ \\
\hline
\end{tabular}

Ang II II (200 ng/kg/min) e/ou espironolactona (100 mg/kg/dia). Valores expressos como média \pm erro padrão ao final do tratamento. ${ }^{*} \mathrm{P}<0.05$ vs. Sham; ${ }^{+} \mathrm{P}<0.05$ vs. Veículo; ${ }^{\$} \mathrm{P}<0.05$ vs. Espironolactona; ${ }^{\#} \mathrm{P}<0.05$ vs. Ang II. Espiro = espironolactona; $(\mathrm{n})=$ número de animais por grupo.

Fonte: O autor. 


\subsection{Efeito do Tratamento com Ang II e/ou epironolactona sobre o desenvolvimento dos animais}

O peso corpóreo foi monitorado semanalmente e os valores apresentados correspondem à variação (peso inicial - peso final) (Tab. 2). De forma geral, o tratamento crônico com Ang II e/ou espironolactona não interferiu no peso dos animais. No entanto, no grupo de Ang II (15 dias), a espironolactona induziu uma queda no ganho de peso, efeito não observado no grupo com Ang II (28 dias).

Tabela 2 - Variação do peso corpóreo.

\begin{tabular}{lccccc}
\hline & \multicolumn{5}{c}{ Variação de Peso Corpóreo (g) (final - inicial) } \\
\hline Tratamento & Sham & Veículo & Ang II & Espiro & $\begin{array}{c}\text { Espiro + } \\
\text { Ang II }\end{array}$ \\
\hline $\mathbf{1 5}$ dias & $99,5 \pm 5,6$ & $79 \pm 1,6$ & $105 \pm 9,2$ & $75 \pm 3,4$ & $64 \pm 7,5^{\#}$ \\
$\mathbf{2 8}$ dias & $165 \pm 11$ & $151 \pm 6,9$ & $155 \pm 10$ & $178 \pm 9,0$ & $147 \pm 6,8$ \\
\hline
\end{tabular}

Efeito da Ang II (200 ng/kg/min) e/ou espironolactona (100 mg/kg/dia) sobre o peso corpóreo dos animais. Espironolactona (Espiro.) gramas (g), número de animais por grupo (n). Valores expressos como média \pm erro padrão. ${ }^{\#} \mathrm{P}<0.05$ vs. Ang II.

Fonte: O autor.

Após cada experimento, se avaliou o peso absoluto de órgãos como rins, coração, pulmões e fígado. O tratamento com Ang II não alterou o peso de nenhum órgão, quando comparado aos respectivos controles (Tab. 3). Como não se observou alterações significativas entre os grupos tratados com Ang II, optamos por não avaliar este parâmetro nos grupos tratados com espironolactona. 
Tabela 3 - Efeito da Ang II sobre o peso absoluto de órgãos.

\begin{tabular}{lcccc}
\hline \multicolumn{5}{c}{ Peso absoluto dos órgãos (g) } \\
\hline & Rim Esquerdo & Coração & Pulmões & Fígado \\
\hline & & & & \\
Sham 15 d (6) & $1.13 \pm 0.04$ & $0.62 \pm 0.05$ & $1.23 \pm 0.06$ & $8.04 \pm 0.34$ \\
Ang II 15 d (6) & $1.01 \pm 0.04$ & $0.59 \pm 0.03$ & $1.27 \pm 0.05$ & $8.03 \pm 0.43$ \\
Sham 28 d (7) & $1.07 \pm 0.02$ & $0.71 \pm 0.03$ & $1.17 \pm 0.12$ & $8.76 \pm 0.33$ \\
Ang II 28 d (7) & $1.07 \pm 0.04$ & $0.75 \pm 0.02$ & $1.48 \pm 0.26$ & $10.93 \pm 2.38$ \\
& & & & \\
\hline
\end{tabular}

Efeito da Ang II (200 ng/kg/min) sobre o peso absoluto de órgãos. Valores expressos como média \pm erro padrão. dias $(\mathrm{d})$, gramas $(\mathrm{g})$, número de animais por grupo $(\mathrm{n})$.

Fonte: O autor.

\subsection{Efeito da Ang II e/ou Espironolactona sobre as concentrações plasmáticas de renina e aldosterona.}

Conforme apresentado na Tabela 4, o tratamento com Ang II por 15 dias aumentou a concentração plasmática de renina, mas não alterou a concentração de aldosterona. A espironolactona aumentou a resposta da Ang II (15 dias) tanto para a renina quanto para aldosterona.

A mesma tabela mostra que o grupo tratado com Ang II por 28 dias não apresentou alteração na concentração plasmática de renina, mas aumentou significantemente a concentração de aldosterona. A espironolactona aumentou a resposta da Ang II para a liberação de aldosterona. 
Tabela 4 - Efeito da Ang II e/ou espironolactona sobre as concentrações plasmáticas de renina e aldosterona.

\begin{tabular}{lcc}
\hline & $\begin{array}{c}{[\text { Renina }]_{\mathbf{p}}} \\
(\mathbf{p g} / \mathbf{m l})\end{array}$ & $\begin{array}{c}\text { [Aldosterona }]_{\mathbf{p}} \\
(\mathbf{p g} / \mathbf{m l})\end{array}$ \\
\hline Sham 15 d (7) & $2,38 \pm 0,30$ & $643 \pm 59,3$ \\
Ang II 15 d (6) & $9,29 \pm 1,8$ & $613 \pm 135$ \\
Espiro + Ang II 15 d (6) & $20,76 \pm 4,4$ & $3.944 \pm 806^{*}$ \\
& & \\
Sham 28 d (6) & $2,58 \pm 0,25$ & $887 \pm 193$ \\
Ang II 28 d (7) & $2,09 \pm 0,24$ & $1.663 \pm 326^{*}$ \\
Espiro + Ang II 28 d (7) & $2,37 \pm 0,42$ & $3.452 \pm 121^{* \#}$ \\
& & \\
\hline
\end{tabular}

${ }^{*} \mathrm{P}<0.05$ vs. Sham; ${ }^{\#} \mathrm{P}<0.05$ vs. Ang II. Dias (d), números de animais (n), plasma (p), picograma (pg).

Fonte: O autor.

\subsection{Estudos de Função Renal}

Os estudos de clearance renal foram realizados em grupos de 5 a 6 animais e em cada experimento se coletou 4 amostras de sangue e urina, para posterior análise.

\subsubsection{Efeito da Ang II e/ou Espironolactona sobre o Fluxo Plasmático Renal (FPR)}

Na figura 4 estão representados os valores médios do FPR dos animais tratados com Ang II por 15 dias (A) ou 28 dias (B). Em ambos os grupos (15 e 28 dias), a Ang II induziu uma queda significante do FPR, quando comparado aos respectivos controles (Sham). A espironolactona sozinha, não afetou o FPR no grupo de Ang II (15 dias), mas reduziu este parâmetro no grupo de Ang II (28 dias). 
Quando associada à Ang II, a espironolactona não só aboliu o efeito inibidor da Ang II sobre o FPR nos dois grupos, como induziu um aumento significante desse parâmetro, quando comparado aos grupos tratados somente com Ang II ou controles. Os valores médios de cada grupo encontram-se na tabela 5.

Figura 4 - Efeito da Ang II e/ou Espironolactona sobre o Fluxo Plasmático Renal (FPR).

A) Grupo 15 dias

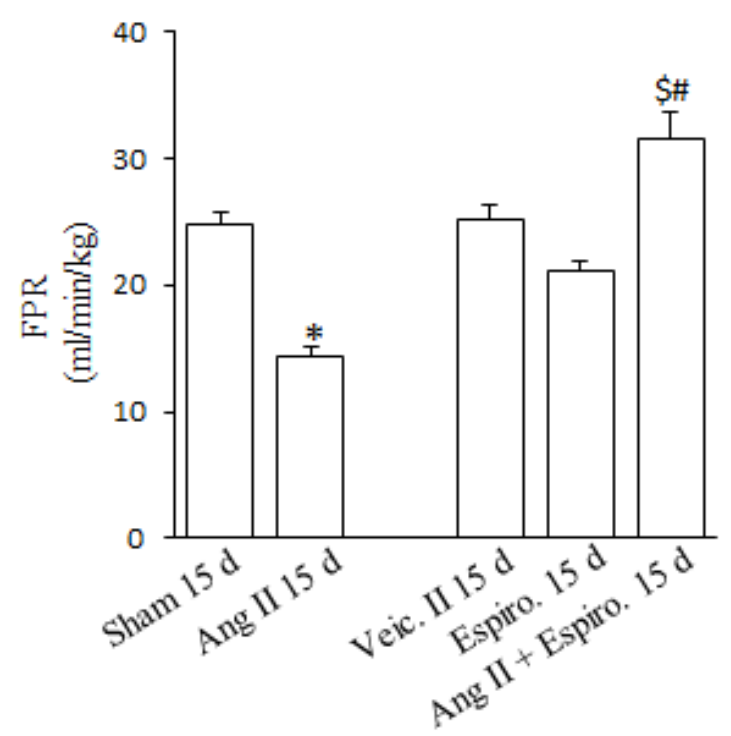

B) Grupo 28 dias

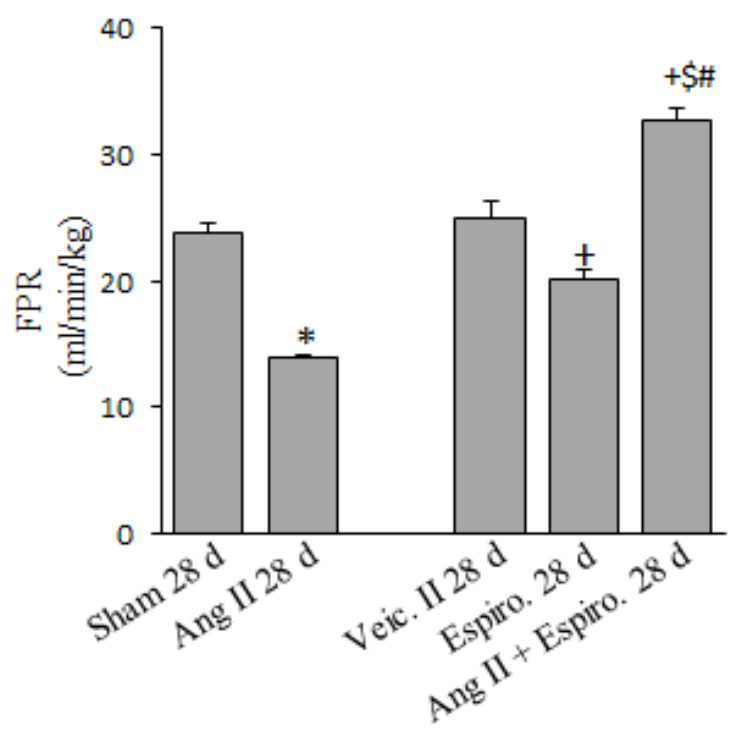

Efeito da Ang II (200 ng/kg/min) e/ou espironolactona (100 mg/kg/dia) sobre o Fluxo Plasmático Renal (FPR). (A) animais com 15 dias de tratamento $(n=5-6)$ e $(\mathbf{B})$ animais com 28 dias de tratamento $(n=5-6)$. Valores expressos como média de 4 coletas por animal em cada grupo \pm erro padrão. ${ }^{*} \mathrm{p}<0.05$ vs Sham; ${ }^{\#} \mathrm{p}<0.05$ vs Ang II; ${ }^{+} \mathrm{p}<0.05$ vs veículo; $\$ \mathrm{p}<0.05$ vs espironolactona (Espiro), dias (d).

Fonte: O autor. 


\subsubsection{Efeito da Ang II e/ou Espironolactona sobre o Rítmo de Filtração Glomerular (RFG)}

Na figura 5 estão representados os valores médios do RFG dos animais tratados com Ang II por 15 dias (A) ou 28 dias (B). Em ambos os grupos estudados, a Ang II induziu uma significante queda no RFG e o mesmo comportamento foi observado nos grupos tratados somente com espironolactona. Por outro lado, a espironolactona como fez no FPR, não apenas aboliu o efeito inibidor da Ang II, como estimulou o aumento do RFG nos dois grupos. Os valores médios de cada grupo encontram-se na tabela 5.

Figura 5 - Efeito da Ang II e/ou Espironolactona sobre o Ritmo de Filtração Glomerular (RFG).

A) Grupo 15 dias

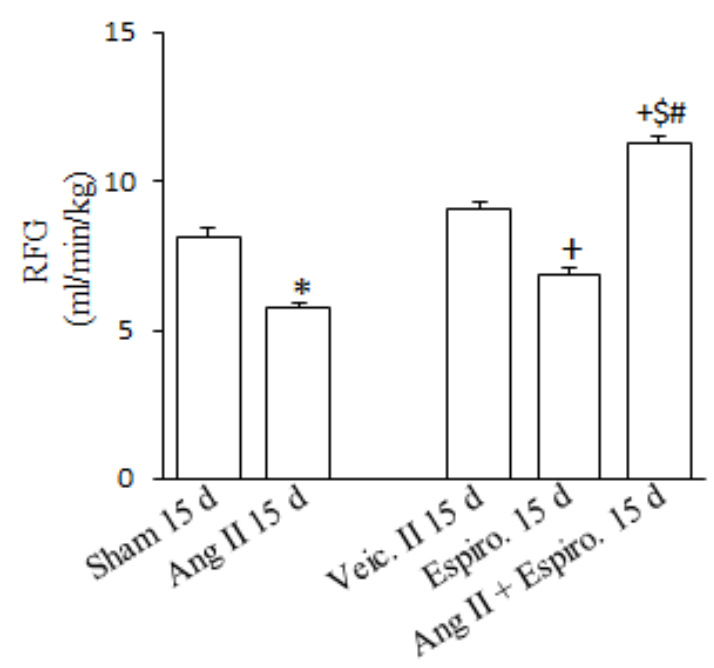

B) Grupo 28 dias

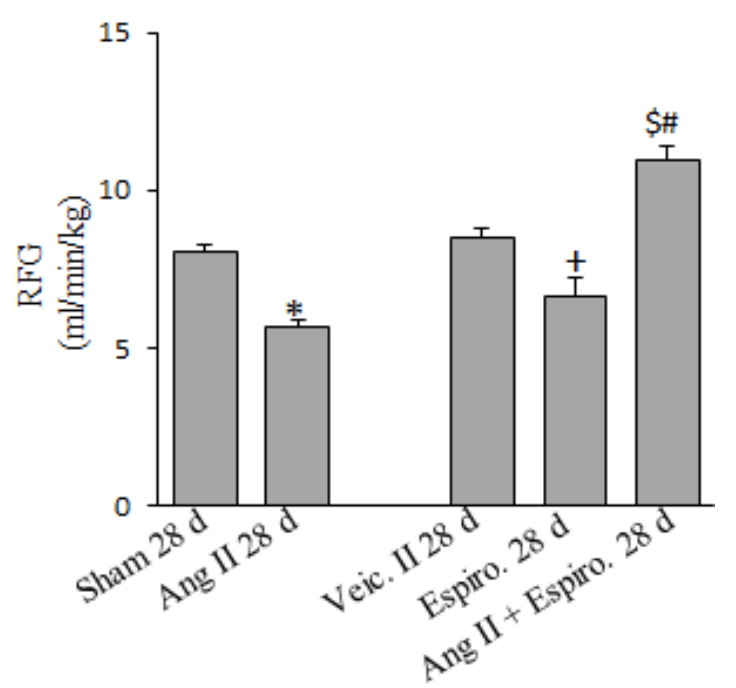

Efeito da Ang II (200 ng/kg/min) e/ou espironolactona (100 mg/kg/dia) sobre o Ritmo de Filtração Glomerular (RFG). (A) animais com 15 dias de tratamento (B) animais com 28 dias de tratamento. Valores expressos como média de 4 coletas por animal em cada grupo \pm erro padrão. ${ }^{*} \mathrm{p}<0.05 \mathrm{vs}$ Sham; ${ }^{\#} \mathrm{p}<0.05 v s$ Ang II; ${ }^{+} \mathrm{p}<0.05 v s$ veículo; ${ }^{\$} \mathrm{p}<0.05 v s$ espironolactona (Espiro), dias (d).

Fonte: O autor. 


\subsubsection{Efeito da Ang II e/ou Espironolactona sobre a Fração de Filtração (FF)}

A fração de filtração (FF) é o porcentual do volume de plasma filtrado em determinado período. Neste caso, a FF é obtida pela razão [(RGF/FPR) x 100]. A Figura 6 mostra que a Ang II (15 ou 28 dias) induziu aumento da FF. A espironolactona, no entanto, corrigiu este parâmetro para valores próximos aos dos controles (sham e veículo). Os valores médios de cada grupo encontram-se na tabela 5.

Figura 6 - Efeito da Ang II e/ou espironolactona sobre a Fração de Filtração (FF).
A) Grupo 15 dias
B) Grupo 28 dias
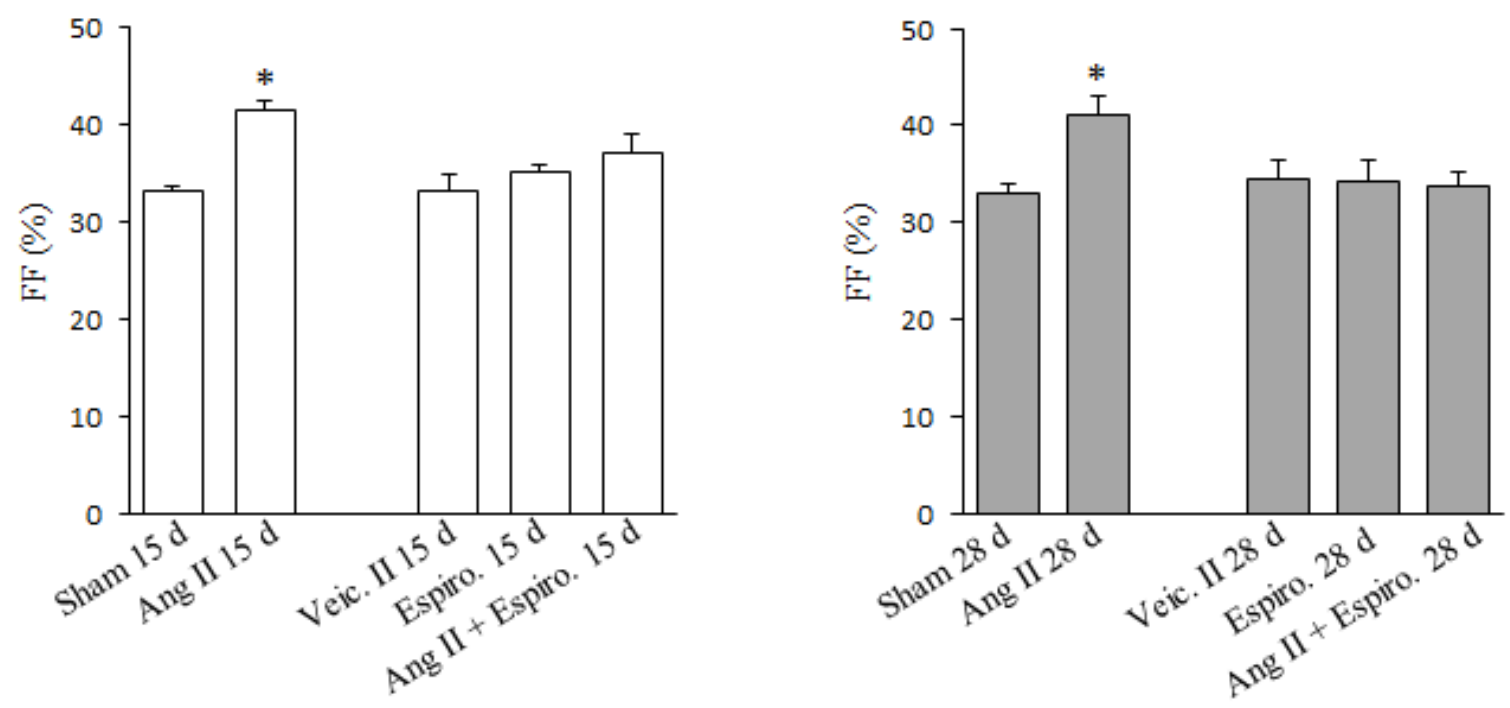

Efeito da Ang II (200 ng/kg/min) e/ou espironolactona (100 mg/kg/min) sobre a fração de filtração (FF). (A) animais com 15 dias de tratamento (B) animais com 28 dias de tratamento. Valores expressos como média de 4 coletas por animal em cada grupo \pm erro padrão. ${ }^{*} \mathrm{p}<0,05$ vs respectivos controles. Veículo (Veic), Espironolactona (Espiro), dias (d). 


\subsubsection{Efeito do tratamento com Ang II e/ou Espironolactona sobre o Fluxo Urinário (V)}

Conforme apresentado na Figura 7, o tratamento com Ang II por 15 (A) ou 28 (B) dias, induziu uma significante queda no fluxo urinário quando comparado aos respectivos grupos controles. Em ambos os grupos, a espironolactona aboliu o efeito da Ang II, permitindo a retomada do fluxo urinário para valores próximos aos controles. Os valores médios de cada grupo encontram-se na tabela 5.

Figura 7 - Efeito da Ang II e/ou espironolactona sobre Fluxo Urinário (V).
A) Grupo 15 dias
B) Grupo 28 dias
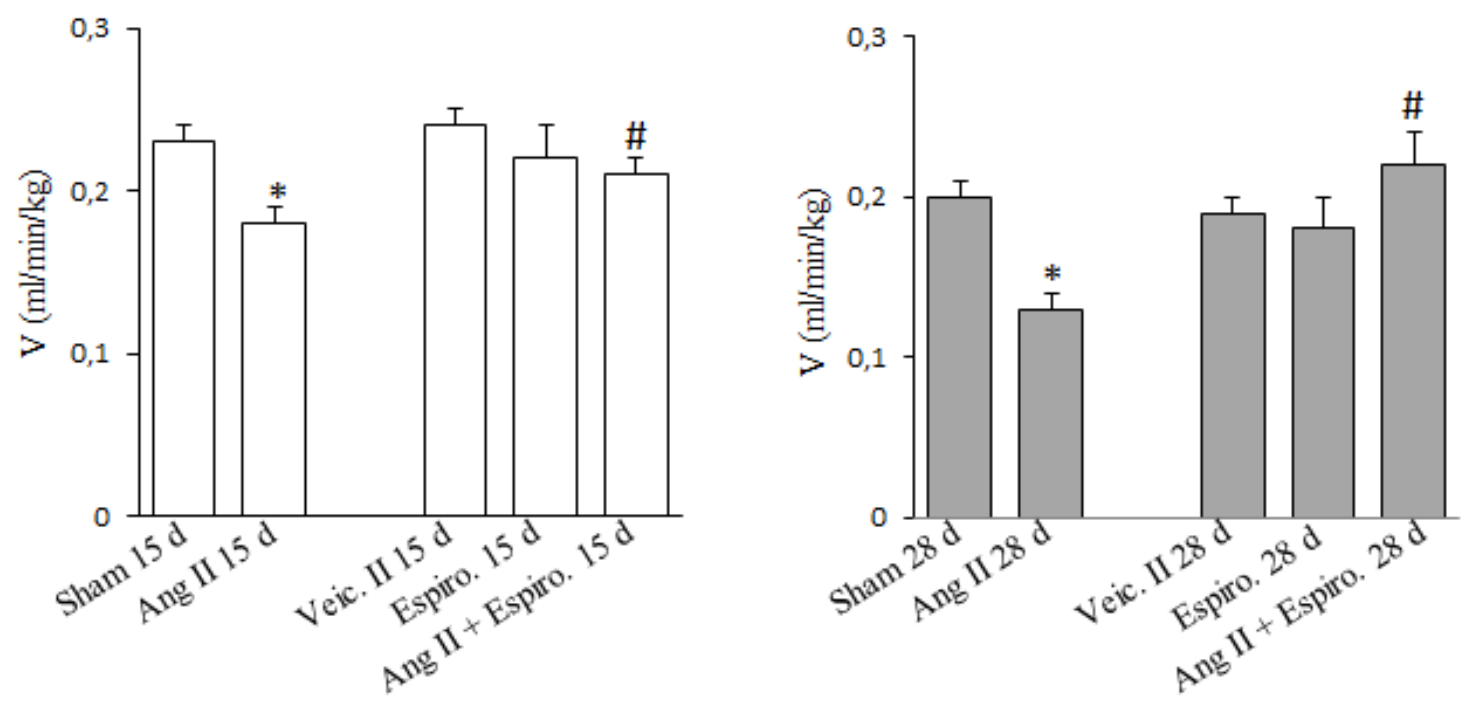

Efeito da Ang II (200 ng/kg/min) e/ou espironolactona (100 mg/kg/dia) sobre Fluxo Urinário (V). (A) animais com 15 dias de tratamento (B) animais com 28 dias de tratamento. Valores expressos como média de 4 coletas por animal em cada grupo \pm erro padrão. ${ }^{*} \mathrm{p}<0,05 v \mathrm{~s}$ Sham e ${ }^{\#} \mathrm{p}<0,05$ vs Ang II. Fluxo urinário (V), Veículo (Veic); Espironolactona (Espiro), $\operatorname{dias}(\mathrm{d})$.

Fonte: $\mathrm{O}$ autor. 
Tabela 5 - Efeito da Ang II e/ou espironolactona sobre os parâmetros hemodinâmicos e de função tubular de ratos.

\begin{tabular}{|c|c|c|c|c|c|}
\hline & \multicolumn{5}{|c|}{ Função Renal } \\
\hline & & $\begin{array}{c}\text { FPR } \\
(\mathrm{ml} / \mathrm{min} / \mathrm{Kg}) \\
\end{array}$ & $\begin{array}{c}\text { RFG } \\
(\mathrm{ml} / \mathrm{min} / \mathrm{Kg}) \\
\end{array}$ & $\begin{array}{l}\text { FF } \\
(\%) \\
\end{array}$ & $\begin{array}{c}\mathrm{V} \\
(\mathrm{ml} / \mathrm{min} / \mathrm{Kg}) \\
\end{array}$ \\
\hline Sham $15 \mathrm{~d}$ & (6) & $24,89 \pm 0,93$ & $8,11 \pm 0,29$ & $33,12 \pm 0,54$ & $0,23 \pm 0,01$ \\
\hline Ang II 15 d & (5) & $14,28 \pm 0,87^{*}$ & $5,77 \pm 0,15^{*}$ & $41,42 \pm 1,07^{*}$ & $0,18 \pm 0,01^{*}$ \\
\hline Veículo 15 d & (6) & $25,50 \pm 1,09$ & $9,08 \pm 0,24$ & $33,11 \pm 1,81$ & $0,24 \pm 0,01$ \\
\hline Espiro $15 \mathrm{~d}$ & (5) & $21,22 \pm 0,66$ & $6,84 \pm 0,26^{+}$ & $35,09 \pm 0,84$ & $0,22 \pm 0,02$ \\
\hline Ang II + Espiro 15 d & (5) & $31,55 \pm 2,17^{\$ \#}$ & $11,24 \pm 0,30^{+\$ \#}$ & $37,13 \pm 2,01$ & $0,21 \pm 0,01^{\#}$ \\
\hline Sham $28 \mathrm{~d}$ & (6) & $23,76 \pm 0,78$ & $8,07 \pm 0,24$ & $33,00 \pm 1,02$ & $0,20 \pm 0,01$ \\
\hline Ang II $28 \mathrm{~d}$ & (5) & $13,91 \pm 0,18^{*}$ & $5,65 \pm 0,25^{*}$ & $41,19 \pm 1,82^{*}$ & $0,13 \pm 0,01^{*}$ \\
\hline Veículo 28 d & (6) & $25,00 \pm 1,3$ & $8,50 \pm 0,31$ & $34,43 \pm 1,89$ & $0,19 \pm 0,01$ \\
\hline Espiro $28 \mathrm{~d}$ & (6) & $20,17 \pm 9,73^{+}$ & $6,66 \pm 0,59^{+}$ & $34,17 \pm 2,29$ & $0,18 \pm 0,02$ \\
\hline Ang II + Espiro $28 \mathrm{~d}$ & (5) & $32,68 \pm 1,02^{+\$ \#}$ & $10,99 \pm 0,44^{\$ \#}$ & $33,76 \pm 1,41$ & $0,22 \pm 0,02^{\#}$ \\
\hline
\end{tabular}

Efeito da Ang II (200 ng/kg/min) e/ou espironolactona (100 mg/kg/dia) sobre os parâmetros hemodinâmicos e de função tubular de ratos tratados com Ang II e/ou Espironolactona por 15 ou 28 dias. Valores expressos como média de 4 coletas por animal em cada grupo \pm erro padrão. * $\mathrm{p}<0,05$ vs Sham; ${ }^{+} \mathrm{p}<0.05$ vs veículo; \# $\mathrm{p}<0.05$ vs Ang II; ${ }^{\$} \mathrm{p}<0,05$ vs Espironolactona (Espiro); número de animais por grupo (n).

Fonte: O autor.

4.5 Efeito da Ang II e/ou Espironolactona sobre os parâmetros urinários

\subsubsection{Efeito da Ang II elou espironolactona sobre o pH e a carga excretada (CE) de $\mathrm{NH}_{4}$}

A Tabela 6, mostra os valores médios de $\mathrm{pH}$ da urina e plasma e da $\mathrm{CE}_{\mathrm{NH} 4}$ dos animais tratados com Ang II por 15 dias (A) ou 28 dias (B). Apenas o grupo de 15 dias (Ang II + espironolactona) apresentou uma queda significativa no pH urinário. Este resultado foi confirmado pelo aumento na carga excretada de $\mathrm{NH}_{4}$, conforme apresentado na Figura 8. 
Tabela 6 - Efeito da Ang II e/ou espironolactona sobre o pH da urina ou plasma e sobre a $\mathrm{CE}_{\mathrm{NH} 4}$.

\begin{tabular}{|c|c|c|c|}
\hline & $\begin{array}{c}\text { pH } \\
\text { Urina }\end{array}$ & $\begin{array}{c}\mathrm{pH} \\
\text { plasma }\end{array}$ & $\begin{array}{c}\mathrm{CE}_{\mathrm{NH} 4} \\
\mathrm{mEq} / \mathrm{min} / \mathrm{Kg}\end{array}$ \\
\hline Sham $15 \mathrm{~d}$ & $6,54 \pm 0,1$ & $7,29 \pm 0,02$ & $2,10 \pm 0,16$ \\
\hline Ang II $15 \mathrm{~d}$ & $6,69 \pm 0,07$ & $7,31 \pm 0,01$ & $1,83 \pm 0,24$ \\
\hline Veículo $15 \mathrm{~d}$ & $6,43 \pm 0,05$ & $7,30 \pm 0,01$ & $2,82 \pm 0,18$ \\
\hline Espiro $15 \mathrm{~d}$ & $6,58 \pm 0,2$ & $7,33 \pm 0,02$ & $2,02 \pm 0,06$ \\
\hline Ang II + Espiro 15 d (5) & $6,35 \pm 0,2^{\#}$ & $7,33 \pm 0,01$ & $2,93 \pm 0,18^{\# \$}$ \\
\hline Sham $28 \mathrm{~d}$ & $6,69 \pm 0,09$ & $7,31 \pm 0,01$ & $2,26 \pm 0,06$ \\
\hline Ang II $28 \mathrm{~d}$ & $6,34 \pm 0,20$ & $7,29 \pm 0,01$ & $2,56 \pm 0,14$ \\
\hline Veículo $28 \mathrm{~d}$ & $6,50 \pm 0,11$ & $7,32 \pm 0,01$ & $2,43 \pm 0,12$ \\
\hline Espiro 28 d & $6,69 \pm 0,03$ & $7,34 \pm 0,01$ & $2,41 \pm 0,09$ \\
\hline Ang II + Espiro 28 d (5) & $6,53 \pm 0,14$ & $7,30 \pm 0,01$ & $2,47 \pm 0,20$ \\
\hline
\end{tabular}

Efeito da Ang II (200 ng/kg/min) e/ou espironolactona (100 mg/kg/dia) sobre o $\mathrm{pH}$ da urina ou plasma e a Carga excretada do íon amônio $\left(\mathrm{CE}_{\mathrm{NH} 4}\right)$. (A) animais com 15 dias de tratamento (B) animais com 28 dias de tratamento. Valores expressos como média \pm erro padrão. ${ }^{\#} \mathrm{p}<0,05$ vs Ang II; ${ }^{\$} \mathrm{p}<0,05$ vs Espironolactona (Espiro), Veículo (Veic.).

Fonte: $\mathrm{O}$ autor. 
Figura 8 - Efeito da Ang II e/ou espironolactona sobre o pH e a carga excretada (CE) de $\mathrm{NH}_{4}$.
A) Grupo 15 dias
B) Grupo 28 dias
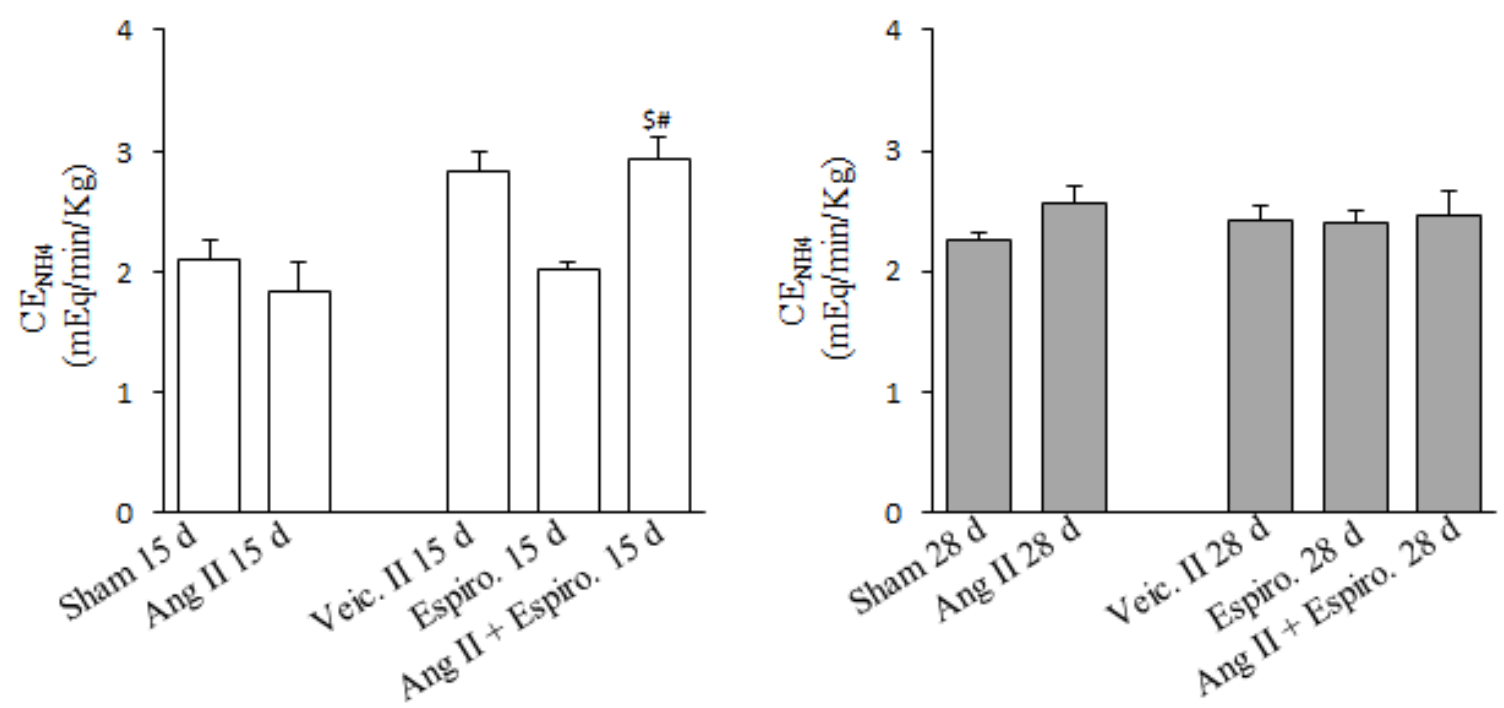

Efeito da Ang II (200 ng/kg/min) e/ou espironolactona (100 mg/kg/dia) carga excretada do íon amônio. (A) animais com 15 dias de tratamento (B) animais com 28 dias de tratamento. Valores expressos como média de 4 coletas por animal em cada grupo \pm erro padrão. ${ }^{\$} \mathrm{p}<$ 0,05 vs espironolactona $\mathrm{e}^{\#} \mathrm{p}<0,05$ vs Ang II. Veículo (Veic); Espironolactona (Espiro), dias (d).

Fonte: $\mathrm{O}$ autor.

\subsubsection{Efeito da Ang II e/ou Espironolactona sobre a Fração de Excreção de $\mathrm{Na}^{+}\left(\mathrm{FE}_{\mathrm{Na+}}\right)$}

Na figura 9 e tabela 7 estão representados os valores médios da Fração de Excreção do íon $\mathrm{Na}^{+}\left(\mathrm{FE}_{\mathrm{Na}}{ }^{+}\right)$dos animais tratados com Ang II por 15 dias (A) ou 28 dias (B). No grupo de 15 dias, a Ang II ou espironolactona não alterou a $\mathrm{FE}_{\mathrm{Na}}{ }^{+}$. No grupo de 28 dias, a Ang II reduziu a $\mathrm{FE}_{\mathrm{Na}}{ }^{+}$e a espironolactona aboliu o efeito da Ang II, levando este parâmetro para um valor próximo ao controle. 
Figura 9 - Efeito da Ang IIe/ou espironolactona sobre a fração de Excreção do íon $\mathrm{Na}^{+}\left(\mathrm{FE}_{\mathrm{Na}+}\right)$.
A) Grupo 15 dias
B) Grupo 28 dias
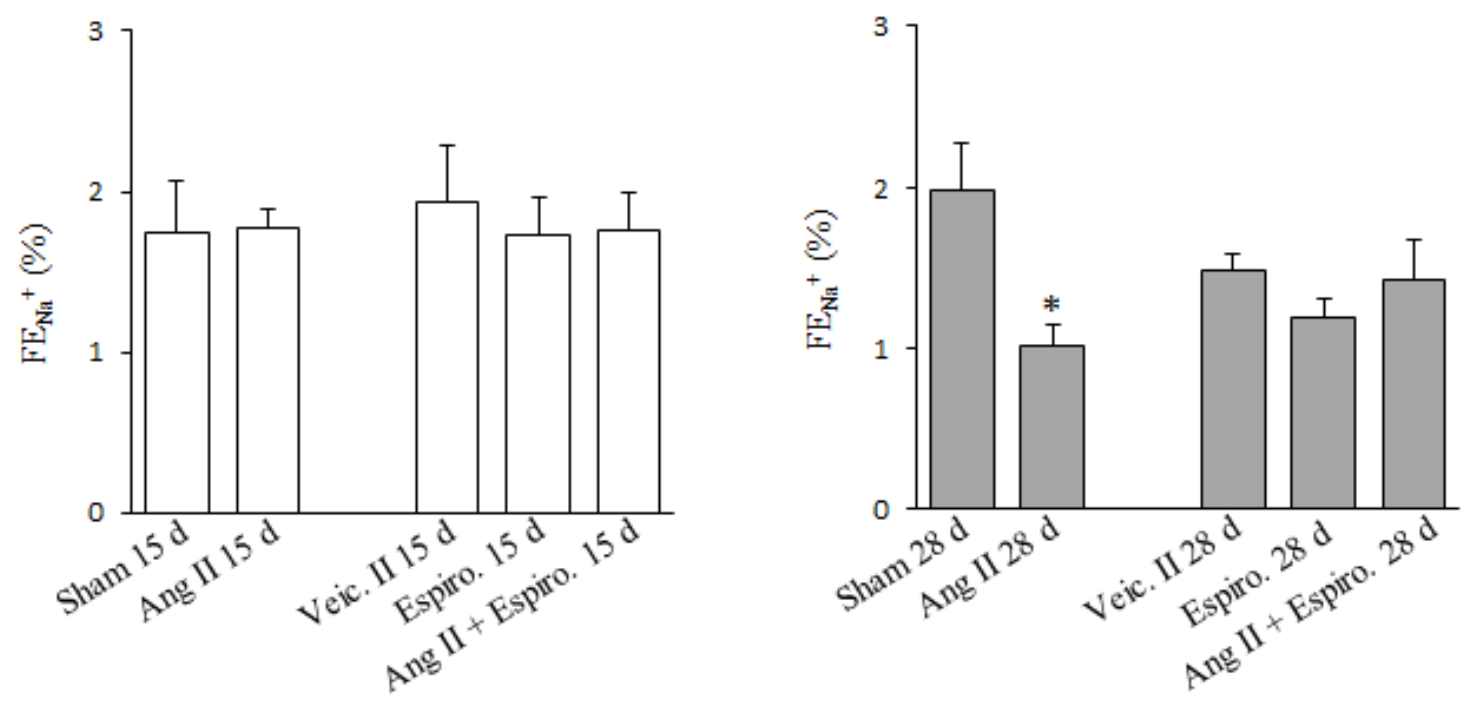

Efeito da Ang II (200 ng/kg/min) e/ou espironolactona (100 mg/kg/dia) sobre a Fração de Excreção de $\mathrm{Na}^{+}\left(\mathrm{FE}_{\mathrm{Na}}^{+}\right)$. (A) animais com 15 dias de tratamento (B) animais com 28 dias de tratamento. Valores expressos como média \pm erro padrão. ${ }^{*} \mathrm{p}<0,05$ vs Sham. Veículo (Veic.); Espironolactona (Espiro).

Fonte: $\mathrm{O}$ autor. 
Tabela 7 - Efeito da Ang II e/ou espironolactona sobre as concentrações do íon $\mathrm{Na}^{+}$no plasma e na urina.

Concentrações de $\mathrm{Na}^{+}$

\begin{tabular}{|c|c|c|c|c|c|c|}
\hline & & $\begin{array}{c}{\left[\mathrm{Na}^{+}\right]_{\mathrm{u}}} \\
(\mathrm{mEq} / \mathrm{min} / \mathrm{Kg}) \\
\end{array}$ & $\begin{array}{c}{\left[\mathrm{Na}^{+}\right]_{\mathrm{p}}} \\
(\mathrm{mEq} / \mathrm{min} / \mathrm{Kg})\end{array}$ & $\begin{array}{c}\mathrm{CF}_{\mathrm{Na}}{ }^{+} \\
(\mathrm{mEq} / \mathrm{min} / \mathrm{Kg})\end{array}$ & $\begin{array}{c}\mathrm{CE} \mathrm{Na}^{+} \\
(\mathrm{mEq} / \mathrm{min} / \mathrm{Kg})\end{array}$ & $\begin{array}{r}\mathrm{FE}_{\mathrm{Na}}^{+} \\
(\%) \\
\end{array}$ \\
\hline Sham 15 d & (6) & $91,67 \pm 7,5$ & $144,51 \pm 0,6$ & $1189,00 \pm 34,9$ & $20,37 \pm 2,8$ & $1,74 \pm 0,3$ \\
\hline Ang II 15 d & (5) & $81,00 \pm 6,3$ & $147,04 \pm 2,0^{*}$ & $848,73 \pm 21,4$ & $14,44 \pm 0,8$ & $1,78 \pm 0,1$ \\
\hline Veículo $15 \mathrm{~d}$ & (6) & $104,70 \pm 13,0$ & $142,31 \pm 1,2$ & $1292,00 \pm 36,3$ & $24,73 \pm 3,1$ & $1,94 \pm 0,3$ \\
\hline Espiro 15 d & (5) & $77,20 \pm 9,9$ & $141,04 \pm 1,5$ & $966,80 \pm 47,1^{+}$ & $16,67 \pm 1,9$ & $1,73 \pm 0,2$ \\
\hline \multicolumn{2}{|c|}{ Ang II + Espiro 15 d (5) } & $147,01 \pm 2,5^{+\# \$}$ & $151,02 \pm 3,2^{+\# \$}$ & $1698,00 \pm 71,6^{\$}$ & $29,41 \pm 1,0$ & $1,76 \pm 0,3$ \\
\hline Sham 28 d & (6) & $124,52 \pm 22,5$ & $151,30 \pm 0,3$ & $1208,01 \pm 58,6$ & $25,01 \pm 4,5$ & $1,98 \pm 0,4$ \\
\hline Ang II 28 d & (5) & $73,40 \pm 22,9$ & $153,82 \pm 1,7$ & $867,73 \pm 35,3$ & $9,52 \pm 3,9$ & $1,03 \pm 0,2^{*}$ \\
\hline Veículo $28 \mathrm{~d}$ & (6) & $90,75 \pm 6,9$ & $146,32 \pm 1,4$ & $1249,05 \pm 85,8$ & $18,00 \pm 1,8$ & $1,49 \pm 0,1$ \\
\hline Espiro $28 \mathrm{~d}$ & (6) & $63,75 \pm 6,9$ & $146,44 \pm 0,8$ & $989,03 \pm 80,5$ & $11,79 \pm 1,0$ & $1,19 \pm 0,1$ \\
\hline \multicolumn{2}{|c|}{ Ang II + Espiro 28 d (5) } & $101,40 \pm 22,1$ & $142,81 \pm 2,7^{\#}$ & $1566,00 \pm 49,0$ & $22,18 \pm 2,5$ & $1,43 \pm 0,2^{\#}$ \\
\hline
\end{tabular}

Efeito da Ang II e/ou espironolactona sobre as concentrações do íon $\mathrm{Na}^{+}$no plasma e na urina de animais tratados com Ang II e/ou espironolactona por 15 ou 28 dias. Valores expressos como média \pm erro padrão. ${ }^{*} \mathrm{p}<0,05$ vs Sham, ${ }^{*} \mathrm{p}<0,05$ vs Ang II, $\$ \mathrm{p}<0,05$ vs Esprironolactona (Espiro) $+\mathrm{p}<0,05 v s$ Veículo (Veic.). Número de animais por grupo (n), dias (d).

Fonte: $\mathrm{O}$ autor. 
4.5.3 Efeito da Ang II e/ou Espironolactona sobre a Fração de Excreção de $\mathrm{K}^{+}\left(\mathrm{FE}_{\mathrm{K}+}\right)$

Conforme apresentado na figura 10 e tabela 8, o tratamento com Ang II e/ou espironolactona por 15 (A) ou 28 dias (B) não alterou a FE de $\mathrm{K}^{+}$.

Figura 10 - Efeito da Ang II e/ou espironolactonasobre a fração de Excreção de $\mathrm{K}^{+}\left(\mathrm{FE}_{\mathrm{K}}^{+}\right)$.
A) Grupo 15 dias
B) Grupo 28 dias
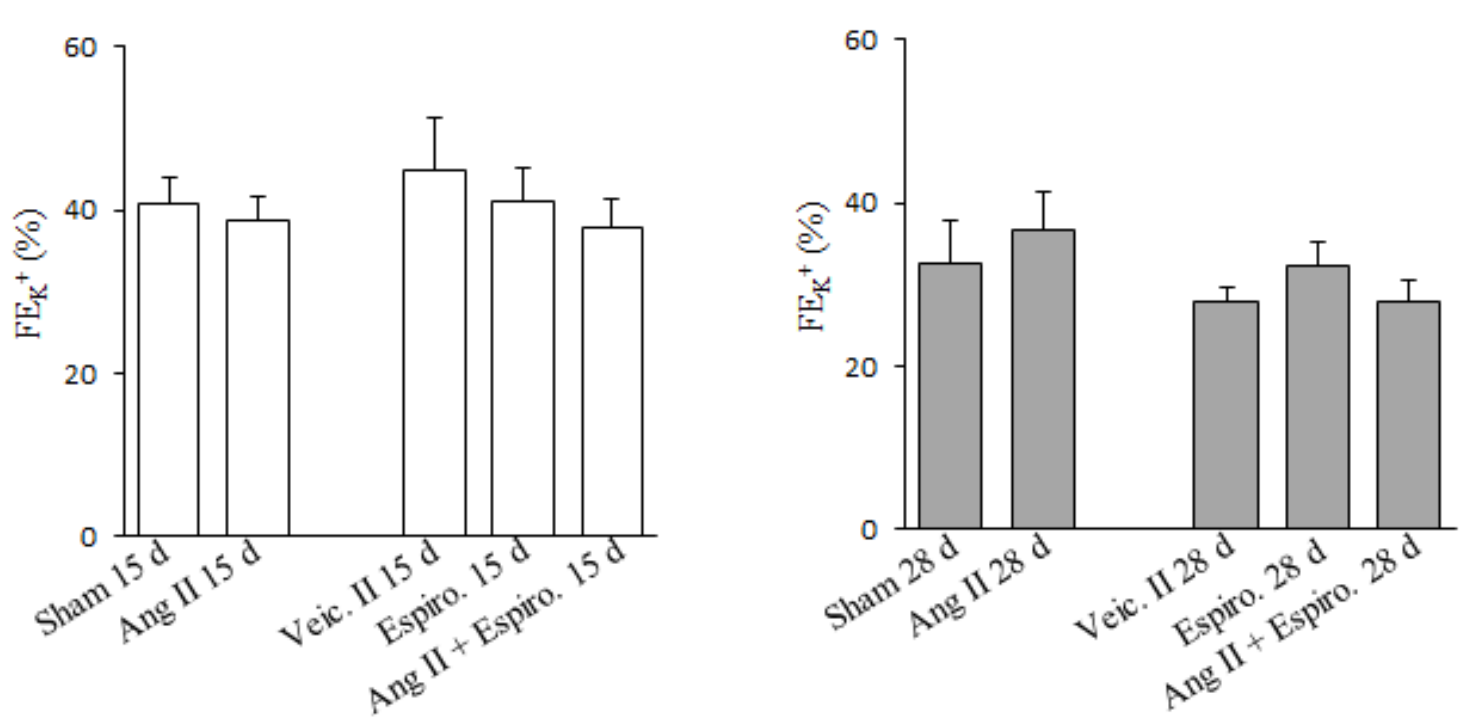

Efeito da Ang II (200 ng/kg/min) e/ou espironolactona (100 mg/kg/dia) sobre a fração de Excreção de $\mathrm{K}^{+}\left(\mathrm{FE}_{\mathrm{K}}{ }^{+}\right)$. (A) animais com 15 dias de tratamento (B) animais com 28 dias de tratamento. Valores expressos como média \pm erro padrão. Veículo (Veíc), Espironolactona (Espiro), dias (d).

Fonte: $\mathrm{O}$ autor. 
Tabela 8 - Efeito da Ang II e/ou espironolactona sobre a fração de Excreção de $\mathrm{K}^{+}\left(\mathrm{FE}_{\mathrm{K}}{ }^{+}\right)$.

Concentrações de $\mathbf{K}^{+}$

\begin{tabular}{|c|c|c|c|c|c|}
\hline & $\begin{array}{c}{\left[\mathrm{K}^{+}\right]_{\mathrm{u}}} \\
(\mathrm{mEq} / \mathrm{min} / \mathrm{Kg})\end{array}$ & $\begin{array}{c}{\left[\mathrm{K}^{+}\right]_{\mathrm{p}}} \\
(\mathrm{mEq} / \mathrm{min} / \mathrm{Kg})\end{array}$ & $\begin{array}{c}\mathrm{CF}_{\mathrm{K}}^{+} \\
(\mathrm{mEq} / \mathrm{min} / \mathrm{Kg})\end{array}$ & $\begin{array}{c}\mathrm{CE}_{\mathrm{K}}^{+} \\
(\mathrm{mEq} / \mathrm{min} / \mathrm{Kg})\end{array}$ & $\begin{array}{l}\mathbf{F E}_{\mathbf{K}+} \\
(\%)\end{array}$ \\
\hline Sham 15 d & $64,83 \pm 4,92$ & $4,50 \pm 0,22$ & $35,97 \pm 1,27$ & $14,91 \pm 1,16$ & $40,85 \pm 5,21$ \\
\hline Ang II 15 d & $58,45 \pm 1,10$ & $4,61 \pm 0,41$ & $25,63 \pm 1,49$ & $10,50 \pm 1,01$ & $38,84 \pm 4,70$ \\
\hline Veículo $15 \mathrm{~d}$ & $78,00 \pm 8,93$ & $5,03 \pm 0,24$ & $44,91 \pm 2,72$ & $18,86 \pm 2,23$ & $44,99 \pm 9,32$ \\
\hline Espiro $15 \mathrm{~d}$ & $49,50 \pm 8,84$ & $4,22 \pm 0,21$ & $28,56 \pm 1,22^{+}$ & $11,56 \pm 1,82$ & $40,90 \pm 5,16$ \\
\hline Ang II + Espiro 15 d (5) & $103,21 \pm 8,04^{+\# \$}$ & $5,03 \pm 0,30$ & $54,39 \pm 5,51^{+\$ \#}$ & $21,71 \pm 1,02^{\$ \#}$ & $37,93 \pm 3,44$ \\
\hline Sham $28 \mathrm{~d}$ & $63,33 \pm 7,91$ & $5,04 \pm 0,40$ & $40,37 \pm 2,80$ & $11,84 \pm 1,72$ & $32,41 \pm 5,35$ \\
\hline Ang II $28 d$ & $63,60 \pm 16,70$ & $4,00 \pm 0,02$ & $21,98 \pm 1,44^{*}$ & $8,44 \pm 0,94$ & $36,72 \pm 4,63$ \\
\hline Veículo $28 \mathrm{~d}$ & $54,00 \pm 8,82$ & $4,53 \pm 0,33$ & $39,29 \pm 3,91$ & $9,86 \pm 0,83$ & $27,85 \pm 1,79$ \\
\hline Espiro $28 \mathrm{~d}$ & $62,25 \pm 5,91$ & $5,15 \pm 0,23$ & $34,50 \pm 3,85$ & $10,94 \pm 0,85$ & $32,35 \pm 2,81$ \\
\hline Ang II + Espiro 28 d (5) & $64,11 \pm 7,18$ & $4,75 \pm 0,44$ & $52,27 \pm 2,91^{\# \$}$ & $13,86 \pm 1,33$ & $27,98 \pm 2,12$ \\
\hline
\end{tabular}

Efeito da Ang II e/ou espironolactona sobre as concentrações do íon $\mathrm{K}^{+}$no plasma e na urina de animais tratados com Ang II e/ou espironolactona por 15 ou 28 dias. Valores expressos como média \pm erro padrão. Veículo (Veic.), Espironolactona (Espiro), dias (d).

Fonte: $\mathrm{O}$ autor.

\subsubsection{Efeito da Ang II e/ou Espironolactona sobre a Osmolalidade da urina e plasma}

$\mathrm{Na}$ Tabela 9 estão representados os valores médios das osmolalidades da urina e plasma dos animais tratados com Ang II por 15 dias ou 28 dias. A osmoliladade da urina não foi alterada em nenhum grupo estudado. No grupo de 15 dias, a osmolalidade do plasma aumentou na vigência de espironolactona e retornou ao valor controle no grupo tratado com espironolactona + Ang II. No grupo de 28 dias, a osmolalidade do plasma sofreu um discreto aumento apenas no grupo tratado com espironolactona + Ang II. 
Tabela 9 - Efeito da Ang II e/ou espironolactona sobre a osmolalidade da urina e plasma

\begin{tabular}{|c|c|c|}
\hline & $\begin{array}{c}\text { Osmolalidade } \\
\text { Urina } \\
\left(\mathrm{mOsm} / \mathrm{KgH}_{2} \mathbf{0}\right) \\
\end{array}$ & $\begin{array}{c}\text { Osmolalidade } \\
\text { Plasma } \\
\left(\mathrm{mOsm} / \mathrm{KgH}_{2} \mathbf{0}\right)\end{array}$ \\
\hline Sham $15 \mathrm{~d}$ & $541,82 \pm 30,40$ & $312,55 \pm 1,33$ \\
\hline Ang II $15 \mathrm{~d}$ & $492,01 \pm 19,93$ & - \\
\hline Veículo $15 \mathrm{~d}$ & $621,00 \pm 38,34$ & $310,34 \pm 2,62$ \\
\hline Espiro $15 \mathrm{~d}$ & $540,33 \pm 67,51$ & $322,80 \pm 2,90^{+}$ \\
\hline Ang II + Espiro 15 d (5) & $666,80 \pm 32,93$ & $300,82 \pm 5,11^{\$}$ \\
\hline Sham $28 \mathrm{~d}$ & $423,22 \pm 33,72$ & $296,30 \pm 5,25$ \\
\hline Ang II 28 d & $565,60 \pm 88,83$ & $289,00 \pm 4,34$ \\
\hline Veículo $28 \mathrm{~d}$ & $429,04 \pm 48,91$ & $306,05 \pm 6,91$ \\
\hline Espiro $28 \mathrm{~d}$ & $482,40 \pm 14,70$ & $312,11 \pm 3,23$ \\
\hline Ang II + Espiro 28 d (5) & $508,74 \pm 71,81$ & $314,73 \pm 2,34^{+}$ \\
\hline
\end{tabular}

Efeito da Ang II (200 ng/kg/min) e/ou espironolactona (100 mg/kg/dia) sobre a osmolalidade da urina e plasma. Valores expressos em média de 4 coletas por animal em cada grupo \pm erro padrão. ${ }^{+} \mathrm{p}<0.0$ vs Veículo; * $\mathrm{p}<0.05$ vs Sham; ${ }^{\#} \mathrm{p}<0,05$ vs Ang II; ${ }^{\$} \mathrm{p}<0,05$ vs Espironolactona; dias (d). No grupo tratado com Ang II por 15 dias a osmolalidade do plasma não foi avaliada porque o osmômetro está quebrado.

Fonte: $\mathrm{O}$ autor.

\subsection{Efeito da Ang II e/ou espironolactona sobre a área glomerular}

\subsection{1 Área Glomerular $\left(\mu^{2}\right)$}

Conforme apresentado na tabela 10, no grupo tratado com Ang II por 15 dias, a área glomerular foi significantemente maior, quando comparado aos animais do grupo controle. A espironolactona reduziu e efeito da Ang II sobre este parâmetro. No grupo de 28 dias, não se observou alterações da área glomerular entre os grupos estudados. 
Tabela 10 - Efeito da Ang II e/ou espironolactona sobre alterações na área glomerular.

\begin{tabular}{lccc}
\hline & & Ang II 15 dias & Ang II 28 dias \\
\hline Sham & $\mathbf{( 5 )}$ & $6039,32 \pm 63,80(322)$ & $7465,20 \pm 66,92(404)$ \\
Ang II & $\mathbf{( 5 )}$ & $6308,11 \pm 79,60(315)^{*}$ & $7399,54 \pm 87,11(393)$ \\
Veículo & $\mathbf{( 5 )}$ & $6135,00 \pm 48,90(328)$ & $7339,28 \pm 99,13(433)$ \\
Espiro & $(\mathbf{6})$ & $6173,03 \pm 62,46(307)$ & $7492,45 \pm 63,86(438)$ \\
Ang II.+ Esp & $(5)$ & $6064,34 \pm 60,83(254)^{\#}$ & $7493,22 \pm 81,28(434)$ \\
\hline
\end{tabular}

Efeito da Ang II (200 ng/kg/min) e/ou espironolactona (100 mg/kg/dia) sobre a área glomerular Valores expressos como média da leitura de 50 campos por lâmina \pm erro padrão. * p $<0.05$ vs Sham; ${ }^{\#} \mathrm{p}<0,05$ vs Ang II., O número de glomérulos estudados encontra-se entre parênteses.

Fonte: $\mathrm{O}$ autor.

\subsection{Efeito da Ang II e/ou Espironolactona sobre e expressão de NHE3}

A figura 11 mostra que o tratamento crônico com Ang II por 15 (A) ou 28 (B) dias, induziu um significante aumento na expressão de NHE3. A espironolactona, no entanto, reduziu o efeito estimulador da Ang II sobre este parâmetro. 
Figura 11 - Efeito da Ang II e/ou espironolactona sobre a expressão de NHE3.

A) Grupo 15 dias
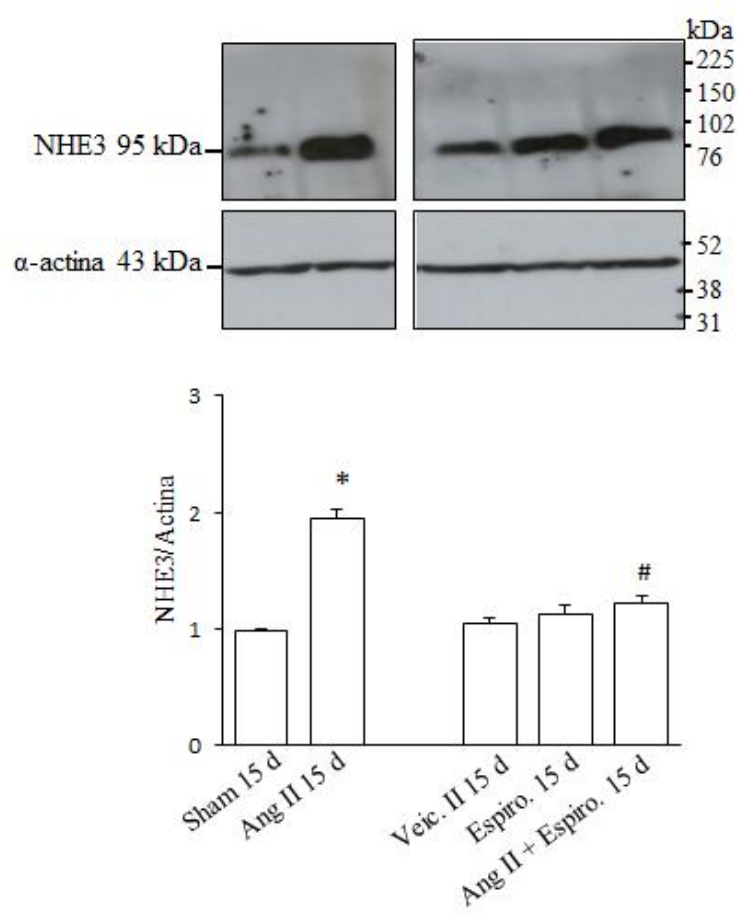

B) Grupo 28 dias
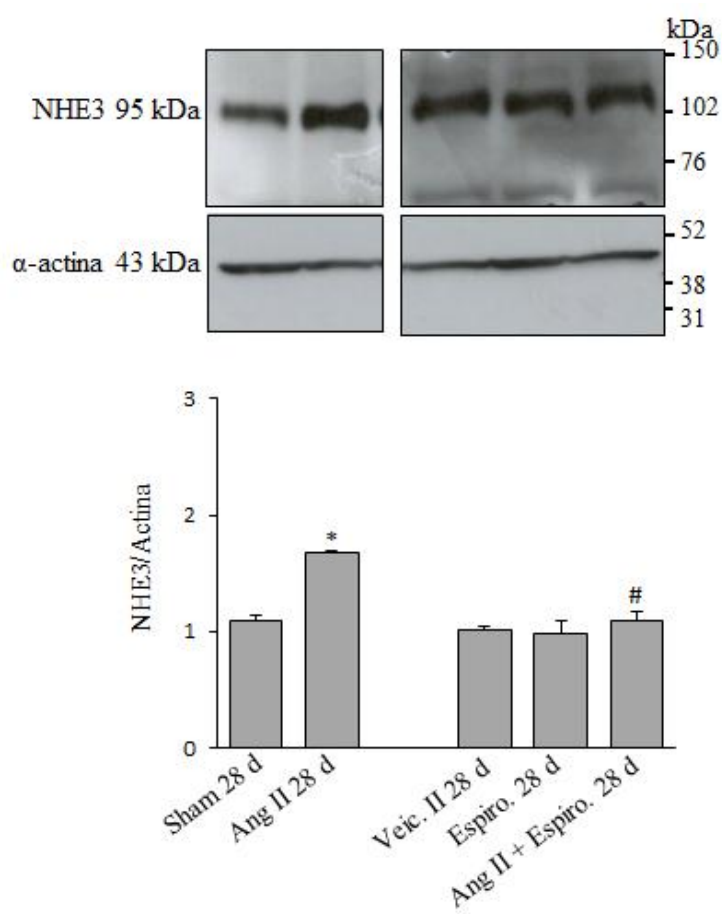

Efeito da Ang II e/ou espironolactona sobre a expressão de NHE3. * $\mathrm{p}<0.05$ vs Sham; ${ }^{\#} \mathrm{p}<$ 0,05 vs Ang II. Experimentos de Western blot demonstrando a expressão total de NHE3 (95 $\mathrm{kDa}$ ) e $\alpha$-actina (43 kDa). Blots em gel de poliacrilamida $10 \%$ com $100 \mu \mathrm{g}$ de proteínas totais. Anticorpo anti-NHE3 da Santa Cruz (1:1000); anti-actina (1:3000) e anticorpo secundário anti-mouse (1:2000 e 1:6000, respectivamente. Os gráficos representam as razões da intensidade de pixels (NHE3/actina).

Fonte: $\mathrm{O}$ autor.

\subsection{Efeito da Ang II e/ou Espironolactona sobre a morfologia renal}

A figura 12 mostra os cortes histológicos (corados por HE) dos rins de animais tratados com Ang II e/ou espironolacton por 15 (Painel 1 A-D) ou 28 dias (Painel 2 A-D). Em ambos os grupos, a Ang II induziu edema intersticial (*), acentuada lesão tubular proximal com perda da borda em escova $(* *)$ e morte celular $(* * *)$. A espironolactona por sua vez, 
permitiu a recuperação parcial da borda em escova do túbulo proximal e induziu melhora no edema intersticial, em comparação com os respectivos controles.

Figura 12 - painel 1 - Grupo tratado com Ang II e/ou espironolactona por 15 dias.
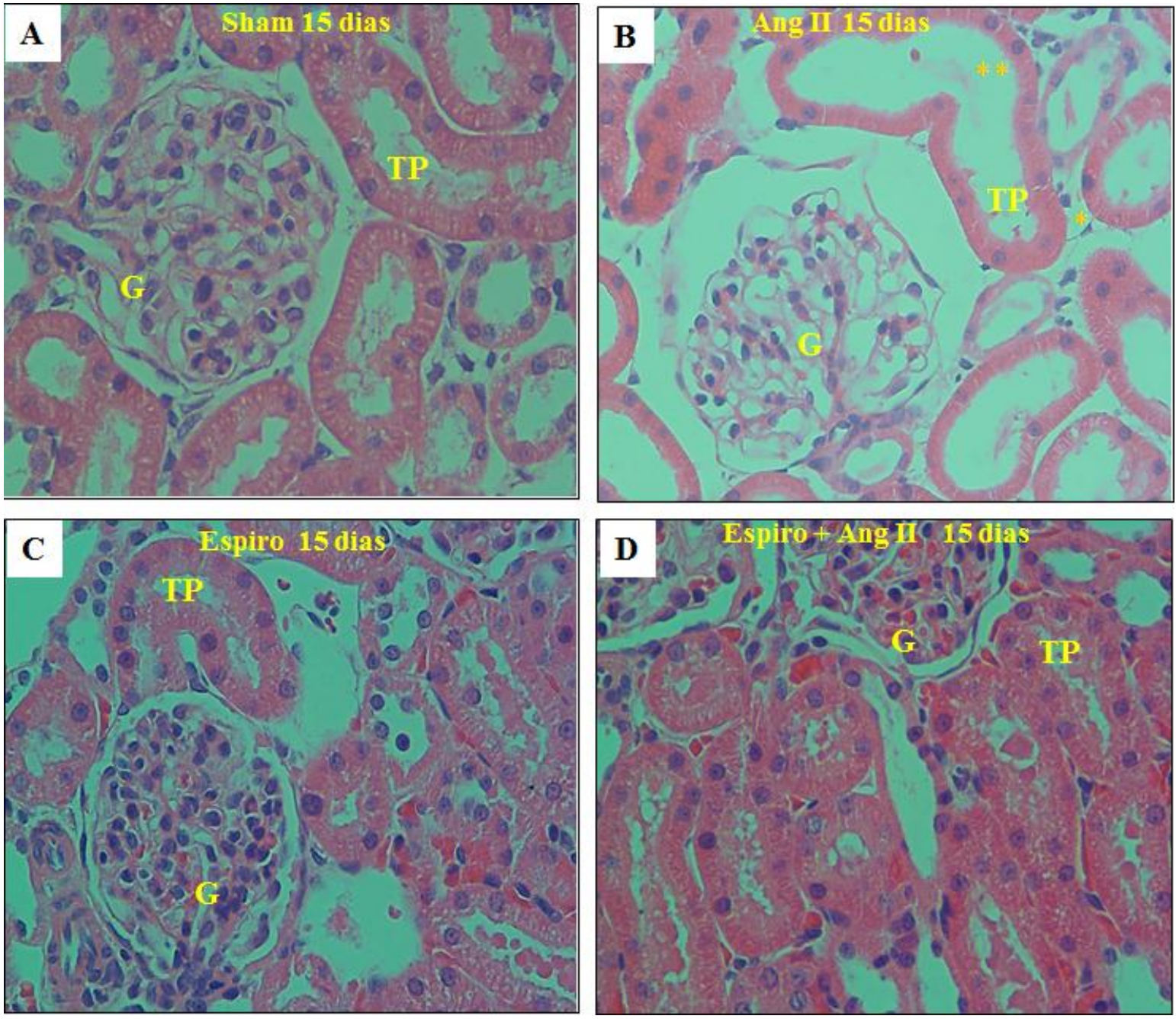
Figura 12 - painel 2 - Grupo tratado com Ang II e/ou espironolactona por 28 dia
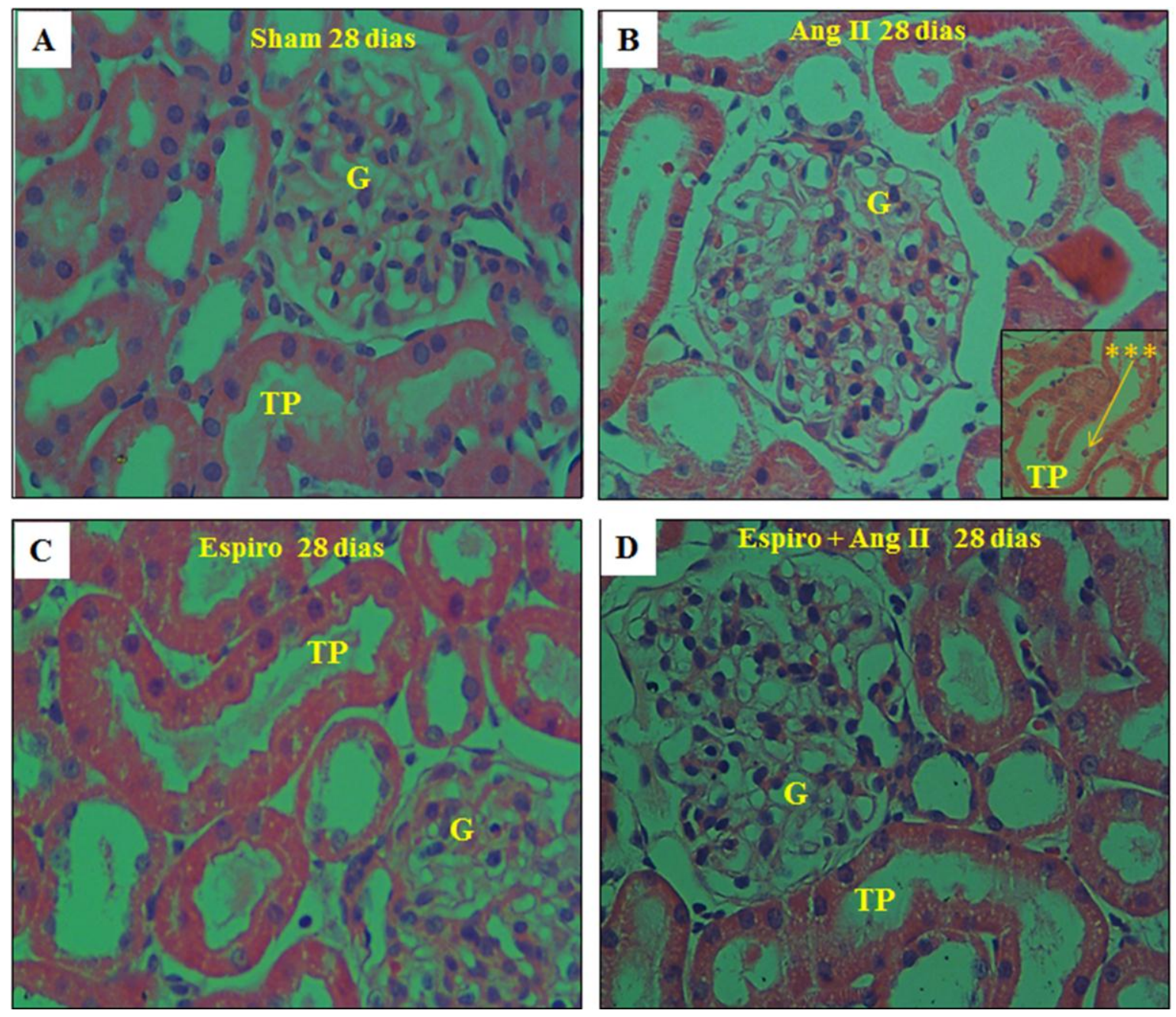

Efeito da Ang II e/ou espironolactona sobre a morfologia renal. Lâminas coradas pela técnica de HE e analisadas por microscopia. Imagens capturadas em $400 \mathrm{x}$, através do programa de análise de imagens (Nis Elements - Nikon), cuja câmaraestá acoplada ao microscópio triocular da Nikon.

Fonte: O autor. 


\section{DISCUSSÃO}

Historicamente, a hiperatividade do SRAA, está associada ao aumento da produção e secreção de aldosterona, hipertensão arterial, disfunção endotelial, cardiopatias e doenças renais crônicas (JAN, 2009). Muitos estudos clínicos mostram que o bloqueio da atividade de alguns dos elementos do SRAA por antagonistas específicos como alisquireno (para renina), ramipril (para a ECA), losartan (para AT1) e espironolactona (para o MR), resultam em recomposição funcional do endotélio e tecido cardíaco (DAHLOF; DEVEREUX; KJELDSEN, 2002; FANESTIL et al., 1988; MARTÍN-FERNÁNDEZ et al.. 2012; PIETER et al., 2009; RAHSHIKH et. al., 2012). No entanto, pouco se sabe sobre os efeitos benéficos desses antagonistas na recuperação de lesões no tecido renal, induzidas pelo aumento da atividade do SRAA. Por outro lado, a idéia que a aldosterona apresenta uma função adicional associada aos processos pró-inflamatórios e pró-fibrótico (SELYE, 1955) aumenta a expectativa de se investigar a participação do receptor MR e em seguida, as vias de sinalização celular envolvidas nesse processo. Assim, no atual estudo, nós optamos por investigar a participação da espironolactona nas respostas renais induzidas pela hiperatividade do SRAA.

Em animais, o modelo de hipertensão arterial induzida por Ang II é bem estabelecido e a dose comumente utilizada é de $200 \mathrm{ng} / \mathrm{kg} / \mathrm{min}$, considerada supra fisiológica por vários pesquisadores (ISHIGURO et al, 2007; NAVAR et al, 1995, WAKUI et al, 2010). Nossos resultados indicam que o tratamento crônico com Ang II por 15 ou 28 dias na dose de 200 $\mathrm{ng} / \mathrm{kg} / \mathrm{min}$ induziu, como esperado, a hipertensão arterial. Observamos também que do $1^{\circ}$ ao $15^{\circ}$ dia de tratamento com Ang II o deslocamento da pressão arterial foi mais efetivo, comparando com o período de $15^{\circ}$ e $28^{\circ}$ dia de tratamento, sugerindo que o organismo desenvolve processos adaptativos em função do deslocamento da pressão arterial.

Em animais normotensos, a espironolactona (100 mg/Kg/dia) não alterou a pressão arterial em relação aos grupos controle, mas reduziu parcialmente este parâmetro nos animais hipertensos, indicando que nesse modelo animal, a aldosterona via receptores MR é importante no desenvolvimento da hipertensão arterial. Esses resultados vão de encontro com outros dados da literatura, os quais demonstram que em pacientes hipertensos, a eficácia da espironolactona sobre a pressão arterial é dose-dependente: doses abaixo de $100 \mathrm{mg} / \mathrm{dia}$ não reduzem a pressão arterial e acima de 100/mg/dia pode induzir efeitos colaterais como a hipercalemia (PIETER et al., 2009). Por outro lado, Pratt et al., (2001) observaram que em indivíduos normotensos, a administração individual de espironolactona (25 mg) ou amiloride 
(5 mg) não apresenta efeito anti-hipertensivo, mas a combinação de ambos, resulta na queda da pressão arterial $(-4,6 \mathrm{mmHg})$, sugerindo um efeito inibitório complementar sobre o canal epitelial de $\mathrm{Na}^{+}(\mathrm{ENaC})$.

Considerando que tanto a Ang II quanto a aldosterona, são agentes hipertróficos (TIMMERMANS et al, 1993, RHIAN et al, 2000, NAVAR et al, 2000), avaliamos inicialmente o efeito da Ang II sobre o peso corpóreo e sobre o peso da massa renal. Nenhum dos tratamentos induziu alterações sobre tais parâmetros, indicando que os períodos e a dose de Ang II utilizados, não foram suficientes para induzir uma acentuada hipertrofia renal a ponto de ser refletida na variação de peso. Por outro lado, dados recentes o nosso grupo (outro projeto de pesquisa), mostram que o tratamento com a mesma dose de Ang II por 42 dias induz aumento da massa renal, indicando que realmente o fator tempo de tratamento foi em grande parte, responsável pelo atual resultado. A espironolactona por sua vez, reduziu o ganho de peso apenas no grupo de 15 dias, o que pode associar-se ao seu efeito diurético. $\mathrm{O}$ fato de não ser observado esta queda de peso no grupo de 28 dias, pode ser associado aos mecanismos adaptativos do organismo, por exemplo, aumento na expressão do canal epitelial de sódio (ENaC) (experimentos de western blot em andamento), já que a hipertensão não foi totalmente abolida com espironolactona.

O passo seguinte foi investigar as concentrações de renina e aldosterona no plasma dos animais. A infusão de Ang II por 15 dias induziu aumento na concentração plasmática de renina, possivelmente por manter a ativação do Sistema Nervoso Simpático, cujas terminações se estendem para as células justaglomerulares, túbulo proximal e distal. Nessa condição, a espironolactona aumentou o efeito da Ang II sobre a concentração plasmática de renina e aumentou a concentração de aldosterona. Sabe-se que a espironolactona reduz a concentração de endotelina-1 no plasma (LANE; BEEVERS, 2007), condição que induz aumento da liberação de renina. A alta concentração de renina amplifica a atividade do SRAA, com consequente aumento da liberação de aldosterona. Com 28 dias de infusão, a Ang II não modificou a concentração plasmática de renina, sugerindo uma resposta associada ao mecanismo e "feedback" negativo promovido pela alta concentração plasmática da Ang II (BROWN, 2006). Por outro lado, o tratamento de 28 dias, aumentou a concentração plasmática de aldosterona, confirmando a ação direta da Ang II na glândula adrenal para estimular a secreção do mineralocorticoide (BADER, 2010; KOBORI et al., 2007). Este aumento, no entanto foi exacerbado com espironolactona, sugerindo que a inibição do MR por um período mais prolongado pode atuar como mecanismo de "feedback" para aumentar a secreção de aldosterona e provavelmente da expressão de receptores MR. 
No presente estudo, a infusão crônica de Ang II (15 ou 28 dias) induziu uma acentuada queda do fluxo plasmático renal (FPR) e do ritmo de filtração glomerular (RFG). Também aumentou a fração de filtração (FF). Tais achados estão de acordo com a literatura. Segundo Harrison et al., (1999), a infusão crônica de Ang II em ratos, aumenta e depois, mantém constante a expressão vascular do receptor AT1, condição que sustenta o efeito vasoconstritor do hormônio sobre as artérias e arteríolas renais e consequentemente, reduz o FPR. Este efeito da Ang II via AT1 sobre o aumento da resistência vascular renal é mediado pelo aumento de estresse oxidativo (KAWADA et al., 2002). A ação da Ang II na regulação da resistência das arteríolas aferente e eferente é também de suma importância para determinar e manter o RFG.

A Ang II induz constrição em ambas as arteríolas. Em altas doses, o hormônio induz uma acentuada constrição na arteríola eferente (por aumentar a expressão de AT1 neste vaso) e nas células mesangiais, o que resulta na redução do coeficiente de ultrafiltração $\left(K_{\mathrm{f}}\right)$ e do RFG (BLATZ; KONNEN; TUCKER, 1976; DWORKIN; BADER; ICHIKAWA, 1983; MENDELSHON, 1986; NAVAR, 1996). A queda no fluxo sanguíneo renal (FSR) pela constrição arteriolar resulta no aumento da fração de filtração (FF) e reduz a pressão hidrostática no capilar peritubular (COWLEY, 1992), o que poderá facilitar a reabsorção de fluido no túbulo proximal. Talvez por isso, houve uma queda do fluxo urinário nos grupos tratados com Ang II. Tal resultado foi observado também em camundongos (ZHAO et al., 2009).

Sabe-se que a hiperatividade do SRAA e o consequente aumento da pressão hidrostática glomerular contribuem para a injúria renal. No entanto, vários antagonistas do SRA (como inibidores de AT1) podem reverter esse quadro e atuar como agentes renoprotetores (BRENNER, 2001). Sabe-se também que há uma acentuada expressão dos receptores MR nas células justaglomerulares e mesangio (WARREN et al, 2011), sugerindo a participação da aldosterona na hemodinâmica renal. Nossos resultados mostram que a espironolactona induziu uma discreta queda no FPR e RFG basal em ambos os grupos de animais (15 e 28 dias), indicando um efetivo efeito da aldosterona via receptores MR no controle hemodinâmico basal. A nossa hipótese é que na condição basal, a via Aldo/MR/AMPc prevalece para manter o tono vascular renal e quando o MR está inibido prevalece a via constritora modulada pela Ang II basal e cálcio, a qual já é bem descrita (CARMINES; NAVAR, 1989).

A espironolactona também suprimiu o efeito inibidor da Ang II sobre o FPR e RFG e causou um aumento acima dos valores basais em ambos os parâmetros. Portanto, de acordo com nossos dados, no tratamento crônico com Ang II, a resposta vasoconstritora sobre a 
hemodinâmica renal parece depender em grande parte, da aldosterona atuando via receptores MR. No tratamento com espironolactona, a FF não foi diferente dos valores controle. Isto se deve ao fato de que houve um aumento concomitante do FSR e RFG. Observamos também que a espironolactona corrigiu a queda do fluxo urinário promovido pela Ang II, indicando que este agente ao aumentar o FSR e o RFG, sugerindo que, a pressão hidrostática nos capilares peritubulares não foi afetada e consequentemente não houve significante aumento na reabsorção de fluido no túbulo proximal, resultando em aumento do fluxo urinário. Este resultado difere do encontrado por Zhao et al., (2009) em camundongos tratados cronicamente com Ang II. Nestes, a espironolactona não produziu efeito sobre o fluxo urinário e tão pouco sobre o efeito pressórico da Ang II. Tal resultado pode estar associado ao modelo animal e ao fato de que a espironolactona foi administrada desde o primeiro dia de infusão de Ang II, ou seja, antes do início do deslocamento da pressão arterial. O que não deixa de ser interessante, pois neste caso a ação foi apenas da Ang II sem a contribuição da aldosterona.

O íon amônio é sintetizado no túbulo proximal, parcialmente reabsorvido na alça de Henle e passivamente secretado nos ductos coletores. No túbulo proximal, o principal transportador envolvido é a isoforma 3 do trocador $\mathrm{Na}^{+} / \mathrm{H}^{+}$(NHE3), enquanto que na alça de Henle é o co-transportador $\mathrm{Na}^{+} / \mathrm{K}^{+} / 2 \mathrm{Cl}^{-}$(NKCC2), sendo neste último o amônio é transportado no lugar no $\mathrm{K}^{+}$(GIEBISCH; WINDHAGER, E., 1994). As porções finais do néfron são responsáveis por cerca de $80 \%$ da secreção de $\mathrm{NH}_{4}{ }^{+}$na luz tubular (KIM, 2009). O tratamento crônico com Ang II por 15 dias não alterou a carga excretada de amônio e a espironolactona aumentou este parâmetro, indicando aumento na secreção de $\mathrm{H}^{+}$, confirmada pela queda do $\mathrm{pH}$ da urina, sugerindo assim a participação da $\mathrm{H}^{+} / \mathrm{K}^{+}$ATPase no ducto coletor. O tratamento com Ang II por 28 dias e/ou espironolactona, não alterou a carga excretada de $\mathrm{NH}_{4}{ }^{+}$. Portanto, parece que o equilíbrio ácido-base dos animais está preservado.

O presente estudo mostra que em ratos, a infusão crônica de Ang II por 28 dias (não por 15 dias), resultou numa acentuada queda da fração de excreção do íon sódio. Tal resultado está de acordo com dados da literatura, os quais relatam que em ratos e camundongos, a infusão crônica de Ang II, induz, após alguns dias, um significante aumento de angiotensinogênio e Ang II intrarenal, a qual reduz a excreção de sódio seguida por um progressivo aumento da pressão arterial (HALL; BRAND; GUYTON et al., 1990; KOBORI; et al., 2001; VAN DER MARK; KLINE 1994). Tal efeito se dá em parte, pelo aumento na expressão de cotransportadores de $\mathrm{Na}^{+}-\mathrm{Cl}^{-}$no túbulo distal e $\mathrm{ENaC}$ no ducto coletor (BEUTLER et al., 2003; SANDBERG et al.,.2007). A espironolactona, no entanto, suprimiu o efeito inibitório da Ang II sobre a excreção renal de sódio em $38 \%$ e reduziu parcialmente a 
hipertensão arterial nesse grupo, indicando um efeito da aldosterona sobre ambos os parâmetros. O fato de Ang II (15 dias) não alterar a fração de excreção de sódio parece está associado ao período de tratamento, no qual a aldosterona tem uma participação efetiva na geração da hipertensão (já que a PA foi reduzida por espironolactona) independentemente do aumento de sódio.

Em relação ao íon $\mathrm{K}^{+}$, o tratamento com Ang II por 15 dias, não alterou a $\mathrm{FE} \mathrm{de} \mathrm{K}^{+}$, o que pode ser justificado pela ausência de efeito da Ang II e/ou espironolactona sobre a FE do íon sódio. No grupo de 28 dias também não houve alteração significativa da $\mathrm{FE}$ de $\mathrm{K}^{+}$, apesar da queda na $\mathrm{FE}$ de $\mathrm{Na}^{+}$nesse grupo. É importante ressaltar que nesse grupo o fluxo urinário estava reduzido e sabe-se que quanto maior o fluxo urinário, maior a secreção de $\mathrm{K}^{+}$pela célula principal do ducto coletor, pois nessa condição de fluxo alto, a concentração de $\mathrm{K}^{+}$na luz tubular é baixa, o que favorece a sua secreção para a luz tubular (MELLO-AIRES, 2008; MALNIC; GIEBISH; MATHEW, 2004).

A espironolactona é considerada uma droga poupadora de $\mathrm{K}^{+}$, mas segundo dados da literatura (GROSS et al., 2005), quando administrada na dose utilizada em nosso estudo (100 $\mathrm{mg} / \mathrm{kg} / \mathrm{min}$ ), não chega a causar hipercalemia. Nossos resultados confirmam esses achados, uma vez que a espironolactona não alterou significantemente as concentrações plasmáticas do íon $\mathrm{K}^{+}$em nenhum grupo estudado.

A idéia de que a Ang II e aldosterona apresentam funções pró-inflamatórias e prófibróticas vem de alguns anos (BROWN, 2005). A questão é: como hormônios tão essenciais para a sobrevivência são ao mesmo tempo causadores de danos teciduais? Estudos clínicos sugerem que a Ang II é em parte, responsável pela hipertensão arterial, via ativação do receptor AT1. Neste caso, a hiperatividade do SRAA potencializa a liberação de aldosterona e também a atividade do SRA intra-renal, condição favorável para a injúria renal (TIMMERMANS et al., 1993; NAVAR et al., 2000). Entre as várias respostas do tecido renal frente às altas concentrações de Ang II, está o aumento da atividade da fosfolipase A2 (PLA2) e fosfolipase D (PLD), o que resulta no aumento de espécies reativas de oxigênio [(ânion super-oxido $\left(\mathrm{O}_{2}^{-}\right)$e peróxido de hidrogênio $\left(\mathrm{H}_{2} \mathrm{O}_{2}\right)$ ], elementos essenciais para estimular o crescimento, diferenciação e migração celular, apoptose e hipertrofia (NAVAR et al., 2000; CASTROP et al., 2010). A aldosterona por sua vez, liga-se ao receptor MR e ativa a via de cascata intracelular modulada pela proteína mTOR (mammalian target of rampamicin), que em excesso, pode estimular á proliferação celular, inflamação insterticial e fibrose. O mTOR também fosforila a SGK1 (sérum and glucocorticoid induced kinase 1) para ativar o ENaC nas células principais do ducto coletor (LIEBERTHAL; LEVINE, 2009; LU et al.,2010). 
Com o intuito de investigar o efeito da Ang II e da aldosterona sobre alterações morfológicas no tecido renal, realizamos análises em cortes renais corados pela técnica HE. Inicialmente, observamos que apenas o grupo com 15 dias de tratamento com Ang II apresentou um aumento significativo da área glomerular, aumento este, corrigido pela espironolactona, indicando que nesse período a aldosterona foi em parte, a responsável pela expansão glomerular. A aldosterona e a Ang II em excesso, via produção de superóxido (espécies reativas de oxigênio), ativam as células $\mathrm{T}$ e as fases iniciais dos processos inflamatórios (MIYATA et al., 2005). Nas células mesangiais, a aldosterona via MR/SGK1, ativa o NFkB (nuclear factor-kB), o qual transloca para o núcleo celular e estimula genes responsáveis pelos processos inflamatórios e fibróticos, inluindo o STGF (Conective tissue growth fator) e TGF $\beta$ (transforming growth fator $\beta_{1}$ ) (ZHANG, et al., 2007). Além disso, a aldoterona via MR também promove apoptose no túbulo proximal e fibrose intersticial (KLANKE et al., 2008). Nossos resultados estão de acordo com dados adicionais da literatura, os quais mostram que em animais tratados com aldosterona, a espironolactona reduziu o RNAm para NFkB (ANDREW et al., 2011).

Nos cortes histológicos observamos que a Ang II (15 e 28 dias) induziu edema intersticial, acentuada lesão tubular proximal com perda acentuada da borda em escova, e morte celular. Essa condição pode ser um estímulo importante para o aumento da expressão de NHE3 observado em ambos os grupos tratados com Ang II. A espironolactona por sua vez, induziu uma expressiva recuperação essencialmente do epitélio tubular proximal, confirmando, portanto, a participação da aldosterona nos processos envolvidos com a morte celular no tecido renal. Fato que pode ter contribuído para um retorno da expressão do NHE3 para próximo do basal.

Estes resultados estão de acordo com dados da literatura, os quais sugerem que a aldosterona apresenta efeitos sobre o epitélio renal e também sobre outros parâmetros como a hipertrofia e fibrose tanto no rim quanto em outros tecidos incluindo vasos e coração (KRUM; GILBERT, 2007; MARTÍN-FERNÁNDEZ et al.. 2012 [ of print]).

No conjunto, os dados atuais sugerem que no modelo estudado, a infusão crônica de Ang II induz, em função do período de tratamento, um significante aumento na concentração plasmática de aldosterona. Esta por sua vez, atua via receptor MR para acentuar os efeitos deletérios induzidos pelas altas doses de Ang II. No atual estudo, a aldosterona foi a principal responsável pela queda acentuada da hemodinâmica renal e da função tubular proximal, uma vez que o tratamento com espironolactona (inibidor de MR) praticamente reverteu todos os parâmetros renais comprometidos pela infusão de Ang II. 


\section{CONCLUSÕES}

Os resultados indicam que:

O tratamento crônico com Ang II na dose de 200 ng/kg/min induziu um acentuado deslocamento da pressão sanguínea nos primeiros 15 dias e manteve a hipertensão arterial até o $28^{\circ}$ dia de tratamento. A espironolactona reduziu o efeito pressórico da Ang II, indicando a participação da aldosterona via receptores MR sobre este parâmetro.

O tratamento com Ang II por 15 dias aumentou a concentração plasmática de renina e com 28 dias não alterou este parâmetro, indicando um possível início de mecanismo de “feedback" negativo para a secreção de renina ao final do tratamento. A espironolactona amplificou o efeito estimulatório da Ang II sobre a liberação de renina, indicando a participação dos receptores MR nesse processo modulatório.

Nos dois períodos de tratamento (15 e 28 dias), a Ang II reduziu o fluxo plasmático renal, o ritmo de filtração glomerular e o fluxo urinário. A espironolactona reverteu os efeitos da Ang II sobre todos os parâmetros acima citados, indicando uma participação da aldosterona, via receptor MR no controle da hemodinâmica renal.

No grupo de 28 dias, a Ang II reduziu a fração de excreção do $\mathrm{Na}^{+}$, indicando reabsorção do íon. Por outro lado, não alterou a fração de excreção do $\mathrm{K}^{+}$, fato que pode ser justificado pela queda do fluxo urinário observado nesse grupo. A espironolactona não alterou a resposta da Ang II sobre este parâmetro.

O tratamento com Ang II nos dois períodos não mudou significantemente os níveis de aldosterona no plasma. No entanto, a espironolactona induziu um grande aumento do mineralocoirticóide no plasma, indicando uma resposta compensatória do organismo pela falta de receptores MR funcionais. 


\section{REFERÊNCIAS}

ABDALlA. S.; LOTHER, H.; AHMED, M. A.; QUITTERER, U. The Angiotensin II AT2 Receptor Is an AT1 Receptor Antagonist. J. Biol. Chem. V. 276, n. 43, p. 39721 - 39726, 2001.

ACKERMANN, D.; GRESKO, N.; CARREL, M.; LOFFING-CUENI, D.; HABERMEHL, D.; GOMEZ-SANCHEZ, C.; BERNARD, C.; LOFFING, J. In vivo nuclear translocation of mineralocorticoid and glucocorticoid receptors in rat kidney: differential effect of corticosteroids along the distal tubule. Am. J. Physiol. Renal Physiol., v. 299, n. 6, p. F1473 - F1485, 2010.

ANDREW, S.; BREM, A. S.; MORRIS, D. J.; GONG, R. Aldosterone-Induced Fibrosis in the Kidney: Questions and Controversies. Am J. Kidney Dis. v. 58, n. 3, p. 471 - 479, 2011.

ARRIZA, J. L.; WEINBERGER, C.; CERELlI, G.; GLASER, T. M.; HANDELIN, B. L.; HOUSMAN, D. E.; EVANS, R. M. Cloning of human mineralocorticoid receptor complementary DNA: structural and functional kinship with the glucocorticoid receptor. Science, v. 237, p. 268 - 275, 1987.

BADER, M. Tissue Renin-Angiotensin-Aldosterone Systems: Targets for Pharmacological Therapy. Annu. Rev. Pharmacol. Toxicol., v. 50, p. 439 - 65, 2010.

BELL, P. D.; LAPOINTE, J. Y.; SABIROV, R.; HAYASHI, S.; PETI-PETERDI, J.; MANABE, K.; KOVACS, G.; OKADA, Y. Macula densa cell signaling involves ATP release through a maxi anion Chanel. Proc. Natl. Acad. Sci. USA, v. 100, n. 7, p. 4322 - 4327, 2003.

De acordo com: ASSOCIAÇÃO BRASILEIRA DE NORMAS TÉCNICAS. NBR 6023: informação e documentação: referências: elaboração. Rio de Janeiro, 2002. 
BEUTLER, K. T.; MASIlAMANI, S.; TURBAN, S.; NIELSEN, J.; BROOKS, H. L. AGELOF, S.; FENTON, R. A.; PACKER, R. K.; KNEPPER, M. A. Long-term regulation of ENaC expression in kidney by angiotensin II. Hypertension, v. 41, p. 1143 - 1150, 2003.

BLATZ, R. C.; KONNEN, K. S.; TUCKER, B. J.; Angiotensin II effects upon the glomerular microcirculation and ultrafiltration coeficient of the rat. J. Clin. Invest., v. 57, n. 2, p. 419 434, 1976.

BOCK, H. A. Pressure dependente modulation of renin release in isolated perfused glomeruli. Kidney Int. v. 41, n. 2, p. 275 - 280, 1992.

BRAGA-SOBRINHO, C.; LEITE-DELLOVA, D. C.; MELLO-AIRES, M. Action of ANP on the nongenomic dose-dependent biphasic effect of aldosterone on NHE1 in proximal S3 segment. J. Steroid. Biochem. Mol. Biol., v. 128, n. 3, p. 89 - 97, 2012.

BRADLEY, A.; MARON, M. D.; JANE, A.; LEOPOLD, M. D. Mineralocorticoid receptor antagonists and endothelial function. Curr. Opin. Investig. Drugs. v. 9, n. 9, p. 963 - 969, 2008.

BRENNER, B. M.; COOPER, M. E.; DE ZEEUW, D.; KEANE, W. F.; MITCH, W. E.; PARVING, H. H.; REMUZZI, G.; SNAPINN, S. M.; ZHANG, Z.; SHAHINFAR, S. Effects of losartan on renal and cardiovascular outcomes in patients with type 2 diabets and nephropaty. N. Engl. J. Med., v. 345, n. 12, p. 861 - 869, 2001.

BROSNIHAN, K. B.; LI, P.; FERRARIO, C. M. Angiotensin-(1-7) dilates canine coronary arteries through kinins and nitric oxide. Hypertension, v. 27,p. 523 - 528, 1996.

BROWN, N. J. Aldosterone and end-organ damage. Curr. Opin. Nephrol. hypertens., v. 14, n. 3, p. $235-241,2005$.

BROWN, N. J. Direct renin inhibition-a new way of targeting the renin system. J. Renin Angiotensin Aldosterone Syst., v. 7, suppl. 2, p. S7 - S11, 2006. 
CAREY, R. M.; SIRAGY, H. M.; Newly recognized components of the renin- angiotensin system: potential roles in cardiovascular and renal regulation. Endocr. Rev., p. 261 - 271, 2003.

CAMPAGLIONE-SANTOS, M. J.; DIZ, D. I.; SANTOS, R. A.; KHOSLA, M. C.; BROSNIHAN K. B.; FERRARIO, C. M. Cardiovascular effects of angiotensin 1-7 injected into the dorsal medulla of rats. Am. J. Physiol., 257, H324 - H329, 1989.

CARMINES, P. K, NAVAR, L. G. Disparate effects of calcium channel blockade on afferent and efferent arteriolar responses to Ang II. Am. J. Physiol., v. 256, n. 6 pt 2, p. F1015 F1020, 1989.

CASTROP, H.; HO CHERL. K.; KURTZ, A.; SCHWEDA, F.; TODOROV, V.; WAGNER, C. Physiology of Kidney Renin. Physiol. Rev. v. 90, p. 607 - 673, 2010.

DAHLÖF, B.; DEVEREUX, R. B.; KJELDSEN, S. E.; JULIUS, S.; BEEVERS, G.; DE FAIRE, U.; FYHRQUIST, F.; IBSEN, H.; KRISTIANSSON, K.; LEDERBALLEPEDERSEN, O.; LINDHOLM, L. H.; NIEMINEN, M. S.; OMVIK, P.; OPARIL, S.; WEDEL, H. LIFE Study Group: Cardiovascular morbidity and mortality in the Losartan Intervention for Endpoint Reduction in Hypertension study (LIFE): A randomised trial against atenolol. Lancet, v. 359, p. 995 - 1003, 2002.

CHAPPELL, M .C.; MODRALL, J. G.; DIZ, D. I.; FERRARIO, C. M. Novel aspects of the renal renin-angiotensin system: angiotensin-(1-7), ACE2 and blood pressure regulation. Contrib. Nephrol. v. 143, p. 77 - 89, 2004.

CHRISTENSEN, E. I.; BIRN, H. Megalin and cubilin: multifunctional endocytic receptors. Nat. Rev. Mol. Cell Biol., v. 3, p. 256 - 266, 2002.

COURETTE, B.; LOMBES, M.; BAULIEU E. E.; RAFESTIN-OBLIN M. E. Aldosterone antagonists destabilize the mineralocorticoid receptor. Biochem. J. v. 282, p. 697 - 702, 1992. COWLEY, A. W.; ROMAN, R. J.; FENOY, F. J.; MATTSON, D. L. Effect of renal medullary circulation on arterial pressure. J. Hypertension. Suppl., v. 10, n.7, S187 - S193, 1992. 
DARBY, I. A.; SERNIA, C. In situ hybridization and immunohistochemistry of renal angiotensinogen in neonatal and adult rat kidneys. Cell Tissue Res., v. 281, p. 197 microalbuminuria in 206, 1995.

DEINUM, J. Increase in sérum prorenin precedes on set of patients with isulin-dependent diabets mellitus. Diabetologia, v. 42, n. 8, p. 1006 - 1010, 1999.

DILAURO, M.; BURNS, K. D. Angiotensin-(1-7) and Its Effects in the Kidney. The Scientific World J., v. 9, p. 522 - 535, 2009.

DWORKIN, L. D.; ICHIKAWA, I.; BRENNER, B. M.; Hormonal modulation of glomerular function. Am. J. Physiol., v. 244, n. 2, F95 - F104, 1983.

DZAU, V. J.; ELLISON, K. E.; BRODY, T.; INGELFINGER, J.; PRATT, R. E. Expression of renin and angiotensin-converting enzyme in human hearts. Heart Vessels, v. 10, p. 285 93, 1987.

EHRLICH, P. Fragekasten. Z. Wiss. Mikrosk. v. 3; p. 150, 1886.

FANESTIL, D. D. Mechanism of action of aldosterone blockers. Sem. Nephrol., v. 8, p. 249 - 263, 1988.

FENTON, R. A; KNEPPER, M. A; Mouse models and the urinary concentrating mechanism in the new millennium; Physiol. Rev., v. 87, p. 1083 - 1112, 2007.

FERRARIO, C. M.; CHAPPELL, M. C.; TALLANT, E. A.; BROSNIHAN, K. B.; DIZ, D. I. Counter regulatory actions of angiotensin 1-7. Hypertension, v. 30, p. 535 - 541, 1997.

FROHLICH E.D. Fibrosis and ischemia: the real risks in hypertensive heart disease. Am. J. Hypertens., v. 14, p. 194S - 199S, 2001.

FUNDER, J. W.; PEARCE, P. T.; SMITH, R.; SMITH, A. I.; Mineralocorticoid action: target tissue specificity is enzyme, not receptor, mediated. Science, v. 242, p. 583 - 585, 1988. 
GARCIA, N. H.; GARVIN, J. L. Angiotensin 1-7 has a biphasic effect on fluid absorption in the proximal straight tubule. J. Am. Soc. Nephrol., v. 5, p. 1133 - 1138, 1994.

GEERING, K.; CLAIRE, M.; GAEGGLER, H. P.; ROSSEIR, B. C. Receptor occupance vs induction of Na-K-Atpase and Na transport by aldosterone. Am. J. Physiol., v. 248, p. C102 C108, 1985.

GIEBISCH, G.; WINDHAGER, E. Transport of acid and bases. In Medical Physiology, boron W.F. and Boulpaep E. L. (Ed), Saunders, NY, p. 845-860, 2005.

GIEBISCH, G. H. A trail of research on potassium. Kidney Int., v. 62, p. 1498 - 512, 2002.

GRIENDLING, K. K.; LASSEGUE, B.; ALEXANDER, R. W.; Angiotensin receptors and their therapeutic implications. Annu. Rev. Pharmacol. Toxicol., v. 36, p. 281-306, 1996.

GROSS, E.; ROTHSTEIN, M.; DOMBEK, S.; JUKNIS, H. I. Effect of spironolactone on blood pressure and the renin-angiotensin-aldosterone system in oligo-anuric hemodialysis patients. Am. J. Kidney Dis., v. 46, p. 94 - 101, 2005.

HALL, J. E.; GUYTON, A. C.; BRANDS, M. W. Control of sodium excretion and arterial pressure by intrarenal mechanisms and the renin-angiotensin system. In: Laragh $\mathrm{J}, \mathrm{H}$.; Brenner, B. M. eds. Hypertension: Pathophysiology, Diagnosis and Management. New York, NY: Raven Press; 1451-1475, 1990.

HAMEL, P.; PAUSAVA, Z.; ADARICHEVA, K.; TREBALAY, J. Hypertension: genes and environment. J. Hypertens., v. 16, p. 397 - 418, 1998.

HARRISON BERNARD, L. M.; EL-DAHR, S. S.; O'LEARY, D. F.; NAVAR, L. G. Regulation of angiotensin II type 1 receptor mRNA and protein in angiotensinII-induced hypertension. Hypertension, v. 33, p. 340 - 346, 1999.

HEITSCH, H.; BROVKOVYCH, S.; MALINSKI, T.; WIEMER, G. Angiotensin-(1-7)Stimulated nitric oxide and superoxide release from endothelial cells. Hypertension, v. 37, p. $72-76,2001$. 
HATAKEYAMA, H.; MIYAMORI, I.; FUJITA, T.; TAKEDA, Y.; TAKEDA, R.; YAMAMOTO H. Vascular aldosterone: Biosynthesis and a link to angiotensin II-induced hypertrophy of vascular smooth muscle cells. J. Biol. Chem., v. 269, p. 24316 - 24320, 1994.

HERNADEZ SCHULMAN I.; ZHOU, M. S.; RAIJ, L. Cross-talk between angiotensin II receptor types 1 and 2: Potential role in vascular remodeling in humans. Hypertension, v. 49, p. $270-271,2007$.

ISHIGURO, K.; SASAMURA, H.; SAKAMAKI, Y.; ITOH, H.; SARUTA, T.; Developmental activity of the renin-angiotensin system during the "critical period" modulates later L-NAME-induced hypertension and renal injury. v.30, n. 1, p. 63 - 75, 2007.

JAN, B. New Therapeutic Options in Patients Prone to Hypertension: A Focus on Direct Renin Inhibition and Aldosterone Blockade. Am. J. Med. Sci., v. 337, n. 6, p. 438 - 444, 2009.

JERMYN, M. A. A new method for the determination of ketohexoses in presence of aldohexoses. Nature, v. 177, p. 38 - 39, 1956.

JULIUS, S.; KJELDSEN, S. E.; WEBER, M.; BRUNNER, H. R.; EKMAN S.; HANSSON, L.; HUA, T.; LARAGH， J.; MCINNES， G. T.; MITCHELL， L.; PLAT F.; SCHORK, A.; SMITH, B.; ZANCHETTI, A. Outcomes in hypertensive patients at high cardiovascular risk treated with regimens based on valsartan or amlodipine:The VALUE randomised trial. Lancet, v. 363, p. 2022 - 2031, 2004.

JUNYA, J.; GUOHUA, D.; JILI, Z.; CHENG, C.; WEI, L.; NICHOLAS, F. P.; SINGHAL, C. Angiotensin II Infusion Induces Nephrin Expression Changes and Podocyte Apoptosis. Am. J. Nephrol., v.28, p. 500 - 507, 2008.

KAGAWA, C. M. Blocking the renal electrolyte effects of mineralocorticoids with a orally active steroidal spironolactone. Endocrinology, v. 65, p. 125 - 132, 1960. 
KAMPER, A. L.; PEDERSEN, E. B.; STRANDGAARD, S. Hypertension and renal disease. Ugeskr Laeger, v. 171, n. 25, p. 2109-2113, 2009.

KAWADA, N.; IMAI, E.; KARBER, A.; WELCH, W. J.; WILCOX, C. S. A mouse model of angiotensin II slow pressor response: role of oxidative stress. J Am Soc Nephrol. v. 13, p. $2860-2868,2002$.

KELlY, D. J.; COX, A. J.; GOW, R. M.; ZHANG, Y.; KEMP, B. E.; GILBERT, RE. Platelet-derived growth factor receptor transactivation mediates the trophic effects of angiotensin II in vivo. Hypertension, v. 44, n. 2, p. 195 - 202, 2004.

KLANKE, B.; CORDASIC, N.; HARTNER, A.; SCHMIEDER, R. E.; VEELKEN, R.; HILGERS, K. F. Blood pressure versus direct mineralocorticoid effects on kidney inflammation and fibrosis in DOCA-salt hypertension. Nephrol. Dial. Transplant., v. 23, n. 11, p. $3456-3463,2008$.

KLAR, J.; SANDNER, P.; MULLER, M. W.; KURTZ, A. cAMP stimulates rennin gene transcription in juxtaglomerular cells. Pflügers Arch., v. 444, p. 335 - 344, 2002.

KLICKSTEIN, L. B.; KAEMPFER, C. E.; WINTROUB, B. U. The granulocyte-angiotensin system: Angiotensin I-converting activity of cathepsin G. J. Biol. Chem., v. 257, p. 15042 46, 1982.

KIM, H. Y. Renal Handling of Ammonium and Acid Base Regulation. Electrolyte Blood Press., v. 7, p. 9 - 13, 2009.

KOBORI, H.; HARRISON-BERNARD, L. M.; NAVAR, L. G. Expression of angiotensinogen mRNA and protein in angiotensin II-dependent hypertension. J. Am. Soc. Nephrol., v.12, p. 431 - 439, 2001.

KOBORI, H.; NANGAKU, M. L.; NAVAR, G.; NISHIYAMA, A. The Intrarenal ReninAngiotensin System: From Physiology to the Pathobiology of Hypertension and Kidney Disease. Pharmacol. Rev., v. 59, p. 251 - 287, 2007. 
KRUM, H.; GILBERT, R. E. Novel therapies blocking the renin-angiotensin aldosterone system in the management of hypertension and related disorders. J. Hypertens., v. 25, p. 25 $35,2007$.

LANE, D. A.; BEEVERS, D. G. Amiloride 10mg is less effective than spironolactone $25 \mathrm{mg}$ in patients with hypertension resistant to a multidrug regime including an angiotensinblocking agent. J. Hypertens., v. 25, p. 2515 - 2516, 2007.

LEITE-DELlOVA, D. C.; MALNIC, G.; MELlO-AIRES, M. Genomic and nongenomic stimulatory effect of aldosterone on H+-ATPase in proximal S3 segments. Am. J. Physiol. Renal Physiol., v. 300, n. 3, F682 - F691, 2011.

LEITE-DELlOVA, D. C.; OLIVEIRA-SOUZA, M.; MALNIC, G.; MELlO-AIRES, M. Genomic and nongenomic dose-dependent biphasic effect of aldosterone on $\mathrm{Na}+\mathrm{H}+$ exchanger in proximal S3 segment: role of cytosolic calcium. Am. J. Physiol. Renal Physiol. v. 295, n. 5, F1342 - F1352, 2008.

LIEBERTHAL, W.; LEVINE, J. S. The role of the mammalian target of rapamycin (mTOR) in renal disease. J. Am. Soc. Nephrol., v. 20, n. 12, p. 2493 - 2502, 2009.

LIDDLE, G. W. Aldosterone antagonists and triamterene. Ann. NY Acad. Sci., v. 134, p. 466 - 460, 1966.

LIEW, D.; KRUN, H. Aldosterone receptor antagonists for hypertension: what do they offer? Drugs, v. 63, p. 1963 - 1972, 2003.

LOMEZ, E. S. L.; ARAUJO, R. C.; BADER, M.; PESQUERO, J. B.; PESQUERO, J. L; Tonin and kallikrein in the brain of transgenic rat line expressing human tissue kallikrein. Hypertension, v. 39, p. 229 - 232, 2002.

LOWRY, O. H.; ROSEBROUGH, N. J.; FARR, A. L.; RANDALL, R. J. Protein measurement with the Folin-Phenol reagents. J. Biol. Chem., v. 193, p. 265 - 275, 1951. 
LU, M.; WANG, J.; JONES, K. T.; IVES, H. E.; FELDMAN, M. E.; YAO, L. J.; SHOKAT, K. M.; ASHRAFI, K.; PEARCE, D. mTOR complex-2 activates ENaC by phosphorylating SGK1. J. Am. Soc. Nephrol., v. 21, n. 5, p. 811 - 818, 2010.

MALNIC, G.; MATHEW, A. B.; GIEBISCH, G. Control of renal potassium excretion. The Kidney, Brenner B.M. (Ed) 7th. Ed. Saundres Philadelphia, Chap 10, p. 453-496, 2004.

MANCIA, G.; BOMBELLI, G.; FACCHETTI, R.; MADOTTO, F.; QUARTI-TREVANO, F.; FRIZ, H. P.; GRASSI, G.; SEGA, R. Long-Term Risk of Sustained Hypertension in White-Coat or Masked Hypertension. Hypertension, v. 54, n. 2, p. 226 - 232, 2009.

MARTÍN-FERNÁNDEZ, B.; DE LAS HERAS, N.; MIANA, M.; BALLESTEROS, S.; VALERO-MUÑOZ, M.; VASSALlO, D.; DAVEL, A. P.; ROSSONI, L. V.; CACHOFEIRO, V.; LAHERA, V. Spironolactone prevents alterations associated with cardiac hypertrophy produced by isoproterenol in rats: involvement of SGK-1. Exp. Physiol., [Inpress], 2012.

MATTHEW, E. D.; CURT, D. S. Genetic Basis of Hypertension: Revisiting Angiotensinogen. Hypertension, v. 48, p. 14 - 20, 2006.

McENEANEY, V.; HARVEY, B. J.; THOMAS, W. Aldosterone regulates rapid trafficking of epithelial sodium channel subunits in renal cortical collecting duct cells via protein kinase D activation. Mol. Endocrinol., v. 22, p. 881 - 892, 2008.

MELlO-AIRES, M.; FISIOLOGIA, 4 ed., Rio de Janeiro: Guanabara Koogan, 934 p., 2008.

MENDELSOHN, F. A.; DUNBAR, M.; ALLEN, A.; CHOU, S. T.; MILlAN, M. A.; AGUILERA, G.; CATT K. J. Angiotensin II receptors in the kidney. Fed. Proc., v. 45, p. $1420-1425,1986$.

MINDEL, G.; MORRISON, A. R. Is hypertension a disorder of volume control? What is the evidence?. Nephron. physiol., v. 101, n. 3, p. 63 - 71, 2005. 
MIYATA, K.; RAHMAN, M.; SHOKOJI, T.; NAGAI, Y.; ZHANG, G. X.; SUN, G. P.; KIMURA, S.; YUKIMURA, T.; KIYOMOTO, H.; KOHNO, M.; ABE, Y.; NISHIYAMA, A. Aldosterone stimulates reactive oxygen species production through activation of NADPH oxidase in rat mesangial cells. J. Am. Soc. Nephrol., v. 16, n. 10, p. 2906 - 2912, 2005.

MONTMINY, M. Transcriptional regulation by cAMP. Annu. Rev. Biochem., v. 66, p. 807 $-822,1997$.

MORGAN, L.; BROUGHTON, P. F.; KALSHEKER, N. Angiotensinogen: molecular biology, biochemistry and physiology. Int. J. Biochem. Cell Biol., v. 28, p. 1211-1222, 1996.

MULLER, D. N.; HILGERS, K. F.; BOHLENDER, J.; LIPPOLDT, A.; WAGNER, J. Angiotensin formation in the isolated rat hindlimb. J. Hypertens., v. 7, p. 789 - 98, 1995.

NAVAR, L. G.; VON THUN, A. M.; ZOU, L.; el-DAHR, S. S.; MITCHELL, K. D. Enhacement of intrarenal angiotensin II levels in 2 kidney 1 clip and angiotensin II induced hypertension. Blood Press. Suppl., v. 2, p. 88 - 92, 1995.

NAVAR, L. G. Paracrine regulation of the renal microcirculation. Physiol. Ver., v. 76, n. 2, p. 425 - 536, 1996.

NAVAR, L. G.; HARRISON-BERNARD, L. M.; IMIG, J. D.; CERVENKA, L.; MITCHELL, K. D. Renal responses to AT1 receptor blockade. Am. J. Hypertens., v. 13, p. $45 \mathrm{~S}-54 \mathrm{~S}, 2000$.

NAVAR, L. G. The role of the kidneys in hypertension. J. Clin. Hypertens., v. 7, p. 542 $549,2005$.

NAVAR, L. G.; PRIETO, M. C.; SATOUAND. R.; KOBORI, H. Intrarenal angiotensin II and its contribution to the genesis of chronic hypertension. Pharmacology, v. 11, p. $1-7$, 2011. 
NGUYEN, G.; DELARUE, F.; BURCKLE, C.; BOUZHIR, L.; GILLER, T.; SRAER, J. D. Pivotal role of the renin/prorenin receptor in angiotensin II production and cellular responses to renin. J. Clin. Invest. v. 109, p. 1417 - 1427, 2002.

NISHIKAWA, T.; SUEMATSU, S.; SAITO, J.; SOYAMA, A; ITO, H.; KINO, T.; CHROUSOS, G. Human renal mesangial cells produce aldosterone in response to low-density lipoprotein (LDL). J. Steroid. Biochem. Mol. Biol., v. 96, p. 309 - 316, 2005.

NISHIYAMA, A.; YAO, L.; FAN, Y.; KYAW, M.; , KATAOKA, N. Involvement of aldosterone and mineralocorticoid receptors in rat mesangial cell proliferation and deformability. Hypertension, v. 45, p. 710 - 716, 2005.

PAECH, M. J. Renin-angiotensin system: biochemistry and mechanisms of action. Physiol. Rer., v. 57, n. 2, p. 313 - 370, 1977.

PAUL, M.; MEHR, A. P.; KREUTZ, R.; Physiology of local renin-angiotensin systems. Physiol. Rev., v.86, p. 747 - 803, 2006.

PAN, L.; BLACK, T. A.; SHI, Q.; JONES, C. A.; PETROVIC, N.; LOUDON, J.; KANE, C.; SIGMUND, C. D.; GROSS, K. W. Critical roles of a cAMP responsive element and an Ebox in regulation of mouse renin gene expression. J. Biol. Chem., v. 276, p. 45530 - 45538, 2001.

PIETER, M.; JANSEN, A. H.; JAN D.;, BEN P. I.; ANTON H. VAN DEN MEIRACKER. Aldosterone-receptor antagonism in hypertension, J. Hypertens., v. 27; p. 680 - 691, 2009.

PITT, B.; ZANNAD, F.; REMME, W. J.; CODY, R.; CASTAIGNE, A.; PEREZ, A.; PALENSKY, J.; WITTES, J. The effect of spironolactone on morbidity and mortality in patients with severe heart failure. Randomized Aldactone Evaluation Study Investigators. N. Engl. J. Med., v. 341, n. 10, p. 709 - 717, 1999.

PRATT, R. E. ; CARLETON, J. E.; RICHIE, J. P. ; HEUSSER, C. ; DZAU, V. J. Human renin biosynthesis and secretion in normal and ischemic kidneys. Proc. Natl. Acad. Sci. USA., v. 84, p. 7837 - 7840, 1987. 
PETI-PETERDI, J.; WARNOCK, D. G.; BELL, P. D.; Angiotensin II directly stimulates ENaC activity in the cortical collecting duct via AT(1) receptors. J. Am. Soc. Nephol., v. 13, p. $1131-1135,2002$.

PINTEROVA, L.; KRIZANOVA, O.; ZORAD, S. Rat epididymal fat tissue express all components of the renin-angiotensin system. Gen. Physiol. Biophys. v.19, p. 329 - 334, 2000.

PRIETO-CARRASQUERO, M. C.; HARRISON-BERNARD, L. M.; KOBORI, H.; OZAWA, Y.; HERING-SMITH, K. S.; HAMM, LL.; NAVAR, L. G. Enhancement of collecting duct renin in angiotensin II-dependent hypertensive rats. Hypertension, v. 44, p. $223-229,2004$.

PRIETO-CARRASQUERO, M. C.; KOBORI, H.; OZAWA, Y.; GUTIERREZ, A.; SETH, D.; NAVAR, L. G. AT1 receptor-mediated enhancement of collecting duct renin in angiotensin II-dependent hypertensive rats. Am. J. Physiol. Renal Physiol., v. 289, p. F632 F637, 2005.

PIETER, M.; JANSEN, A. H.; JAN D.; BEN P. I.; ANTON, H.; VAN DEN, M. Aldosteronereceptor antagonism in hypertension, J. Hypertens., v. 27, p. $680-691,2009$.

PRATT, J. H.; ECKERT, G. J, NEWMAN, S.; AMBROSIUS, W. T. Blood pressure responses to small doses of amiloride and spironolactone in normotensive subjects. Hypertension, V. 38, P. $1124-1129,2001$.

PRIETO-CARRASQUERO, M. C.; BOTROS, F. T.; PAGAN, J.; KOBORI, H.; SETH, D. M.; CASARINI, D. E.; NAVAR, L. G. Collecting duct renin is upregulated in both kidneys of 2-kidney, 1-clip goldblatt hypertensive rats. Hypertension, v. 51, p. 1590 - 1596, 2008.

RASHIKH, A.; AHMAD, S. J.; PILLAI, K.K.; NAJMI, A. K. Aliskiren as a novel therapeutic agent for hypertension and cardio-renal diseas. J. Pharm. Pharmacol. v. 64, n. 4, p. 470 481, 2012. 
REUDELHUBER, T. L. The renin-angiotensin system: peptides and enzymes beyond angiotensin II. Curr. Opin. Nephrol. Hypertens., v. 14, p. 155 - 159, 2005.

RHIAN, M. T.; ERNEST, L. S. Signal Transduction Mechanisms Mediating the Physiological and Pathophysiological Actions of Angiotensin II in Vascular Smooth Muscle Cells. Pharmacol. Rev., v. 52, p. 639 - 672, 2000.

SANDBERG, M. B.; RIQUIER, A. D.; PIHAKASKI-MAUNSBACH, K.; MCDONOUGH, A. A.; MAUNSBACH, A. B. ANG II provokes acute trafficking of distal tubule Na_-Clcotransporter to apical membrane. Am. J. Physiol. Renal Physiol., v. 293, F662 - F669, 2007.

SEALEY, J. E.; GERTEN-BANES, J.; LARAGH. J. H. The renin system: Variations in man measuredby radioimmunoassay or bioassay. Kidney International, v. 1, p. 240 - 253, 1972.

SELYE, H. Anticortisol action of aldosterone. Science, v. 121, p. 368 - 369, 1955.

SHANMUGAM, S.; SANDBERG, K. Ontogeny of angiotensin II receptors. Cell. Biol. Int., v. 20, p. $169-176,1996$.

SILVESTRE, J. S.; HEYMES, O.; ROBERT, A. C.; AUPETIT-FAISANT, V. B.; CARAYON, A.; SWYNGHEDAUW, B.; DELCAYRE, C. Activation of cardiac aldosterone production in rat myocardial infarction: effect of angiotensin II receptor blockade and role in cardiac fibrosis. Circulation, v. 99, p. 2694 - 2701, 1999.

SMITH, H. W.; FINKELSTEIN, N.; ALIMINOSA, L.; CRAWFORD, B.; GRABER M. The renal clearances of substituted hippuric acid derivatives and other aromatic acids in dogs and men. J. Clin. Invest., v. 24, p. 388 - 404, 1945.

SANTOS, R.A.; BROSNIHAN, K. B.; CHAPPELL, M. C.; PESQUEIRO, J.; CHERNICKY, C. L.; GREENE, L. J.; FERRARIO, C. M. Converting enzyme activity and angiotensin metabolism in the dog brainstem. Hypertension, 11, 1153-157, 1988. 
SANTOS, R.A.; CAMPAGLIONE-SANTOS, M. J.; ANDRADE, S. P. Angiotensin 1-7: na update. Regul. Pept., v. 91, p. 45 - 62, 2000.

SCHIAVONE, M. T.; SANTOS, R. A.; BROSNIHAN, K. B.; KROSLA, M. C.; FERRÁRIO, C. M. Release of vasopressin from the rat hypotalamu-neurohypophysial system by angiotensin 1-7 heptapeptide. Proc. Natl. Acad. Sci. USA., v. 85, p. 4095 -98, 1988.

SIMPSON, S. A.; TAIT, J. F.; WETTSTEIN, A.; NEHER, R.; VON EUW, J.; REICHSTEIN, T. Isolation from the adrenalsof a new crystalline hormone with especially high effectiveness on mineral metabolism. Experientia, v. 9, p. 333 - 35, 1953.

SPAT, A.; HUNYADY, L. Control of aldosterone secretion: a model for convergence in cellular signaling pathways. Physiol. Rev., v. 84, p. 489 - 539, 2004.

SUBRAMANYA, A. R.; YANG, C. L.; MCCORMICK, J. A.; ELLISON, D. H. WNK kinases regulate sodium chloride and potassium transport by the aldosterone sensitive distal nephron. Kidney Int.; v. 70, p. 630 - 634, 2006.

TAKEI, Y.; JOSS, J. M.; KLOAS, W.; RANKIN, J. C. Identification of angiotensin I in several vertebrate species: its structural and functional evolution. Gen. Comp. Endocrinol. v. 135, n. 3, p. 286 - 92, 2004.

Tigersted, T. R.; Bergman, P. G. Niere und Krieslauf. Scand. Arch. Physiol., v. 8, p. $223-271,1898$.

TIMMERMANS, P. B.; WONG, P. C.; CHIU, A. T.; HERBLIN, W. F.; BENFIELD, P.; CARINI, D. J.; LEE, R. J.; WEXLER, R. R.; SAYE, J. A.; SMITH, R. D. Angiotensin II receptors and angiotensin II receptor antagonists. Pharmacol. Rev., v. 45, p. 205 - 251, 1993.

TOFFELMIRE, E. B.; SLATER, K.; CORVOL, P.; MENARD, J.; SCHAMBELAN, M. Response of plasma prorenin and active renin to chronic and acute alterations of renin secretion in normal humans; Studies using a direct immunoradiometric assay. J. Clin. Inves.,, v. 83 , p. $679-687,1989$. 
VAN DER MARK, J.; KLINE, R. L. Altered pressure natriuresis in chronic angiotensin II hypertension in rats. Am. J. Physiol., v. 266, p. R739 - R748, 1994.

WAKUI H.; TAMURA K.; MATSUDA, M.; BAI, Y.; DEJIMA, T.; SHINEGANA, A.; TOYA, Y.; YBANA M.; MINAMISAWA, S.; UMAMURA, S.; Intrarenal supression of angiotensin II type receptor binding molecule in angiotensin II-infused mice; Am. J. Physiol. Renal Physiol., v. 299, p. F991 - F1003, 2010.

WARREN, T.; BRIAN, J. H. Mechanisms Underlying Rapid Aldosterone Effects in the Kidney. Annu. Rev. Physiol ., v. 17, n. 73, p. 335 - 357, 2011.

WELlinG, P. A.; CAPLAN, M.; SUTTERS, M.; GIEBISCH, G. Aldosterone-mediated $\mathrm{Na} / \mathrm{K}$-ATPase expression is alpha 1 isoform specific in the renal cortical collecting duct. $\mathbf{J}$. Biol. Chem., v. 268, p. 23469 - 23476, 1993.

WILKINSON-BERKA, J. L.; TAN, G. J. A.; WORSKI, K.; MILLER, A. G. Identification of retinal aldosterone system and the protective effects of mineralocorticoid receptor antagonism on retinal vascular pathology. Circ. Res., v. 104, n. 1, p. 124 - 133, 2009.

WU, R.; LAPLANTE, M. A.; DE CHAMPLAIN, J. Prevention of angiotensin II-induced hypertension, cardiovascular hypertrophy and oxidative stress by acetylsalicylic acid in rats. v. 22, n. 4, p. $793-801,2004$.

YAMAMOTO, T.; HAYASHI, K.; MARSUD, H.; KUBOTA, E.; TANAKA, H.; OGASAWARA, Y.; NAKAMOTO, H.; SUZUKI, H.; SARUTA, T.; KAJIYA, F. In vivo visualization of angiotensin II and tubuloglomerular feedback-mediated renal vasoconstriction. Kidney Int,, (60): 864 - 869, 2001.

YOO, T. H.; LI J. J.; KIM J. J; JUNG D. S.; KWAK S.; J.; RYU D. R.; CHOI H. Y.; KIM J. S.; KIM H. J.; HAN S. H.; LEE J. E.; HAN D. S.; KANG S. W.; Activation of reninangiotensin system within podocytes in diabetes. Kidney Int., v. 71, p. 1019 - 1027, 2007. 
ZHANG, A.; JIA, Z.; GUO, X.;YANG, T. Aldosterone induces epithelial-mesenchymal transition via ROS of mitochondrial origin. Am. J. Physiol. Renal Physiol., v. 293, n. 3, p. F723 - F731, 2007.

ZHAO, D.; SETH, D. M.; NAVAR, L. G. Enhanced distal nephron sodium reabsorption in chronic angiotensin II-infused mice. Hyertension, v. 54, n. 1, p. 120 - 126, 2009.

ZIMPELMANN, J.; BURNS, K. D. Angiotensin-(1-7) activates growth-stimulatory pathways in human mesangial cells. Am. J. Physiol. Renal Physiol., v. 296, n. 2, F337 - F346, 2009. 